Débora Silva de Oliveira

Rigidez de preços no Brasil: Evidências microeconômicas e impactos macroeconômicos

São Paulo 
Prof. Dr. Vahan Agopyan

Reitor da Universidade de São Paulo

Prof. Dr. Fábio Frezatti

Diretor da Faculdade de Economia, Administração e Contabilidade

Prof. Dr. José Carlos de Souza Santos

Chefe do Departamento de Economia

Prof Dr. Ariaster Baumgratz Chimeli

Coordenador do Programa de Pós-Graduação em Economia 
Débora Silva de Oliveira

\title{
Rigidez de preços no Brasil: Evidências microeconômicas e impactos macroeconômicos
}

\begin{abstract}
Dissertação apresentada ao Programa de PósGraduação em Economia do Departamento de Economia da Faculdade de Economia, Administração e Contabilidade da Universidade de São Paulo, como requisito parcial para a obtenção do título de Mestre em Ciências.
\end{abstract}

Orientador: Prof. Dr. Mauro Rodrigues

Coorientador: Prof. Dr. Márcio Issao Nakane

Versão Corrigida

São Paulo 
Catalogação na Publicação (CIP)

Ficha Catalográfica com dados inseridos pelo autor

Oliveira, Débora Silva de

Rigidez de preços no Brasil: Evidências microeconômicas e impactos macroeconômicos / Débora Silva de Oliveira. - São Paulo, 2021.

$60 \mathrm{p}$.

Dissertação (Mestrado) - Universidade de São Paulo, 2021.

Orientador: Prof. Dr. Mauro Rodrigues.

Coorientador: Prof. Dr. Márcio Issao Nakane.

1. Preços. 2. Rigidez de preços. 3. Não neutralidade monetária. 4. Custo de Menu. 5. CalvoPlus. I. Universidade de São Paulo. Faculdade de Economia, Administração e Contabilidade. II. Título. 


\section{Rigidez de preços no Brasil: Evidências microeconômicas é impactos macroeconômicos}

Dissertação apresentada ao Programa de PósGraduação em Economia do Departamento de Economia da Faculdade de Economia, Administração e Contabilidade da Universidade de São Paulo, como requisito parcial para a obtenção do título de Mestre em Ciências.

Prof. Dr. Mauro Rodrigues

IPE-USP

Prof. Dr. Ricardo Brito

IPE-USP

Prof. Dr. Marco Antônio Bonomo

Insper

Dr. Júlia Passabom Araujo

Doutora em Economia pelo IPE-USP

São Paulo 


\section{Agradecimentos}

Aos meus pais, Maria da Glória e Luiz Carlos. Vocês abriram mão de alguns sonhos pra investir em mim e no meu irmão. Nunca hesitaram em nos apoiar quando decidíamos estudar mais um pouco. Mesmo sem entender ao certo o caminho que queríamos seguir, nos estendiam a mão e proporcionavam todo o suporte necessário. Vocês são parte essencial desta história. Ao meu irmão, que desde que eu era pequena é minha fonte de inspiração. Além de irmão, o meu melhor amigo e conselheiro de todas as horas. Que sorte eu tenho de ter vocês três. Vó, muito obrigada por me acolher nas suas tardes, por aquele abraço no dia que você soube que eu passei no mestrado e por muito mais. Me sinto ingrata por não citar diretamente mais nomes da minha família, mas todos vocês sabem que a minha caminhada se torna mais agradável e fácil com vocês ao meu lado.

Ao meu orientador de longa data, Mauro Rodrigues, que me acompanha desde a graduação. Obrigada pelos conselhos precisos quando nem eu sabia para onde ir e por toda paciência. Saio com a certeza de que fiz a escolha certa. Obrigada ao Márcio Nakane que me coorientou e me ajudou a dar os primeiros passos da dissertação. Agradeço também as EconomistAs, que me abriram ótimas oportunidades. Obrigada por serem inspirações como professoras, pesquisadoras e mulheres.

Aos meus amigos que ingressaram no mestrado junto comigo, que conseguiram em meio ao caos do primeiro semestre encontrar um lugar de risadas e companheirismo. Às risadas na salinha, idas na vivência pós prova ou bares no final de semestre, obrigada. Um obrigada especial ao Rodrigo Pacheco, pelas caronas e paciência, Pedro Oliveira, pela coautoria e companheirismo, e Lucas Chang, pela paciência e por partilhar seu conhecimento. Àquele que tornou o IPE um lugar mais acolhedor e divertido, obrigada por tudo, Raphael.

Às minhas amigas da graduação, Beatriz Bidutte, Nathália Barros e Gabriela Yumi, vocês são a certeza de amizade. Obrigada por todo apoio e por mesmo de longe me fazerem sentir sempre abraçada e acolhida. Àqueles que foram meus roomies ano passado e me mostraram que em qualquer momento do dia há espaço pra risadas e bons conselhos, obrigada Isis e Marcondes. Obrigada por acreditarem em mim quando eu mesma duvidava. Obrigada a todos aqueles que não consegui citar diretamente, amigos do cursinho, da Social, da graduação e de longa data, levo um pedaço de cada um comigo.

Entre tantas coisas que a USP me proporcionou, ela conseguiu me surpreender novamente na peruada de 2015. Lucas, obrigada por estar ao meu lado e sempre me incentivar a ir mais longe. Você preenche minha vida de muitas formas.

Por fim, agradeço à FIPE pela base de dados e à CAPES pelo apoio financeiro. 


\section{Resumo}

O principal objetivo desta dissertação é calibrar modelos multissetoriais de Custo de Menu com insumos intermediários às evidências brasileiras e estimar o grau de não neutralidade da moeda gerado pela rigidez de preços. O modelo utilizado foi proposto por Nakamura e Steinsson (2010). Para melhor dimensionar a não neutralidade monetária gerada por estes modelos, será estimado o modelo VAR inspirado em Shapiro e Watson (1988), que mensura a porcentagem da variação do produto real devida aos choques nominais. Desse modo, será possível comparar os resultados do presente trabalho, que dimensionam a não neutralidade gerada pela rigidez de preços, frente a não neutralidade da monetária total gerada pelos choques nominais, mensurada pelo VAR. O período analisado será de Janeiro de 2000 a Dezembro de 2019. O período de hiperinflação no Brasil não será abrangido por este trabalho, visto o consenso de que não há evidências de rigidez de preços na época frente à alta frequência de reajuste de preços. Os resultados deste trabalho mostram que os modelos multissetoriais estimados explicam até 12,6\% das flutuações no produto real. Em outras palavras, 12,6\% da variação no produto é devida a rigidez nominal de preços. Os resultados encontrados são consistentes com a estimação de choques nominais nas flutuações de curto prazo do produto, representada pelo modelo VAR. Neste modelo, aproximadamente $15 \%$ da variação do produto real é gerada pelos choques nominais. Os resultados mostram que a introdução de heterogeneidade na frequência de mudança de preço triplica o grau de não neutralidade monetária gerado pelo modelo. Em linha com a literatura internacional, os modelos multissetoriais ampliam a não neutralidade monetária em comparação ao modelo unissetorial. Por sua vez, a introdução de insumos intermediários também aumenta o grau de não neutralidade monetária por um fator próximo a três.

Palavras-chave: Rigidez de preços; Não neutralidade monetária; Microdados. 


\begin{abstract}
The main objective of this dissertation is to calibrate multisectoral models of Menu Cost with inputs intermediate to the Brazilian evidence and estimate of the degree of non-neutrality of the currency generated by price rigidity. The model was proposed by Nakamura e Steinsson (2010). To better compare the non-monetary neutrality generated by these models, the VAR model, inspired by Shapiro e Watson (1988), will be estimated. The model measures the percentage of real product variation due to nominal shocks. In this way, it will be possible to compare the results of the present work, non-neutrality due to price rigidity, in face of the non-neutrality of the total monetary generated by the nominal shocks, measured by the VAR. The analyzed period will be from January 2000 to December 2019. The hyperinflation period in Brazil will not be covered by this work, given the consensus that there is no evidence of price rigidity at the time in view of the high frequency of price readjustments. The results show that the estimated multisector models explain up to $12.6 \%$ of the fluctuations in the real product. In other words, $12.6 \%$ of the variation in the product is due to nominal price rigidity. The results found are consistent with the estimation of nominal shocks in the short term fluctuations of the product, represented by the VAR model. In this model, approximately $15 \%$ of the variation in the real product is due to nominal shocks. The results show that the introduction of heterogeneity in the frequency of price change triples the degree of monetary non-neutrality generated by the model. In line with the international literature, multisectoral models expand monetary non-neutrality compared to the unisectoral model. In turn, the introduction of intermediate inputs also increases the degree of monetary non-neutrality by a factor close to three. In the face of models without intermediate inputs, the non-neutrality of models with inputs is up to three times higher.
\end{abstract}

Keywords: Price rigidity; monetary non-neutrality; Microdata. 
Sumário

INTRODUÇÃO . . . . . . . . . . . . . . . . . 1

2

REVISÃO DE LITERATURA . . . . . . . . . . . . . . . . . . . . . . 4

2.1 Fatos sobre rigidez de micropreços . . . . . . . . . . . . . . 4

2.1.1 Heterogeneidade .................... . 4

2.1.2 Efeito de seleção . . . . . . . . . . . . . . . . 6

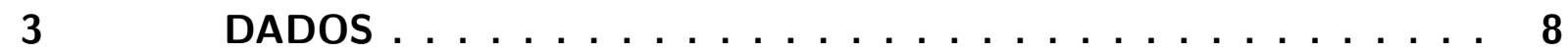

$3.1 \quad$ Base de dados . . . . . . . . . . . . . . . . . . 8

3.2 Tratamento da amostra . . . . . . . . . . . . . 10

$3.3 \quad$ Definições . . . . . . . . . . . . . . . . . . . . 13

$3.4 \quad$ Principais resultados empíricos . . . . . . . . . . . . . . 16

3.5 Evidências da Heterogeneidade . . . . . . . . . . . . . . . . . 19

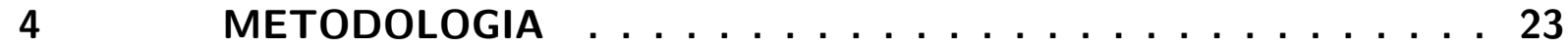

$4.1 \quad$ Modelo . . . . . . . . . . . . . . . . 23

$4.1 .1 \quad$ Famílias . . . . . . . . . . . . . . . . 23

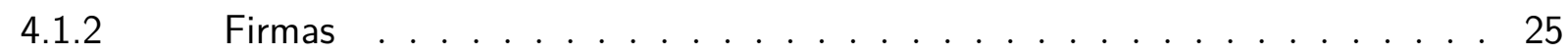

$4.1 .3 \quad$ Equilíbrio . . . . . . . . . . . . . . . . 27

$4.1 .4 \quad$ Estratégia computacional . . . . . . . . . . . . . . . 27

$4.2 \quad 0$ modelo de CalvoPlus . . . . . . . . . . . . . . . . 28

$4.3 \quad$ Parâmetros . . . . . . . . . . . . . . . . . . . . 29

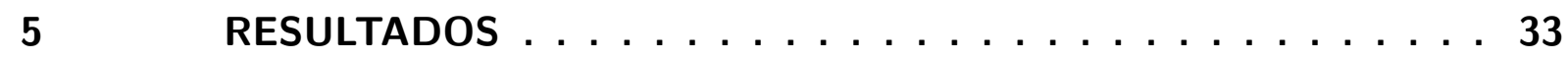

5.1 Modelo de Custo de menu - Baseline . . . . . . . . . . . . . . 33

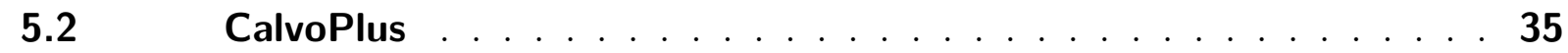

$5.3 \quad$ Heterogeneidade e não neutralidade . . . . . . . . . . . . 36

5.4 Dimensionamento da não neutralidade monetária . . . . . . . . . . 38

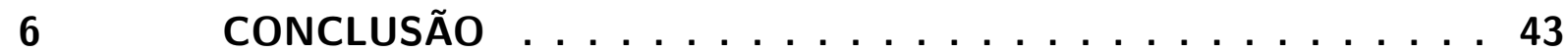

REFERÊNCIAS ..................... . . 44

APÊNDICE ......................... 48

Apêndice A ADERÊNCIA DOS DADOS DE SÃO PAULO AOS DO BRASIL . . . . . . . . . . . . . . . 48 
Apêndice B PERÍODO 1994 A $2000 \ldots$. . . . . . . . . . . . 50

Apêndice C PREÇOS ADMINISTRADOS . . . . . . . . . . 52

Apêndice D ESTRATÉGIA COMPUTACIONAL . . . . . . . . . 53

Apêndice E VETOR AUTORREGRESSIVO - VAR . . . . . . 55 


\section{Lista de ilustrações}

Figura 1 - Trajetória de preços - Itens de alimentação e serviços . . . . . . . . . . 10

Figura 2 - Densidade do comprimento das trajetórias de preço . . . . . . . . . . 12

Figura 3 - Densidade da frequência da variação de preços . . . . . . . . . . . 17

Figura 4 - Frequência de variação de preços ao longo do período analisado . . . . 18

Figura 5 - Densidade dos tamanhos dos ajustes de preços . . . . . . . . . . . 19

Figura 6 - Frequência e tamanho das variações de preços entre diferentes setores . 22

Figura 7 - Diagrama de representação dos modelos . . . . . . . . . . . . . . 29

Figura 8 - Comparação Inflação: INPC - Brasil x IPC - Capital Paulista . . . . . 49

Figura 9 - Frequência de variação de preços mensal . . . . . . . . . . . . 50

Figura 10 - Função impulso resposta da variável Inflação . . . . . . . . . . . . . . . 58

Figura 11 - Função impulso resposta da variável Horas trabalhadas . . . . . . . . . 58

Figura 12 - Função impulso resposta da variável Juros nominal . . . . . . . . . . . 59

Figura 13 - Função impulso resposta da variável Produto Real . . . . . . . . . . . . 59 


\section{Lista de tabelas}

Tabela 1 - Base de dados tratada . . . . . . . . . . . . . . . . . . 11

Tabela 2 - Estatísticas das trajetórias de preços . . . . . . . . . . . . 11

Tabela 3 - Ponderações da POF ao longo do período analisado . . . . . . . . . . 13

Tabela 4 - Frequência e tamanho das variações de preços $(\%) \ldots \ldots$

Tabela 5 - Comparação entre $\operatorname{artigos}(\%) \ldots \ldots \ldots \ldots \ldots$

Tabela 6 - Estatísticas da distribuição de preços (\%) . . . . . . . . . . . 19

Tabela 7 - Critérios utilizados para separação dos produtos em setores . . . . . 20

Tabela 8 - Características dos setores para os modelos multissetoriais (\%) . . . . 21

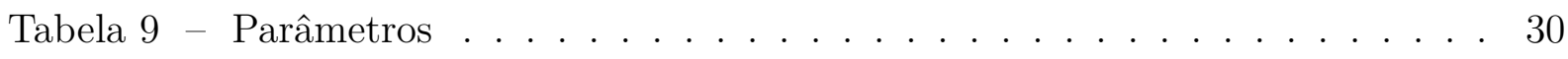

Tabela 10 - Insumos intermediários . . . . . . . . . . . . . . . . . . 31

Tabela 11 - Resultados dos modelos de Custo de Menu unissetoriais . . . . . . . . 34

Tabela 12 - Resultados dos modelos CalvoPlus unissetoriais . . . . . . . . . . 35

Tabela 13 - Calibração dos parâmetros nos modelos multissetoriais . . . . . . . . 37

Tabela 14 - Heterogeneidade e Não neutralidade monetária $\left(\times 10^{-6}\right) \ldots \ldots$. . . 38

Tabela 15 - Decomposição da variância do produto real . . . . . . . . . . . . . 40

Tabela 16 - Não neutralidade monetária em termos da variância total do produto (\%) 40

Tabela 17 - Frequência das variações de preços $(\%) \ldots \ldots \ldots \ldots$. . . . . . 51

Tabela 18 - Preços administrados . . . . . . . . . . . . . . . . . 52

Tabela 19 - Estimação dos resultados para a variável dependente inflação . . . . . 55

Tabela 20 - Estimação dos resultados para a variável dependente horas totais trabalhadas . . . . . . . . . . . . . . . . 5 56

Tabela 21 - Estimação dos resultados para a variável dependente juros nominais . . 56

Tabela 22 - Estimação dos resultados para a variável dependente produto real . . . 57

Tabela 23 - Decomposição da variância . . . . . . . . . . . . . . . . . 60 


\section{Introdução}

Na última década, parte da literatura empírica em economia monetária se propôs a entender quais as implicações macroeconômicas da rigidez de preços com base em microdados. A principal hipótese que circunda os novos estudos em economia monetária é que a rigidez nominal de preços é o principal canal que gera a não neutralidade monetária. Quando os preços exibem padrões de rigidez, a política monetária tem efeitos econômicos reais. Assim, a velocidade com que a economia se ajusta aos choques torna-se diretamente relacionada com a morosidade das firmas que compõem tal economia em ajustarem seus preços. A compreensão no nível microeconômico dos ajustes de preço torna-se, então, essencial para entender os impactos de choques agregados na economia. Nakamura e Zerom (2010), Alvarez e Lippi (2014), Lucas e Golosov (2004), Midrigan (2011), Smets e Maćkowiak (2008) e Midrigan (2008) são alguns trabalhos que compõem esta literatura.

À medida em que são disponibilizadas novas fontes de microdados, os modelos de custo de menu se tornam mais recorrentes e passam a incorporar características antes pouco documentadas sobre rigidez de preços. Assim, o principal objetivo desta dissertação é calibrar um modelo multissetorial de Custo de Menu com insumos intermediários às evidências brasileiras e estimar o grau de não neutralidade da moeda gerado pela rigidez de preços. Adicionalmente, será proposta uma extensão do modelo de Custo de Menu em que será inserido um componente state dependent, chamado de modelo CalvoPlus. Os modelos foram desenvolvidos por Nakamura e Steinsson (2010). Para melhor dimensionar a não neutralidade monetária gerada por estes modelos, será estimado o modelo VAR proposto por Shapiro e Watson (1988), que mensura a porcentagem da variação do produto real devida aos choques nominais. Desse modo, será possível comparar os resultados do presente trabalho, que mensuram a não neutralidade gerada pela rigidez de preços, frente a não neutralidade da monetária total gerada pelos choques nominais, mensurada pelo VAR.

Os modelos calibrados incorporam duas hipóteses relevantes na literatura, a heterogeneidade entre os setores e a introdução de inputs intermediários. Para melhor considerar a heterogeneidade entre os produtos e os setores, foram construídos 3 painéis com números distintos de setores. Para cada um destes painéis foram estimados 4 modelos diferentes, modelo de custo de menu sem insumos intermediários e com insumos, além de dois modelos CalvoPlus, com e sem inputs intermediários. Por sua vez, a introdução de insumos intermediários adiciona ao modelo a estratégia de complementariedade da fixação de preços entre os setores.

Assim, este trabalho contribui para a literatura ao documentar as evidências sobre microdados de preços, ao aplicar modelos de notável importância para mensurar a rigidez 
de preços e, especialmente, ao estimar um modelo VAR, que mensura a porcentagem da variação do produto real devida aos choques nominais. A análise sobre a frequência e tamanho das mudanças de preços com base em microdados já foi feita por outros autores, mas para períodos diferentes. De todo modo, este trabalho consolida fatos já notados por esta literatura e se aprofunda sobre o estudo da heterogeneidade entre os setores ao construir 3 painéis distintos. Com relação à calibração dos modelos, o presente trabalho contribui ao aplicar os modelos para o contexto brasileiro e mensurar o custo de menu gerados por eles. Por fim, o modelo VAR estimado é de extrema relevância nesta literatura, sendo citado em trabalhos como Nakamura e Zerom (2010) e Lucas (2003). Sua aplicação permite dimensionar resultados importantes sobre a não neutralidade monetária gerada por choques nominais. Neste estudo, o VAR também será utilizado para comparar os resultados dos modelos de custo de menu.

O período analisado será de Janeiro de 2000 a Dezembro de 2019. O período de hiperinflação no Brasil não será abrangido por este trabalho, visto o consenso de que não há evidências de rigidez de preços na época frente à alta frequência de reajuste de preços $^{1}$. A decisão de observar apenas pós anos 2000 tem como base verificar somente o período de vigência do regime de metas de inflação. Adicionalmente, há evidências de que o comportamento de frequência da mudança de preços é distinto entre os períodos 1994-1999 e 2000-2019².

Os resultados deste trabalho mostram que os modelos multissetoriais estimados explicam até $12,6 \%$ das flutuações no produto real. Em outras palavras, 12,6\% da variação no produto é devida à rigidez nominal de preços. Os resultados encontrados são consistentes com a estimação de choques nominais nas flutuações de curto prazo do produto, representada pelo modelo VAR. Neste modelo, aproximadamente $15 \%$ da variação do produto real decorre dos choques nominais.

Os resultados mostram que a introdução de heterogeneidade na frequência de mudança de preço triplica o grau de não neutralidade monetária gerado pelo modelo. Em linha com a literatura internacional, os modelos multissetoriais ampliam a não neutralidade monetária em comparação ao modelo unissetorial. Isto ocorre uma vez que o grau de não neutralidade entre os diferentes setores da economia é uma função convexa da frequência de variação dos preços entre os setores. A assimetria com relação às estatísticas de frequência de preços entre os setores também corrobora para a ampliação da não neutralidade. Por sua vez, a introdução de insumos intermediários também aumenta o grau de não neutralidade monetária por um fator próximo a três. Frente aos modelos sem insumos intermediários, a não neutralidade dos modelos com inputs é até três vezes maior. A utilização de outros produtos como insumos introduz aos modelos a complementariedade na estratégia de

1 Araujo (2018), Barros (2009) e Lopes (2008)

2 A explicação completa sobre o corte realizado é dada no Apêndice B. 
fixação de preços entre as diferentes firmas. Em outras palavras, a escolha da empresa em ajustar os preços se torna dependente do time em que as outras empresas, que produzem seus insumos, corrigem seus preços.

Esta dissertação, então, está disposta de tal forma. O próximo capítulo será uma revisão dos principais fatos sobre rigidez de micropreços e características bem consolidadas na literatura. A base de dados, o tratamento feito na amostra e os primeiros resultados empíricos são apresentados no capítulo 3. A seção 3.5 abordará as evidências sobre heterogeneidade na definição dos preços entre os setores. O capítulo 4 apresentará a metodologia utilizada, descrevendo o modelo e definindo os parâmetros utilizados na calibração. Os resultados da calibração dos modelos serão apresentados no capítulo 5, que estão segmentados da seguinte forma: os resultados do modelo de custo de menu (5.1) e do modelo CalvoPlus (5.2), os resultados dos modelos multissetoriais (5.3) e, por último, a comparação dos resultados apresentados e do modelo VAR que estima a não neutralidade gerada por choques nominais (5.4). Por fim, a conclusão compõe o capítulo 6 . 


\section{Revisão de Literatura}

No capítulo The staying power of staggered wage and price setting models in macroeconomics do livro "Handbook of Macroeconomics", Taylor (2016) observou as evidências microeconômicas sobre a fixação de preços e salários. O autor documenta alguns fatos importantes que se tornaram essenciais nessa literatura, como a heterogeneidade na fixação de preços entre os setores e os efeitos de seleção gerados pelos modelos propostos. Nos últimos anos, as novas fontes de microdados permitiram que a literatura se aprofundasse na análise das principais características de ajustes dos preços. A próxima seção irá abordar tais características sobre rigidez de micropreços e que se tornam a base para a construção de modelos que visam estimar os mecanismos que levam as empresas a reajustarem seus valores.

\subsection{Fatos sobre rigidez de micropreços}

\subsubsection{Heterogeneidade}

A pergunta inicial com que nos deparamos é "com que frequência os preços mudam?". Embora a pergunta pareça simples, a análise sobre a frequência da mudança de preços se depara com diversos desafios. Entre as dificuldades que essa literatura enfrenta, alguns exemplos são distinguir variações de preços decorrentes de promoções ${ }^{3}$ e variações de preços regulares. Além disso é necessário incorporar a presença de vendas temporárias, bens substitutos, entre outros, na análise. Alguns produtos também tendem a ter preços mais voláteis, como produtos agrícolas, que dependem de clima, produção, entre outros fatores. Assim, ao documentar variações de preços é essencial observar que os preços dos produtos variam em tamanhos e frequências distintos. Nota-se que para o Brasil, autoras como Araujo (2018) e Barros (2009) já apresentaram evidências de heterogeneidade, e tais estudos serão retomados ao descrever os principais resultados empíricos da base de dados utilizada nesta dissertação.

Os microdados mostram que existe grande heterogeneidade na fixação de preços, em termos de frequência e de tamanho das mudanças de preço. Nakamura e Steinsson (2008) mostram como a frequência do ajuste de preços difere entre diferentes categorias: o grupo de itens com a menor frequência de alterações dos preços é de "serviços jurídicos" $(1,6 \%)$, ou seja, em média, apenas 1,6\% dos preços da categoria mudam dentro de um mês. Por outro lado, a categoria com maior frequência é de "carros usados", cujo índice é de 100\% - todos

3 Nota-se que é frequente na literatura a distinção de preços entre regulares e promocionais. Mesmo quando a base de dados apresenta flag sale, é recorrente o uso de alguns métodos para estimar se uma determinada observação é uma promoção ou um preço regular. 
os preços desta categoria mudam mensalmente. Os autores concluem que a distribuição da frequência de mudança de preços é altamente assimétrica, sendo a cauda direita mais longa do que a esquerda.

Do mesmo modo, Klenow e Kryvtsov (2008) estimam a frequência mediana de variações de preços para os Estados Unidos considerando o período de 1988 a 2004. Os resultados encontrados pelos autores mostram que a frequência de ajuste dos preços é de 27,3\% ou, de outro modo, a duração mediana de um preço é de aproximadamente 3,7 meses. Como observado por outros autores, há diferenças expressivas com relação à frequência e ao tamanho absoluto das variações de preços entre os setores. Assim, seguindo Bils e Klenow (2004) e Nakamura e Steinsson (2008), este trabalho irá utilizar a frequência média ponderada do ajuste de preços entre categorias de produtos. Utilizar tal métrica, além de considerar a heterogeneidade entre os setores, também ameniza o problema da falta de identificação de preços promocionais, uma vez que as promoções estão concentradas em poucos setores da economia, como alimentos e vestuário.

Quais as implicações da heterogeneidade na frequência das mudanças de preço nos modelos macroeconômicos? Uma suposição usual em modelos macroeconômicos é que há uma empresa representativa, ou seja, implicitamente o modelo supõe homogeneidade entre os agentes da economia. No entanto, modelos com bases microfundamentadas mostram que a hipótese de uma única empresa representativa poderia simplificar demasiadamente questões relevantes para entender rigidez de preços (SMETS; MAćKOWIAK, 2008).

Por sua vez, Carvalho (2006) e Nakamura e Steinsson (2008) introduzem heterogeneidade setorial na definição de preços em modelos macroeconômicos. Carvalho (2006) estuda a heterogeneidade setorial com base em modelos de interdependência entre períodos. Através da calibração do modelo, os resultados encontrados mostram que choques monetários tendem a ter efeitos reais, maiores e mais persistentes em economias heterogêneas em comparação a economias com empresas idênticas. Segundo o autor, após uma economia heterogênea ser atingida por um choque, os primeiros setores a reajustarem os preços são aqueles com maior frequência de reajuste. Após essa primeira etapa, a distribuição de frequência de variações de preços entre as empresas que ainda não reajustaram seus preços torna-se progressivamente representada por empresas cujo setor realiza reajustes com baixa frequência, processo chamado pelo autor de "efeito composição de frequência". Os primeiros períodos após o choque são dominados por setores com alta frequência, enquanto os setores de baixa frequência têm maior peso na dinâmica de mudanças de preços após um longo intervalo do choque inicial.

Nakamura e Steinsson (2008) apresentam um modelo de Custo de Menu Multissetorial com insumos intermediários. Os autores mostram que a introdução da heterogeneidade na frequência de ajustes dos preços triplica o grau de não neutralidade monetária do modelo, em comparação ao modelo com um único setor. No mesmo sentido, a introdução 
de insumos intermediários aumenta o grau de não neutralidade monetária do modelo. Com isso, apesar da metodologia utilizada ser diferente daquela usada por Carvalho (2006), ambos autores concluem que a heterogeneidade amplia os efeitos de choques nominais em variáveis reais.

Em modelos que visam estimar a não neutralidade, nota-se a relevância da heterogeneidade de preços entre os setores. Nakamura e Steinsson (2010) e Golosov e Lucas (2007) encontram resultados expressivamente distintos com relação ao grau de neutralidade monetária. Enquanto aqueles consideraram heterogeneidade de preços, via modelo multissetorial, estes consideraram um modelo com um único setor representativo para a economia inteira. O modelo de Nakamura e Steinsson (2010) gera três vezes mais não neutralidade monetária frente ao de Golosov e Lucas (2007). Nakamura e Steinsson (2010) atribuem metade dessa diferença à introdução da heterogeneidade.

\subsubsection{Efeito de seleção}

Recorrente na literatura, o efeito de seleção é definido segundo Golosov e Lucas (2007) como as mudanças ótimas de preços em resposta a choques macroeconômicos. Para exemplificar o efeito de seleção, o modelo Caplin \& Spulber (1987) é ilustrativo. Neste modelo, as empresas enfrentam um custo fixo de alterar o preço, mas escolhem o momento ideal para a alterá-los. Assim, as empresas adotam a política chamada de "Ss"(Sheshinski e Weiss 1977, 1983), em que as empresas esperam seus preços relativos alcançarem o "nível de gatilho", chamado de s, para então os ajustarem para o "preço-alvo", chamado de S.

Diferente do modelo de Calvo (1983), em que as empresas são selecionadas aleatoriamente para ajustarem seus preços, o modelo de Caplin \& Spulber (1987) elenca as empresas sob a necessidade de alteração de seu preço. Isso implica que os preços variam mais do que se fossem selecionados aleatoriamente e o nível de preço responde mais rápido aos choques nominais (Caballero e Engel (1991), Caballero e Engel (1993); Caplin e Leahy (1991); Danziger (1999)).

Os modelos indicados acima são casos extremos e os dados mostram que as calibrações destes modelos são incompatíveis com a frequência e tamanho das variações de preços observadas empiricamente. Os modelos de Calvo e Caplin-Spulber supõem que o único determinante para ocorrer o ajuste de preços é a inflação agregada e, segundo Klenow e Kryvtsov (2008), tal suposição é o que ocasiona as divergências dos modelos com os dados empíricos.

Golosov e Lucas (2007) desenvolvem um modelo com custos fixos de ajuste de preços e calibram choques agregados e idiossincráticos para responder ao tamanho das mudanças agregadas de preço. Os autores concluem que o modelo de custo do menu desenvolvido por eles ainda resulta em um forte efeito de seleção, reduzindo demasiadamente o grau de 
não neutralidade monetária em comparação ao Modelo Calvo.

Por sua vez, Midrigan (2011) argumenta que os resultados encontrados por Golosov e Lucas (2007) são sensíveis à distribuição de choques idiossincráticos, de modo que em casos extremos o efeito de seleção seria nulo, o que levaria o modelo a se assemelhar ao modelo de Calvo. Midrigan (2011) também mostra que o modelo de Golosov-Lucas não é compatível com as estatísticas observadas nas bases de dados, especialmente àquelas referentes aos pequenos ajustes de preços. O autor argumenta que no modelo de Golosov e Lucas, ao optarem por variar seus preços, as empresas têm fortes incentivos para variar seus valores em um tamanho relativamente maior. No entanto, Nakamura e Steinsson (2013) notam que uma vez que o modelo de Golosov-Lucas é unissetorial, e por isso, o modelo não é condizente com as evidências empíricas. Visando mitigar esse impasse, os autores propõem agrupar os produtos em setores, em que os produtos são agrupados por características semelhantes, e desenvolvem um modelo de custo de menu multissetorial.

Com o objetivo de incorporar a discussão acima proposta, este trabalho irá estimar dois modelos. O primeiro é o Modelo de Custo de Menu, que incorpora os efeitos de seleção, uma vez que em todos os períodos as firmas escolhem seus preços de modo a maximizar seu lucro. Adicionalmente, será estimado o mesmo modelo mas com múltiplos setores, para considerar a crítica feita por Nakamura e Steinsson (2013). O segundo modelo é o Modelo de CalvoPlus, que irá incorporar as considerações feitas ao modelo de Golosov e Lucas (2007) e irá amenizar os efeitos de seleção ao incorporar um componente de time dependent. 


\section{Dados}

\subsection{Base de dados}

A principal base de dados desta dissertação será a de microdados de preços da Fundação Instituto de Pesquisa Econômica - FIPE, originalmente usada para construir o Índice de Preços ao Consumidor (IPC-FIPE). A base contém informações semanais de preços para uma ampla gama de produtos e serviços no nível de estabelecimentos na cidade de São Paulo. Nota-se que apesar dos dados utilizados contemplarem apenas São Paulo, a correlação do índice agregado da inflação medido pelo IPC-FIPE e a inflação do IPCA, que engloba capitais de todo país, é elevada. Tal fato já está bem documentado por Araujo (2018), Gouvea (2007) e Barros (2009), de todo modo, o apêndice A visa ilustrar a alta correlação entre a inflação da capital paulista e o correspondente índice no nível Brasil e, portanto, corroborar a validade dos resultados que serão encontrados pela dissertação.

Ressalta-se que o período observado neste trabalho será de Janeiro de 2000 a Dezembro de 2019. Como visto por Barros (2009) e Gouvea (2007), de meados da década de 70 até Junho de 1994 observa-se um período bem determinado de hiperinflação, em que não há evidências de rigidez de preços. Adicionalmente, com a finalidade de analisar um período com maior homogeneidade de dados, o período de 1994 a 1999 também foi excluído da amostra. Além do período escolhido compreender apenas o regime de metas da inflação ${ }^{4}$, há evidências de que o comportamento de frequência de mudança de preços é distinto entre os períodos 1994-1999 e 2000-20195 . Assim, o período delimitado além de concentrar uma maior gama de produtos, abrange um período extenso, contemplando 240 meses.

A base de dados original contém um total de 20.414.307 preços, coletados em 12.648 estabelecimentos diferentes. Há um total de 620 diferentes tipos de produtos e 15.190 marcas. Ressalta-se que a abertura por produto divulgada pela FIPE é equivalente às aberturas Entry Level Items (ELIs) da base de dados dos EUA utilizada por Nakamura e Steinsson (2010). A base de dados da FIPE segmenta cada produto entre sete diferentes grupos: i) Habitação; ii) Alimentação; iii) Transportes; iv) Despesas Pessoais; v) Saúde; vi) Vestuário; vii) Educação. Como previamente sinalizado, os produtos serão separados em três painéis distintos com números diferentes de setores, método já utilizado por Nakamura

4 Regime monetário no qual o banco central está comprometido em atuar de forma a garantir que a inflação efetiva esteja em linha com uma meta pré-estabelecida e anunciada anteriormente. O Brasil adotou formalmente o regime de metas para a inflação como diretriz de política monetária em junho de 1999 .

5 As estatísticas de frequência de preço utilizadas para embasar a delimitação do período estão no apêndice B. 
e Steinsson (2010), Klenow e Malin (2010) e Gagnon (2009). Um dos painéis feitos utilizará as categorias da FIPE.

O conjunto de dados inclui informações específicas sobre a marca de cada produto. Cada marca é associada a um determinado produto e constitui o menor nível de desagregação observado pela base de dados. Um produto é uma combinação de uma ou mais marcas. Produtos não industrializados ou homogêneos apresentam poucas segregações de marcas. O produto "Abacaxi", por exemplo, é segmentado entre 13 marcas, que se dividem entre o produto em "unidade", em "kg", ou tipos de abacaxi. Produtos industrializados, por sua vez, têm maior amplitude de marcas. Por exemplo, os produtos "Geladeira" ou "Microcomputador" compreendem, respectivamente, um total de 124 e 797 marcas na amostra.

A base de dados não contempla substituições de produtos ou marcas, de modo que frente a alterações marginais nas características de um produto, um novo código será criado, e o código antigo será descontinuado. Os dados também não contemplam flag de promoção ${ }^{6}$.

A abertura relevante para o presente estudo é o preço de uma determinada marca associada a um estabelecimento. Assim como pontua Araujo (2018), essa abertura será chamada de item. A base de dados contém originalmente 592.122 itens. A composição dos itens na amostra muda ao longo dos anos devido a criação de novos itens e descontinuidade de antigos. Dessa forma, uma trajetória de preços será o conjunto dos preços de um item ao longo do tempo. Na figura 1, há alguns exemplos de itens e suas respectivas trajetórias de preços. As Figuras 1a e 1b são as trajetórias de preços de 1 quilograma de frango e de um pacote de 500 gramas de café em pó, respectivamente, sendo que ambos estão inclusos no setor de Alimentos, segundo a classificação da FIPE. Por sua vez, as Figuras 1c e 1d são as trajetórias do serviço de reparação em veículos, custo por hora, e lavagem simples de veículos pequenos, inclusos no setor de Serviços. ${ }^{7}$. Os dois itens do setor de alimentos apresentam maior volatilidade, a trajetória de seus preços variam mais, ou seja, apresentam maior frequência de variação de preços e o tamanho dos ajustes de preços varia expressivamente ao longo do período analisado. Por sua vez, os gráficos referentes aos itens de serviços são mais "lineares", se aproximando mais de uma linha reta ascendente. O tamanho das variações de preços são mais constantes frente aos itens de alimentos. Apesar dos gráficos representarem uma pequena amostra de produtos, é possível notar que há heterogeneidade entre os setores, tanto com relação à frequência quanto com relação ao tamanho das mudanças de preços, característica em linha com a literatura e que será pautada nas próximas seções.

6 Há alguns métodos sugeridos por Nakamura e Steinsson (2008) que visam distinguir preços promocionais de preços regulares e serão aplicados futuramente neste estudo.

7 Itens semelhantes foram reportados por Araujo (2018) e estão em linha com os gráficos reportados por este trabalho. 
Figura 1 - Trajetória de preços - Itens de alimentação e serviços

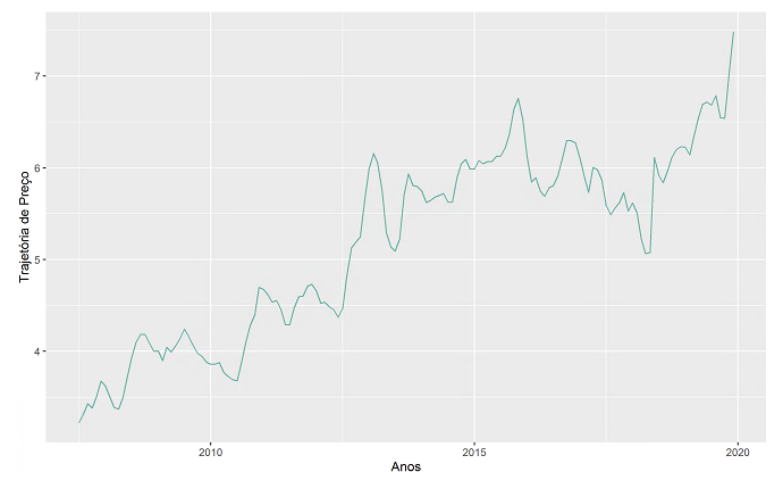

(a) Trajetória de preço do frango

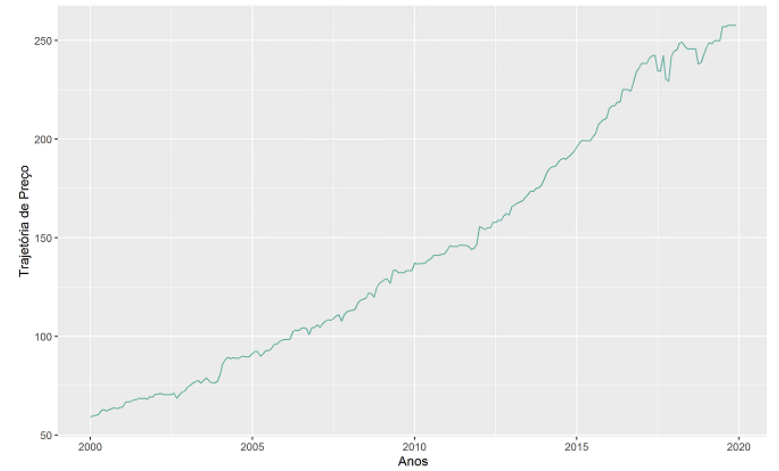

(c) Trajetória de preço de serviços de mecânica Notas: Elaboração Próprio autor

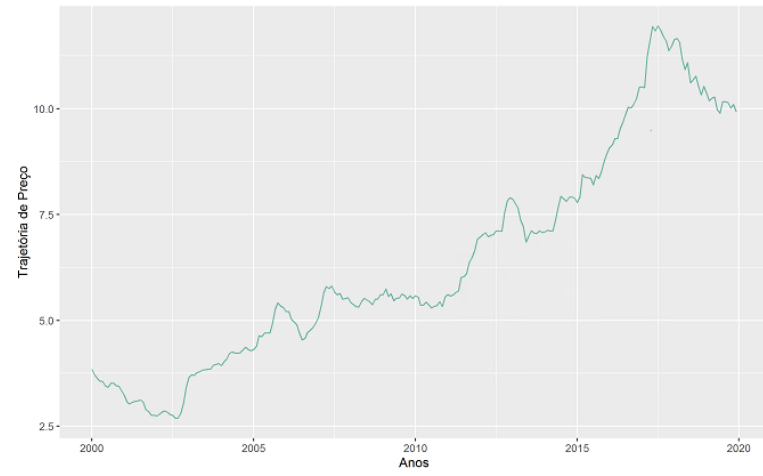

(b) Trajetória de preço do café

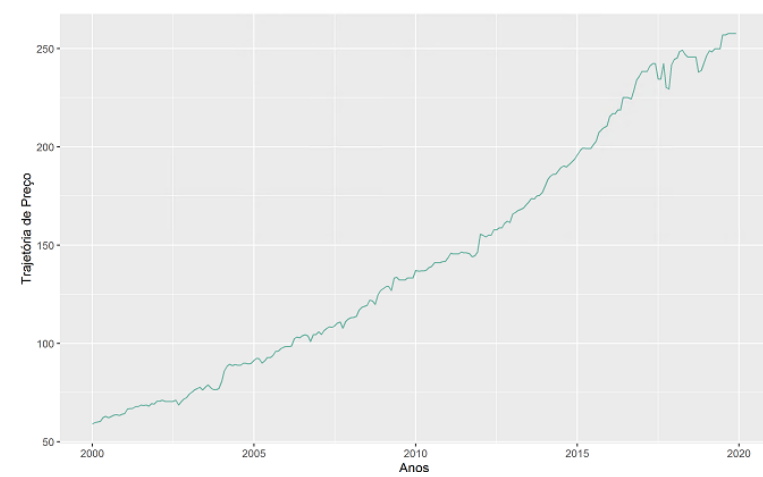

(d) Trajetória de preço da lavagem de carros

\subsection{Tratamento da amostra}

A base de dados foi previamente tratada para apresentação dos resultados presentes nos próximos capítulos. Os principais filtros aplicados foram a delimitação do período analisado por este trabalho e a exclusão de preços administrados por contratos e monitorados, sejam eles regulados pelo Governo Federal, Estadual, Municipal ou agências reguladoras. O período analisado compreende de Janeiro de 2000 a Dezembro de 2019 e os motivos para escolha do período já foram definidos. Preços administrados são estabelecidos por contrato ou órgão público, sendo assim, menos sensíveis às condições de oferta e de demanda. Em suma maioria, os contratos preveem reajustes de acordo com a inflação passada, de modo que essa indexação torna esses preços "dependentes do passado" e pouco sensíveis aos ciclos econômicos. São preços administrados os valores de remédios, combustíveis e tarifas associadas a serviços de utilidade pública, entre outros. O Apêndice C apresenta todos produtos cujos preços são regulados. No total, tais preços representam 996.301 observações, equivalente a $4,7 \%$ da base de dados original e somam 25,5\% na ponderação dos pesos da Pesquisa de Orçamento Familiar - POF da FIPE de 2011-2013. A Tabela 1 sumariza as 
principais aberturas da base de dados original e após o tratamento da amostra.

Tabela 1 - Base de dados tratada

\begin{tabular}{lcc}
\hline & Original & Tratada \\
\hline \hline Número de observações & 20.414 .307 & 16.884 .946 \\
Número de itens & 592.122 & 525.447 \\
Estabelecimentos & 12.648 & 11.544 \\
Produtos & 726 & 571 \\
Marcas & 15.190 & 13.278
\end{tabular}

Notas: Elaboração Próprio autor. A Tabela mostra as principais aberturas da base de dados utilizada. A base de dados original representa a base recebida da FIPE, sem nenhum filtro. A base de dados tratada representa a base original excluindo os meses de janeiro de 1994 a dezembro de 1999 e excluídos os preços administrados por contratos e monitorados.

A base de dados após o tratamento representa $74,5 \%$ da ponderação dos pesos da última POF-FIPE e 82,7\% do número de observações da base de dados original. A extensão média de uma série de preço é 30,2 meses (o período abrangido pela base de dados é de 240 meses), como visto na Figura 2 e na Tabela 2. A curta extensão média de uma série de preços reflete uma característica comum às bases de dados em que não há substituição de produtos, ou seja, qualquer alteração nos produtos resulta em um novo código. Apesar desta metodologia implicar em séries de preços mais curtas, a metodologia garante a consistência do mesmo produto ser observado ao longo do tempo sem nenhuma alteração. Autores que analisam dados sem substituições encontram médias semelhante a encontrada neste trabalho: ao analisar a mesma base de dados da FIPE do período de 1989 a 2007, Araujo (2018) encontra uma média de 21 meses. No mesmo sentido, Klenow e Kryvtsov (2008) encontram média de 43 meses por trajetória de preço ao analisar a base de dados da Bureau - Bureau Labor Statistics, dos Estados Unidos para o período de 1988 a 2005.

Tabela 2 - Estatísticas das trajetórias de preços

\begin{tabular}{lc}
\hline & Meses \\
\hline \hline Mínimo & 1,0 \\
Média & 30,2 \\
Máximo & 240,0 \\
Desvio Padrão & 41,0 \\
p25 & 4,0 \\
p50 & 14,0 \\
p75 & 38,0 \\
\hline
\end{tabular}

Notas: Elaboração Próprio autor 
Figura 2 - Densidade do comprimento das trajetórias de preço

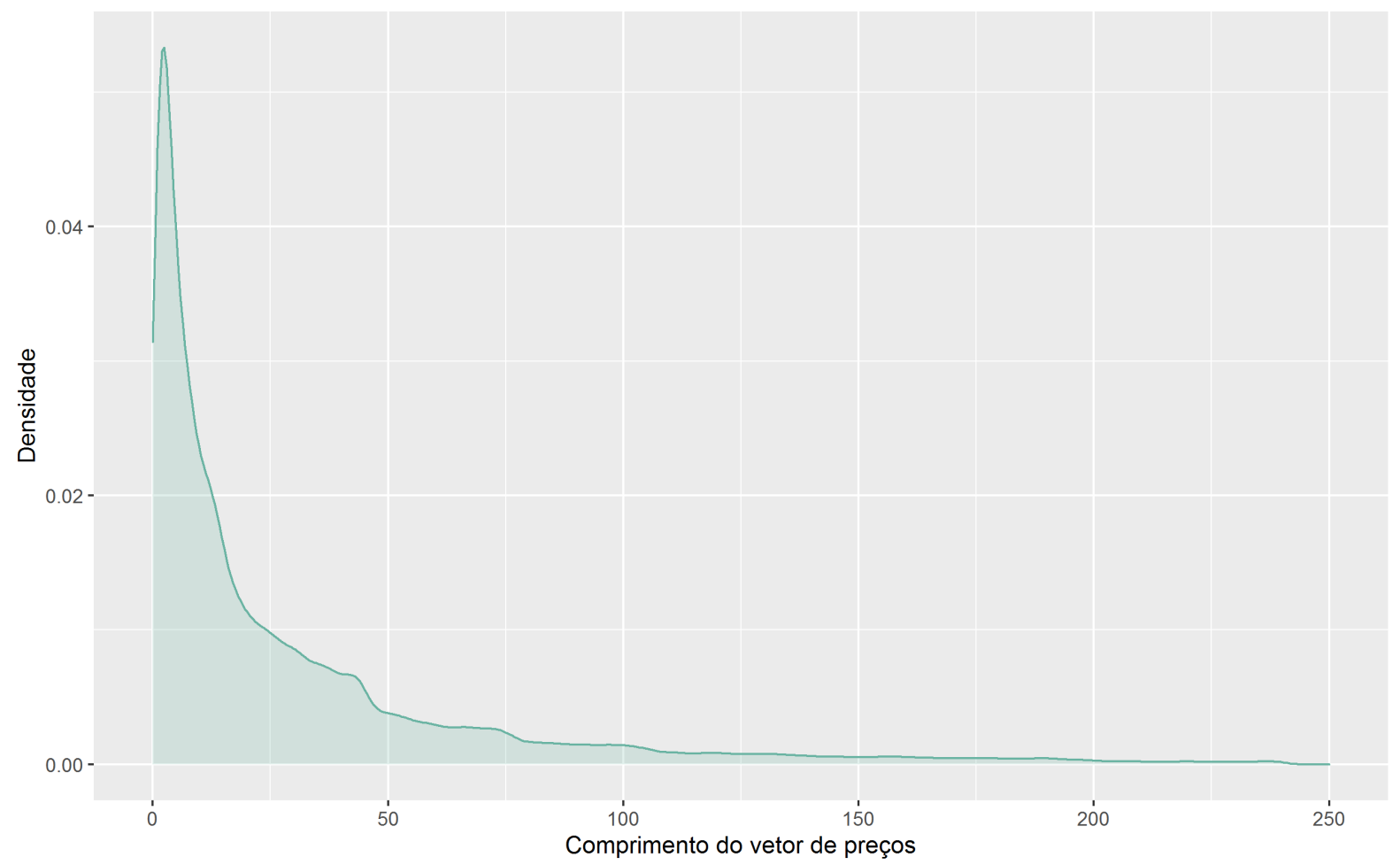

Notas: Elaboração Próprio autor

Para construir o IPC, a FIPE utiliza as ponderações da POF - Pesquisa de Orçamentos Familiares, calculada pela própria instituição. A Pesquisa de Orçamentos Familiares é um levantamento de dados realizado junto às "unidades de consumo", que podem ser famílias ou pessoas morando sozinhas. A população alvo da pesquisa é a residente no município de São Paulo. Para calcular o IPC, a FIPE pondera cada produto pelo respectivo peso na POF, sendo que essas ponderações utilizadas mudam conforme novas pesquisas se tornam disponíveis. As pesquisas de orçamentos são realizadas em média a cada 10 anos, mas nos últimos anos, este intervalo foi reduzido, de modo que durante o período observado por este trabalho, foram realizadas 3 pesquisas. As ponderações dos setores ao longo do período analisado se comportaram tal como descrito na Tabela 3. 
Tabela 3 - Ponderações da POF ao longo do período analisado

\begin{tabular}{lccc}
\hline \multicolumn{4}{c}{ Ponderações (\%) } \\
\hline \hline Setores & POF 98/99 & POF 09/10 & POF 11/13 \\
Período & $2000-2010$ & $07 / 2011-06 / 2015$ & $07 / 2015-2019$ \\
\hline Habitação & 32,79 & 30,94 & 31,12 \\
Alimentação & 22,73 & 22,92 & 24,55 \\
Transportes & 16,03 & 17,58 & 14,72 \\
Despesas pessoais & 12,30 & 11,91 & 13,64 \\
Saúde & 7,08 & 7,71 & 6,09 \\
Vestuário & 5,29 & 5,25 & 6,62 \\
Educação & 3,78 & 3,68 & 3,25 \\
\hline
\end{tabular}

Notas: Elaboração Próprio autor

\subsection{Definições}

As definições descritas nesta seção são utilizadas para calcular as frequências e tamanhos das variações de preços e se assemelham àquelas usadas por Araujo (2018) e Barros $(2009)^{8}$. Seja $p_{i, t}$ o preço do item $i$ no período $t$, sendo $t=1, \ldots, T$. $I_{i t}$ é uma variável indicadora dada por:

$$
I_{i t}= \begin{cases}1 & \text { se } p_{i t} \neq p_{i t-1} \\ 0 & \text { se } p_{i t}=p_{i t-1}\end{cases}
$$

A variável $I_{i t}$ é definida apenas se as observações $t$ e $t-1$ forem observadas (diferentes de missing).

Cada item $i$ pertence a uma categoria de produtos $y$, sendo $y=1, \ldots, Y$. A frequência de mudanças de preços para um determinado produto $y$ em um determinado período $t$ é dado por:

$$
f_{y t}=\sum_{i \in S_{y t}} \frac{I_{i t}}{N_{y t}}
$$

Sendo:

$$
S_{y t}=\left\{i \in y, I_{i t} \in\{0,1\}\right\}
$$

$S_{y t}$ é o conjunto de preços diferentes de missing do item $i$ pertencentes ao setor $y$ e $N_{y t} \equiv \# S_{y t}$ denota o número de elementos no conjunto $S_{y t}$, portanto, é um número

\footnotetext{
8 Nota-se que o trabalho citado define $p_{i, t}$ como o logaritmo do preço do item $i$ no período $t$, enquanto o
} presente estudo define $p_{i, t}$ como o preço do item $i$ no período $t$. 
cardinal. A frequência das mudanças de preço para um produto y é definida como a fração de todas as observações cujos preços sofreram alterações em relação ao total de observações do produto $y$.

Por sua vez, cada categoria de produto $y$ pertence a um setor $j$, sendo que $j=1, \ldots, J$. A separação por setores é a agregação que será mais utilizada nesta dissertação. A frequência de mudanças de preço para um determinado setor $j, f_{j}$, é a média da frequência de todos os produtos pertencentes ao setor ponderada pelos seus respectivos pesos na POF-FIPE, $\omega_{y t}$ :

$$
f_{j t}=\sum_{y \in j} \omega_{y t} f_{y t}
$$

O vetor de ponderações dos produtos, $\omega_{y t}$, varia ao longo do tempo de acordo com as variações na POF-FIPE, assim como sumarizado na Tabela 3. Os pesos são recalculados de modo que $\sum_{y=1}^{Y} \omega_{y t}=1$ para todo período $t$. É importante notar que ao longo desta dissertação foram utilizadas três formas distintas de categorizar os produtos em setores. Então, entre os painéis, a única diferença é a composição dos produtos y nos setores $j$. Ainda, as definições de frequências dos ajustes positivos e negativos para um dado setor $j$ são dadas, respectivamente, por:

$$
\begin{aligned}
& f_{j t}^{+}=\sum_{y \in j}\left(\frac{\omega_{y t}}{N_{y t}} \sum_{i \in S_{y t}} I_{i t}^{+}\right) \\
& f_{j t}^{-}=\sum_{y \in j}\left(\frac{\omega_{y t}}{N_{y t}} \sum_{i \in S_{y t}} I_{i t}^{-}\right)
\end{aligned}
$$

Em que $I_{i t}^{+}=1$ se $p_{i t}>p_{i t-1}$ e, analogamente, $I_{i t}^{-}=1$ se $p_{i t}<p_{i t-1}$.

Por fim, a frequência total de variações de preços, considerando todos os produtos contidos na amostra, em um determinado período $t$ é dada por:

$$
f_{t}=\sum_{y}^{Y} \omega_{y t} f_{y t}
$$

Assim, as frequências dos ajustes positivos e negativos, considerando toda amostra, são dadas por:

$$
\begin{aligned}
& f_{t}^{+}=\sum_{y=1}^{Y}\left(\frac{\omega_{y t}}{N_{y t}} \sum_{i \in S_{y t}} I_{i t}^{+}\right) \\
& f_{t}^{-}=\sum_{y=1}^{Y}\left(\frac{\omega_{y t}}{N_{y t}} \sum_{i \in S_{y t}} I_{i t}^{-}\right)
\end{aligned}
$$


Por definição, $f_{t}=f_{t}^{+}+f_{t}^{-}$.

As próximas definições se referem ao tamanho das variações preços. O tamanho médio dos ajustes de preços de um determinado produto $y$ em um período $t$ é dado por:

$$
\Delta p_{y t}=\sum_{i \in S_{y t}^{*}} \frac{\left|\Delta p_{i t}\right|}{N_{y t}^{*}}
$$

Sendo, $S_{y t}^{*}$ definido como:

$$
S_{y t}^{*}=\left\{i \in y, I_{i t}=1\right\}
$$

$S_{y t}^{*}$ é o conjunto de observações em que o item $i$, pertencente ao setor $y$, varia de preço e, analogamente, $N_{y t}^{*} \equiv \# S_{y t}^{*}$. Enquanto, $\left|\Delta p_{i t}\right|=\left|\frac{p_{i t}}{p_{i t-1}}-1\right|$.

O tamanho médio dos ajustes de preços de um determinado setor $j$ em um período $t$ é dado por:

$$
\Delta p_{j t}=\sum_{y \in j} \omega_{y t}\left|\Delta p_{y t}\right|=\sum_{y \in j}\left(\frac{\omega_{y t}}{N_{y t}^{*}} \sum_{i \in S_{y t}^{*}}\left|\Delta p_{i t}\right|\right)
$$

Os tamanhos médios absolutos das mudanças de preços positivas e negativas para um setor $j$ são dados, respectivamente, por:

$$
\begin{aligned}
& \Delta p_{j t}^{+}=\sum_{y \in j} \omega_{y t}\left|\Delta p_{y t}^{+}\right|=\sum_{y \in j}\left(\frac{\omega_{y t}}{N_{y t}^{*+}} \sum_{i \in S_{y t}^{*+}}\left|\Delta p_{i t}^{+}\right|\right) \\
& \Delta p_{j t}^{-}=\sum_{y \in j} \omega_{y t}\left|\Delta p_{y t}^{-}\right|=\sum_{y \in j}\left(\frac{\omega_{y t}}{N_{y t}^{*-}} \sum_{i \in S_{y t}^{*-}}\left|\Delta p_{i t}^{-}\right|\right)
\end{aligned}
$$

Em que, novamente, são definidos os conjuntos $S_{y t}^{*+}=\left\{i \in y, p_{i t}>p_{i t-1}\right\}$ e $S_{y t}^{*-}=$ $\left\{i \in y, p_{i t}<p_{i t-1}\right\}$, e o número de elementos em cada um desses conjuntos é dado por $N_{y t}^{*+} \equiv \# S_{y t}^{*+}$ e $N_{y t}^{*-} \equiv \# S_{j t}^{*-}$.

Para o tamanho das variações de preços considerando toda a amostra, aplicam-se as definições abaixo, análogas as apresentadas acima:

$$
\begin{aligned}
& \Delta p_{t}=\sum_{y=1}^{Y} \omega_{y t}\left|\Delta p_{y t}\right| \\
& \Delta p_{t}^{+}=\sum_{y=1}^{Y} \omega_{y t}\left|\Delta p_{y t}^{+}\right|
\end{aligned}
$$




$$
\Delta p_{t}^{-}=\sum_{y=1}^{Y} \omega_{y t}\left|\Delta p_{y t}^{-}\right|
$$

Das definições, segue-se a identidade $\Delta p_{t}=\frac{f_{t}^{+}}{f_{t}} \Delta p_{t}^{+}+\frac{f_{t}^{-}}{f_{t}} \Delta p_{t}^{-}$.

\subsection{Principais resultados empíricos}

A Tabela 4 apresenta a frequência média das mudanças de preços e o tamanho médio das variações de preços durante todo o período analisado. Em média, 38,9\% variam mensalmente e, condicional a mudança de preço, a magnitude média da variação é de 9,6\%. Entre os preços que variam, os aumentos de preços são mais frequentes $(56 \%$ dos ajustes) e maiores (10,0\% frente a 7,6\%), na média, do que quedas de preços. Os resultados encontrados estão em linha com os reportados na literatura, como descrito na Tabela 5. Ao analisar o período pós Plano Real, 1995 a 2007, Araujo (2018) mostra que 36,8\% dos preços variam mensalmente, sendo que estes aumentam, em média, 11,4\% e reduzem em 9,9\%. Gouvea (2007) analisa os microdados do IPE-FGV de 1996 a 2006, em que o tamanho do aumento médio de preços é maior do que o tamanho da queda, $16 \%$ frente a $12,6 \%$. Todos os trabalhos citados não descartam os preços promocionais de suas amostras. Barros (2009), por sua vez, descarta os preços promocionais e os resultados encontrados mostram que aproximadamente $37,2 \%$ dos preços variam mensalmente, e as quedas de preços passam a ser mais expressivas do que os aumentos, $14,6 \%$ frente a $12,0 \%$.

Tabela 4 - Frequência e tamanho das variações de preços (\%)

\begin{tabular}{lcccc}
\hline & Média & Mediana & Aumentos & Quedas \\
\hline \hline Frequência de mudanças de preços & 38,9 & 39,0 & 21,8 & 17,1 \\
Tamanho das mudanças de preços & 9,6 & 9,5 & 10,0 & 7,6 \\
\hline
\end{tabular}

Notas: Elaboração Próprio autor. A primeira linha da tabela mostra a frequência de mudança de preços observada entre todos os períodos da base de dados. A linha seguinte apresenta o tamanho destas variações.

Tabela 5 - Comparação entre artigos (\%)

\begin{tabular}{lccc}
\hline Base de dados & $\begin{array}{c}\text { Presente estudo } \\
\text { IPC-FIPE } \\
\text { Período analisado }\end{array}$ & $\begin{array}{c}\text { Araujo (2008) } \\
\text { IPC-FIPE } \\
1999-2019\end{array}$ & $\begin{array}{c}\text { Barros (2009) } \\
\text { IPC-FGV } \\
\text { 1995-2007 }\end{array}$ \\
\hline \hline Frequência de mudanças de preços & 38,9 & 36,8 & 37,2 \\
Tamanho das mudanças de preços & 9,6 & 11,5 & 13,0 \\
\hline
\end{tabular}

Notas: Elaboração Próprio autor. A primeira linha da tabela mostra a frequência de mudança de preços observada entre todos os períodos da base de dados. A linha seguinte apresenta o tamanho destas variações. 
A distribuição da frequência dos ajustes de preços entre os itens da amostra é reportada na Figura 3. Apesar da média e da mediana da frequência da mudança de preço serem próximas (38,9 e 39,0, respectivamente, assim como reportado na Tabela 4), nota-se que a distribuição é assimétrica com calda mais grossa à esquerda, ou seja, a maior parte dos itens apresentam baixa frequência de variação de preço. Os itens da amostra que apresentam variação de preço próxima a um, ou seja, em quase todos os meses seus preços são alterados, estão especialmente relacionados à aquisição de veículos e motocicletas ou a seguros de vida.

Figura 3 - Densidade da frequência da variação de preços

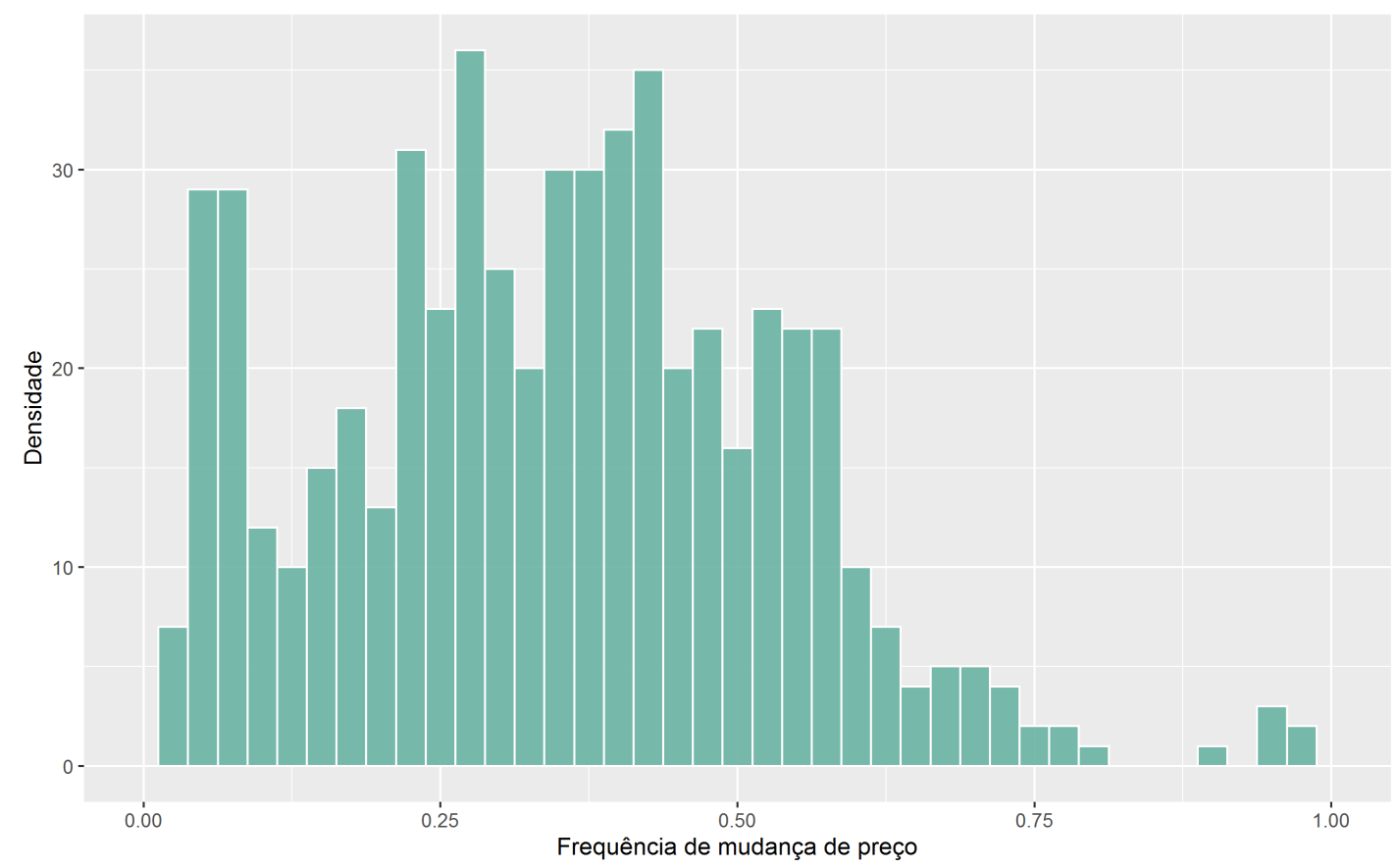

Notas: Elaboração Próprio autor

A Figura 4 apresenta a frequência mensal da variação de preços ao longo do período analisado. A figura apresenta as estatísticas referentes a aumentos de preço (linha vermelha), quedas de preço (linha azul escura) e variações de preços totais, que considera tanto aumento quanto queda de preços (linha azul clara). A frequência de ajustes de preços não apresenta grandes variações ao longo do período analisado, especialmente, a frequência de quedas de preços, que oscila entre $10 \%$ e $20 \%$. A frequência do aumento de preços, por sua vez, apresenta alguns picos no começo dos anos 2000 em que a frequência de ajuste mensal se aproxima de $40 \%$, enquanto nos últimos anos oscilou abaixo de $20 \%$. Inicialmente, foi considerado estudar neste trabalho o período pós Plano Real, desde 1994 até 2019. Todavia, há uma diferença expressiva no comportamento da frequência de 
mudança de preços em 1999 com o período analisado ${ }^{9}$. Assim, frente ao cenário em que não há quebras expressivas, a analise deste trabalho mantém consistência ao analisar o período de 2000 a 2019.

Figura 4 - Frequência de variação de preços ao longo do período analisado

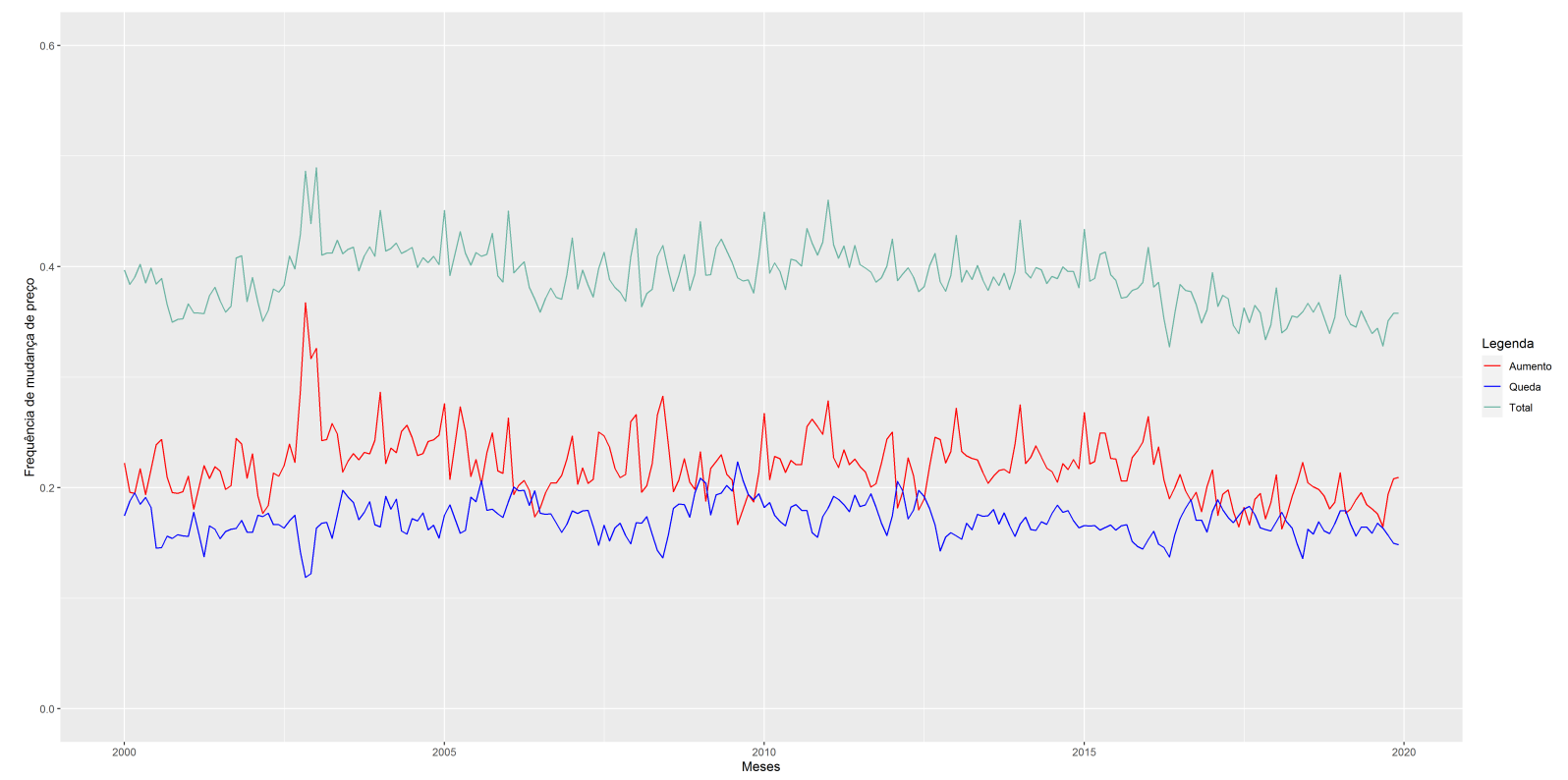

Notas: Elaboração Próprio autor

Segmentando as estatísticas descritivas das frequências de mudança de preço entre quedas e aumentos de preços, a Tabela 6 reporta a distribuição do tamanho de ajustes de preços condicional à mudança de preço. Quase um terço dos ajustes de preços apresentam variações menores que $5 \%$ e mais da metade apresentam variações menores que $10 \%$. A distribuição do ajuste de preços se desvia de uma normal pela grande proporção de preços cujo ajuste de valor é pequeno. Nota-se também que a assimetria entre os ajustes de preços negativos e positivos é pequena, característica corroborada pela Figura 5. Barros (2009) encontra uma assimetria entre preços positivos e negativos maior do que encontrada no presente trabalho. Considerando apenas as variações de preços menores que 2,5\%, a autora mostra que a porcentagem correspondente a variações positivas é de aproximadamente $20 \%$, enquanto o mesmo número para as quedas de preços é menor do que $13 \%$. Tais diferenças podem ser atribuídas à exclusão dos preços promocionais da amostra da autora, de modo que parte dos preços que esta dissertação entende como variações pequenas de preço são decorrentes de promoções.

9 Maiores detalhes estão presentes no Apêndice B. 
Tabela 6 - Estatísticas da distribuição de preços (\%)

\begin{tabular}{lcccc}
\hline Variação de preço & $<2,5 \%$ & $<5 \%$ & $<10 \%$ & $<20 \%$ \\
\hline \hline Total & 15,3 & 30,5 & 56,2 & 83,3 \\
Positivo & 14,9 & 30,1 & 55,5 & 81,7 \\
Negativo & 15,9 & 31,0 & 57,0 & 85,2 \\
\hline
\end{tabular}

Notas: Elaboração Próprio autor

Figura 5 - Densidade dos tamanhos dos ajustes de preços

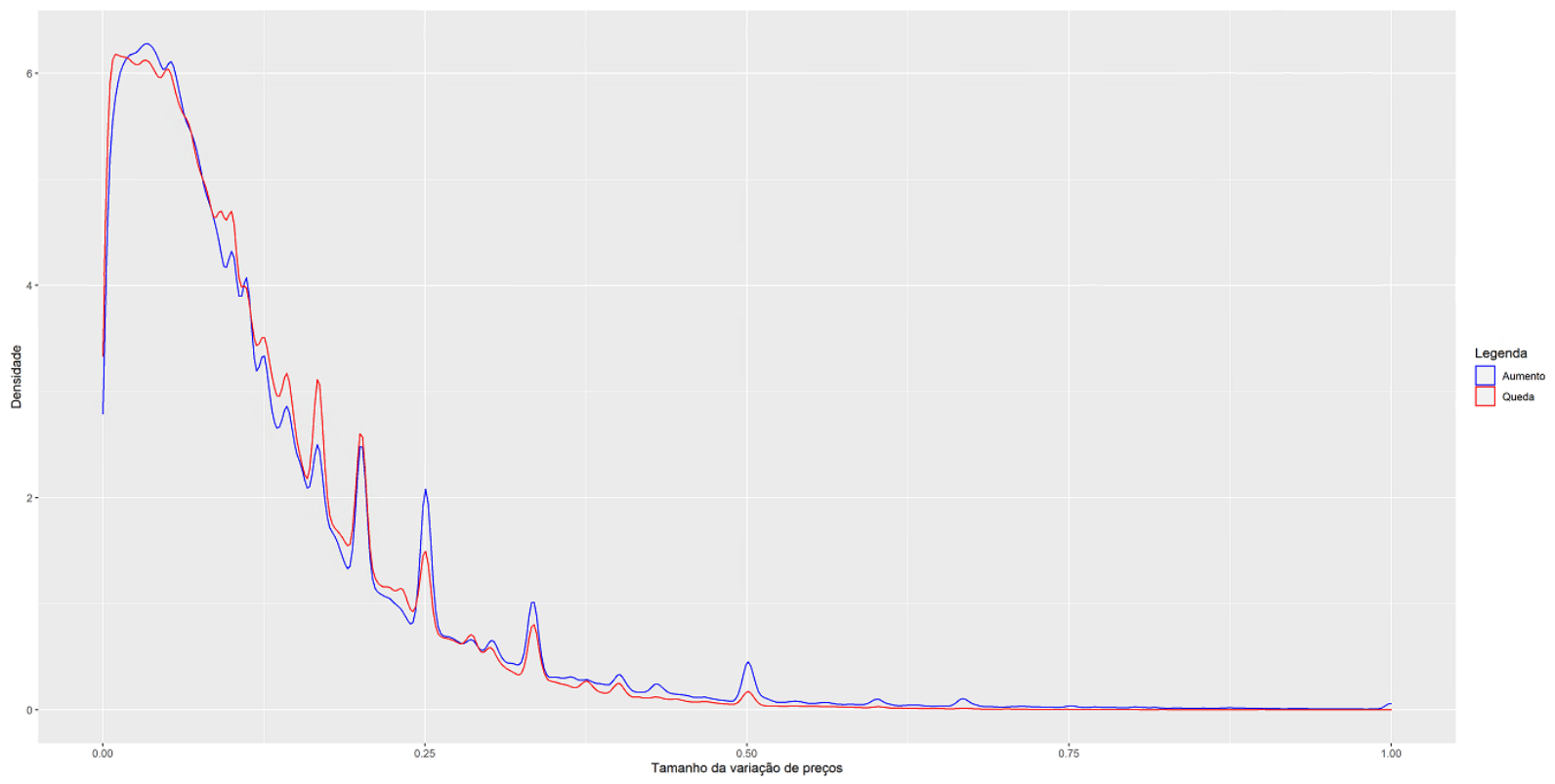

Notas: Elaboração Próprio autor

\subsection{Evidências da Heterogeneidade}

Heterogeneidade e assimetria da frequência do ajuste de preços são temas recorrentes na literatura. Esta subseção apresenta as evidências de heterogeneidade entre setores. A estratégia utilizada é construir três painéis distintos, cada um destes painéis contém números diferentes de setores, que por sua vez contemplam os produtos. Foram feitos 3 painéis. Como descrito na tabela abaixo, o painel A, com 3 setores, segue a divisão de produtos do Índice de preços ao consumidor (IPCA - IBGE) para os preços livres ${ }^{10}$, agrupamento similar ao utilizado por Araujo (2018) e Barros (2009); O painel B apresenta 7 setores, divisão feita com base na segmentação da POF-FIPE; e por fim, o painel C

10 Nota-se que a divisão original consiste em 4 grandes setores, Alimentos, Serviços, Bens Industriais e Monitorados. No entanto, os preços administrados foram excluídos da base utilizada neste estudo. 
apresenta 12 setores, separados com base nos subgrupos do IPCA-IBGE ${ }^{11}$. A separação dos produtos entre setores demonstra a heterogeneidade entre setores, enquanto a comparação entre os painéis corrobora para a heterogeneidade entre os produtos, uma vez que os produtos são separados de maneiras distintas na comparação dos painéis. ${ }^{12}$

Tabela 7 - Critérios utilizados para separação dos produtos em setores

\begin{tabular}{ccc}
\hline Painéis & Número de setores & Critério para divisão \\
\hline $\mathrm{A}$ & 3 setores & IPCA - IBGE \\
$\mathrm{B}$ & 7 setores & POF-FIPE \\
$\mathrm{C}$ & 12 setores & Subgrupos do IPCA-IBGE \\
\hline
\end{tabular}

Notas: Elaboração Próprio autor.

A Tabela 8 apresenta os três painéis e os respectivos pesos e estatísticas descritivas de cada setor. As estatísticas mostram que as frequências de mudanças de preços variam de aproximadamente $3 \%$ até $53 \%$ aproximadamente. O tamanho das variações de preço está dentro de um intervalo expressivamente menor, de $3 \%$ a 20\%. A assimetria entre os setores é clara. Considerando o painel com 12 setores, a relação entre a frequência de aumentos de preços e quedas de preços é de aproximadamente 1,1 no setor de "Alimentos in natura", por sua vez, a mesma relação é de 7,2 no setor de "Serviços e produtos de saúde". Apesar da frequência e do tamanho das variações de preços variarem significativamente entre os setores, é possível observar que há uma relação negativa entre as variáveis. Setores que apresentam elevada frequência de variação tendem a apresentar mudanças de preços menores, tal relação fica mais clara na Figura 6. A figura contempla todos setores dos três painéis e mostra a relação entre a variável de frequência e tamanho da mudança de preço. Nota-se que apesar da média da frequência e a mediana serem próximas, a segmentação em setores evidencia melhor a heterogeneidade e assimetria destes.

Os resultados observados estão em linha com o apresentado por Araujo (2018) e Barros (2009), que também mostram evidências de heterogeneidade para o caso brasileiro. Ao analisar o período pós Plano Real (1994-2007), Araujo (2018) segmenta os produtos em três setores: Alimentos em casa, Produtos industriais e Serviços. No período pós Plano-Real, a autora documenta que a menor frequência é dada por Serviços, 15,4\%, e a maior é dada por Alimentos em casa, 26,5\%. Ao segmentar os produtos em 7 grupos, os resultados encontrados pela autora também corroboram para a presença de elevada heterogeneidade.

11 Nota-se que a divisão do IPCA-IBGE contempla mais setores do que os doze setores apresentados aqui. No entanto, alguns setores contemplavam apenas produtos administrados, portanto, não foram inclusos na presente análise

12 Em todos os painéis foram realizadas ponderações nos pesos dos setores para que a soma de todos os setores seja um. Tal ponderação é necessária uma vez que excluídos os preços administrados, a soma dos produtos é menor que um. 
Barros (2009) analisa o IPC-FGV de 1996 a 2008. A autora também utiliza a estratégia de dividir a amostra em três grupos distintos: bens, serviços e produtos regulamentados. A autora nota as assimetrias na frequência e tamanho do ajuste de preços entre os grupos. A frequência dos ajustes positivos no setor de serviços é cerca de cinco vezes a frequência dos ajustes negativos, enquanto essa relação é de aproximadamente 1,4 na categoria de bens. A autora apresenta também os produtos da amostra divididos em 17 grupos e prova que o grau de heterogeneidade é alto entre os setores. A autora pontua também que os grupos com preços mais rígidos tendem a apresentar frequência e tamanho mais assimétricos de ajustes.

Tabela 8 - Características dos setores para os modelos multissetoriais (\%)

\begin{tabular}{|c|c|c|c|c|c|c|c|}
\hline \multirow[b]{2}{*}{ Nome } & \multirow[b]{2}{*}{ Peso } & \multicolumn{3}{|c|}{ Frequência } & \multicolumn{3}{|c|}{ Tamanho } \\
\hline & & Total & Aumento & Queda & Total & Aumento & Queda \\
\hline & \multicolumn{7}{|c|}{ Painel A: Três Setores } \\
\hline I. Alimentos & 27,6 & 44,0 & 24,0 & 19,9 & 14,1 & 15,1 & 12,6 \\
\hline II. Bens Industriais & 29,6 & 39,0 & 21,3 & 17,7 & 10,1 & 10,1 & 9,5 \\
\hline \multirow[t]{2}{*}{ III. Serviços } & 42,8 & 19,8 & 12,5 & 7,3 & 6,9 & 6,9 & 5,5 \\
\hline & \multicolumn{7}{|c|}{ Painel B: Sete Setores } \\
\hline I. Alimentação & 23,1 & 42,7 & 23,5 & 19,2 & 14,0 & 15,2 & 12,5 \\
\hline II. Despesas Pessoais & 12,5 & 26,8 & 15,8 & 10,9 & 11,1 & 11,6 & 10,5 \\
\hline III. Educação & 3,6 & 15,9 & 10,4 & 5,4 & 10,2 & 10,8 & 9,4 \\
\hline IV. Habitação & 32,1 & 34,7 & 19,6 & 15,4 & 9,3 & 9,7 & 8,9 \\
\hline V. Saúde & 7,2 & 4,2 & 3,6 & 1,0 & 16,1 & 16,5 & 13,6 \\
\hline VI. Transportes & 16,0 & 32,9 & 18,8 & 14,0 & 3,3 & 3,8 & 2,7 \\
\hline \multirow[t]{2}{*}{ VII. Vestuário } & 5,5 & 53,0 & 27,5 & 25,3 & 9,8 & 10,4 & 9,2 \\
\hline & \multicolumn{7}{|c|}{ Painel C: Doze Setores } \\
\hline I. Alimentos in natura & 7,3 & 52,7 & 27,4 & 25,3 & 19,2 & 21,9 & 16,3 \\
\hline II. Alimentos semielaborados & 20,2 & 43,5 & 24,3 & 19,1 & 11,0 & 11,8 & 9,9 \\
\hline III. Alimentação fora do domicílio & 4,7 & 11,1 & 8,6 & 2,4 & 12,7 & 11,7 & 11,6 \\
\hline IV. Habitação & 9,5 & 33,2 & 19,1 & 14,1 & 9,9 & 10,3 & 9,3 \\
\hline V. Móveis e eletrodomésticos & 5,0 & 42,5 & 22,7 & 19,7 & 9,0 & 9,5 & 8,5 \\
\hline VI. Roupas e calçados & 7,4 & 53,7 & 28,5 & 25,3 & 9,6 & 10,2 & 8,9 \\
\hline VII. Transporte público & 7,5 & 4,9 & 4,5 & 0,4 & 12,0 & 12,2 & 9,3 \\
\hline VIII. Veículo próprio & 8,8 & 33,8 & 19,1 & 14,7 & 3,2 & 3,7 & 2,7 \\
\hline IX. Serviços e produtos de saúde & 7,8 & 4,2 & 3,6 & 0,5 & 16,1 & 16,5 & 13,6 \\
\hline X. Cuidados e serviços pessoais & 4,4 & 19,9 & 12,1 & 7,8 & 11,6 & 1201 & 10,9 \\
\hline XI. Recreação, fumo e fotografia & 4,7 & 32,1 & 17,8 & 14,2 & 9,7 & 10,4 & 8,8 \\
\hline XII. Educação & 12,7 & 13,2 & 8,5 & 4,6 & 11,7 & 11,9 & 11,3 \\
\hline
\end{tabular}

Notas: Elaboração Próprio autor 
Figura 6 - Frequência e tamanho das variações de preços entre diferentes setores

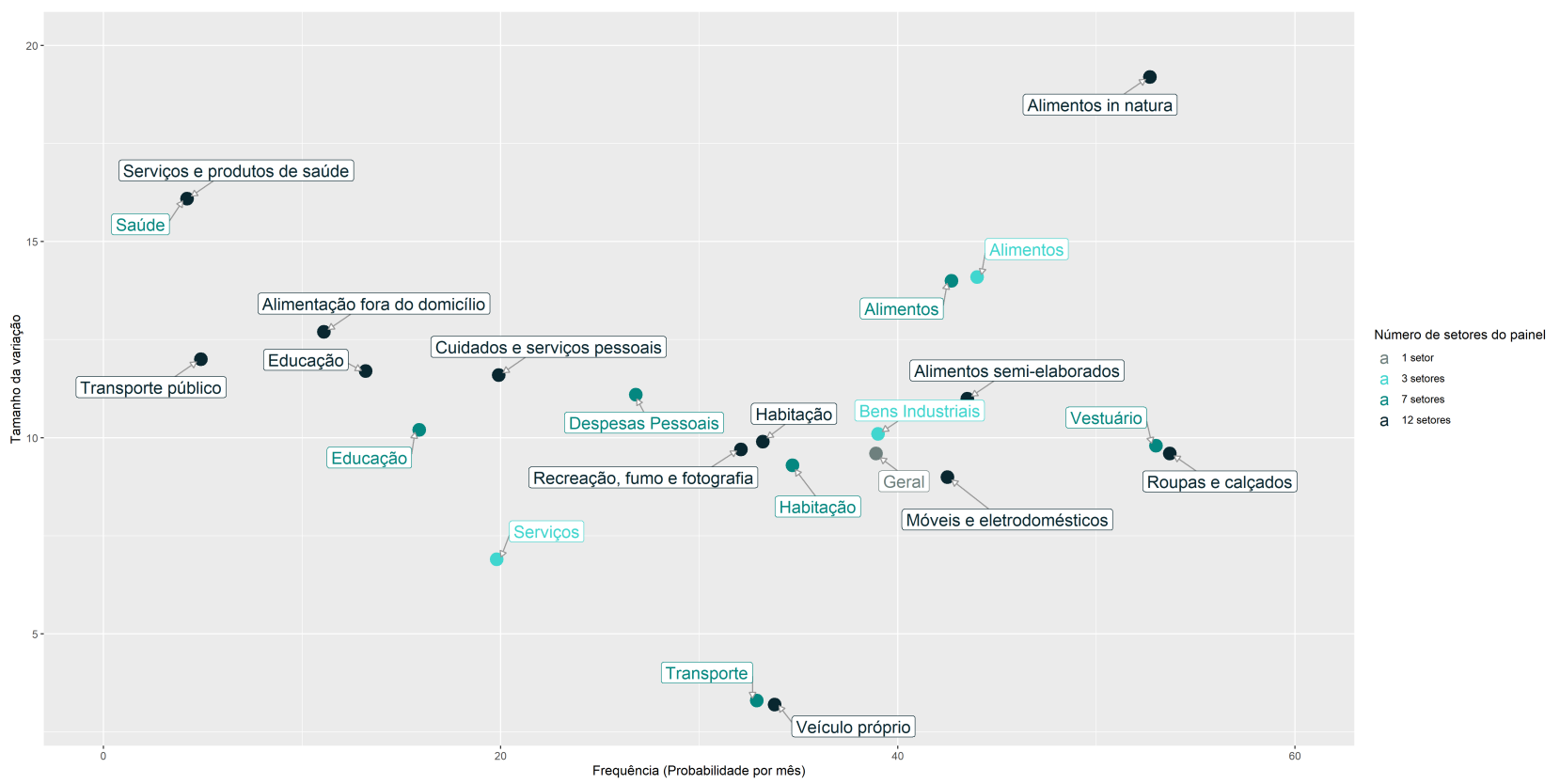

Notas: Elaboração Próprio autor 


\section{Metodologia}

\subsection{Modelo}

Inspirado nos preceitos e na modelagem da Nakamura e Steinsson (2010) este trabalho irá recorrer a um Modelo de custo de menu multissetorial para avaliar o comportamento da fixação de preços entre os diferentes setores. O modelo se assemelha ao utilizado por Golosov e Lucas (2007), mas introduz a heterogeneidade através da separação dos produtos em múltiplos setores. Adicionalmente, para fins comparativos, também será calibrada uma extensão do modelo de Custo de Menu que incorpora alguns preceitos do modelo de Calvo (1983), modelo denominado por Nakamura e Steinsson (2010) como "CalvoPlus". Neste modelo, haverá a inclusão de um componente time dependent no custo de menu. Em cada período, as firmas poderão se defrontar com um custo de menu relativamente baixo, com probabilidade $1-\alpha_{j}$, ou com um custo de menu alto, com probabilidade $\alpha_{j}$. Portanto, em ambas situações alterações de preços são factíveis. Estas suposições mantêm a tratabilidade do modelo Calvo, mas ao mesmo tempo, capturam a ideia de que o momento em que a empresa recebe a oportunidade de ajustar seus preços ao baixo custo é amplamente ortogonal à vontade da empresa de alterar seu preço.

Nota-se que tanto no modelo de Custo de Menu quanto no CalvoPlus, será feita a calibração dos modelos considerando todas as firmas em um único setor, unissetorial, quanto segmentado as firmas em vários setores, modelos multissetoriais. A estratégia utilizada é construir três painéis distintos, já apresentados anteriormente, cada um destes painéis contendo números diferentes de setores, que por sua vez contemplam os produtos. Para cada painel apresentado serão calibrados os modelos utilizados acima.

\subsubsection{Famílias}

O modelo contempla que há um contínuo de famílias idênticas distribuídas uniformemente no intervalo $[0,1]$. As famílias maximizam a utilidade esperada, sendo o desconto a utilidade futura dado por um fator $\beta$ por período. As famílias têm aversão ao risco relativo constante (CRRA) e igual a $\gamma$; com relação à desutilidade relacionada ao trabalho, as famílias têm nível e convexidade dadas pelos parâmetros $\omega$ e $\psi$, respectivamente. Assim:

$$
E_{t} \sum_{\tau=0}^{\infty} \beta^{\tau}\left[\frac{1}{1-\gamma} C_{t+\tau}^{1-\gamma}-\frac{\omega}{\psi+1} L_{t+\tau}^{\psi+1}\right]
$$

Onde $E_{t}$ denota o operador de expectativas condicionado à informação conhecida no período $t, C_{t}$ indica o consumo das famílias de um bem composto e $L_{t}$ denota o 
número de horas de trabalho ofertado pelas famílias. As famílias consomem um contínuo de diferentes bens indexados por $z$, de modo que o consumo agregado das famílias $C_{t}$ é um índice Dixit-Stiglitz dos diferentes bens:

$$
C_{t}=\left[\int_{0}^{1} c_{t}(z)^{\frac{\theta-1}{\theta}}\right]^{\frac{\theta}{\theta-1}}
$$

Onde $c_{t}(z)$ é o consumo do bem $z$ pelas famílias no instante $t$ e $\theta$ denota a elasticidade de substituição entre diferentes bens em um mesmo instante de tempo.

Um ativo contingente, que pode ser comprado em qualquer período $t, B_{t}$, é negociado nesta economia, de modo que a restrição orçamentária das famílias é dada por:

$$
P_{t} C_{t}+E_{t}\left[D_{t, t+1} B_{t+1}\right] \leq B_{t}+W_{t} L_{t}+\int_{0}^{1} \Pi_{t}(z) d z
$$

Onde $B_{t+1}$ é a quantidade de ativos comprada no período $t$ e vendido em $t+1$. $D_{t, t+1}$ é o preço do ativo no período $t$. Tais títulos são vendidos no período seguinte ao da compra a um preço unitário, de modo que no período $t$, o indivíduo vende os títulos comprados no período $t-1$ e obtém $B_{t} ; \Pi_{t}(z)$ denota o lucro da firma $z$ no período $t$; e, por fim, $P_{t}$ é o nível de preços agregado desta economia tal que:

$$
P_{t}=\left[\int_{0}^{1} p_{t}(z)^{1-\theta} d z\right]^{\frac{1}{1-\theta}}
$$

Onde $p_{t}(z)$ é o preço do bem $z$ no instante $t$.

Assim, inicialmente, as famílias maximizam seu consumo sujeito a um valor estipulado para o gasto com consumo total, denotado por $k_{t}$ :

$$
\operatorname{Max}_{c_{t}(z)}\left[\int_{0}^{1} c_{t}(z)^{\frac{\theta-1}{\theta}} d z\right]^{\frac{\theta}{\theta-1}}-\lambda\left[\int_{0}^{1} p_{t}(z) c_{t}(z) d z-k_{t}\right]
$$

sujeito às equações (19), (20) e (21), além da condição de Non-Ponzi game, dada por:

$$
\lim _{t \rightarrow \infty} E_{t}\left[D_{t-1, t} B_{t}\right] \geq 0 \quad \forall t
$$

A demanda da família por um determinado bem $z$ no período $t$ será então:

$$
c_{t}(z)=C_{t}\left(\frac{p_{t}(z)}{P_{t}}\right)^{-\theta}
$$

Dada a relação entre o consumo dos diferentes bens $z$ e o consumo agregado, as condições de primeira ordem do problema das famílias são dadas por: 


$$
\begin{gathered}
D_{t, T}=\beta^{T-t}\left(\frac{C_{T}}{C_{t}}\right)^{-\gamma} \frac{P_{t}}{P_{T}} \\
\frac{W_{t}}{P_{t}}=\omega L_{t}^{\psi} C_{t}^{\gamma}
\end{gathered}
$$

Além da condição de transversalidade. A equação (25) é a equação de Euler enquanto a equação (26) descreve a quantidade de trabalho ofertada pelas famílias com relação ao salário real.

\subsubsection{Firmas}

O modelo considera que há um número contínuo de firmas indexado por z. Cada empresa pertence a um setor $j$, em que $j \in J$, sendo $J$ o número de setores presentes na economia. Cada empresa é especializada na produção de um produto distinto, de modo que a produção de uma determinada firma $z$ é dada por:

$$
y_{t}(z)=A_{t} L_{t}(z)^{1-s_{m}} M_{t}(z)^{s_{m}}
$$

Onde $y_{t}(z)$ denota a produção da firma $z$ no período $t, L_{t}(z)$ denota a quantidade de trabalho que a firma $z$ emprega no período $t, M_{t}(z)$ é um índice de insumos intermediários usados na produção de produto $z$ no período $t, s_{m}$ denota a participação de insumos intermediários na produção da firma $z$ e $A_{t}(z)$ é a produtividade de $z$ no período $t$.

Como no modelo de Basu (1994), o modelo supõe que todos os produtos são tanto produtos finais quanto insumos. Assim, a quantidade de insumos intermediários usados para produzir z é dado por:

$$
M_{t}(z)=\left(\int_{0}^{1} m_{t}\left(z, z^{\prime}\right)^{\frac{\theta-1}{\theta}} d z^{\prime}\right)^{\frac{\theta}{\theta-1}}
$$

Onde $m_{t}\left(z, z^{\prime}\right)$ é a quantidade de $z^{\prime}$ utilizado como insumo intermediário pela firma z. O problema inicial de uma firma $z$ é minimizar o custo com insumos intermediários sujeito à regra de agregação de preço dada pela equação (21). Manipulando a condição de primeira ordem do problema da firma:

$$
m_{t}\left(z, z^{\prime}\right)=M_{t}(z)\left(\frac{p_{t}\left(z^{\prime}\right)}{P_{t}}\right)^{-\theta}
$$

A firma $z$, pertencente ao setor $j$, maximiza seu lucro esperado:

$$
E_{t} \sum_{\tau=0}^{\infty} D_{t, t+\tau} \Pi_{t+\tau}(z)
$$


em que os lucros em um dado período $t$ é:

$$
\Pi_{t}(z)=p_{t}(z) y_{t}(z)-W_{t} L_{t}(z)-P_{t} M_{t}(z)-\chi_{j} W_{t} I_{t}(z)-P_{t} U
$$

Onde $W_{t}$ é o salário por unidade de trabalho na economia. $I_{t}(z)$ é uma variável indicadora igual a 1 se a empresa alterar seu preço no período $t$ e 0 caso contrário. $\mathrm{O}$ custo de menu é representado no modelo por meio do número de unidades adicionais de trabalho para que uma determinada firma $z$ altere o preço de seu produto. O custo de menu é diferente entre cada setor, de modo que as empresas do setor $j$ devem contratar $\chi_{j}$ unidades adicionais de trabalho caso decidam alterar seus preços no período $t$. Por fim, U são os custos fixos de cada empresa. Segundo Nakamura e Steinsson (2010) "o nível desses custos afeta o nível de lucros da empresa como fração da produção, possibilitando conciliar grandes mark-ups estimados na literatura de organização industrial".

Seja $Y_{t}=C_{t}+\int_{0}^{1} M_{t}(z) d z$, em que $Y_{t}$ representa o produto bruto, enquanto $C_{t}$ representa o valor adicionado ao produto. Combinando as equações (19) e (29) na equação de produto:

$$
y_{t}(z)=Y_{t}\left(\frac{p_{t}(z)}{P_{t}}\right)^{-\theta}
$$

Para uma dada firma $z$, a função de produtividade da firma é um processo autorregressivo de ordem 1:

$$
\log A_{t}(z)=\rho \log A_{t-1}(z)+\epsilon_{t}(z)
$$

Em que $\epsilon_{t}(z) \sim N\left(0, \sigma_{\epsilon, j}^{2}\right)$ são independentes. Nota-se que os choques idiossincráticos das empresas são específicos a cada setor.

Assim, a firma maximiza seus lucros esperados, equação (30), sujeito à função de produtividade.

O produto agregado nominal, $S_{t}$, é dado por $S_{t}=P_{t} C_{t}$ e segue uma função autorregressiva de ordem 1 com drift:

$$
\log S_{t}=\mu+\log S_{t-1}+\eta
$$

onde $\eta \sim N\left(0, \sigma_{\eta}^{2}\right)$ são independentes.

No entanto, é necessário reduzir o problema da firma, uma vez que este depende da distribuição conjunta dos preços de todas as empresas e níveis de produtividade. Incorporando as premissas de Krusell e Smith (1998), o problema se torna tratável ao supor que as empresas incorporam a evolução do nível de preços agregado em função de 
um número determinado de momentos dessa distribuição. Assim, a seguinte hipótese é feita:

$$
\frac{P_{t}}{P_{t-1}}=\Gamma\left(\frac{S_{t}}{P_{t-1}}\right)
$$

Como proposto por Nakamura e Steinsson (2010), a lei de percepção de preços das firmas utilizada será a função logarítmica, de modo que $\frac{P_{t}}{P_{t-1}}=\log \left(\frac{S_{t}}{P_{t-1}}\right)$. Por meio de simulações, os autores concluem que esta lei de percepção usada para formar expectativas sobre o nível de preços por parte das empresas é altamente precisa. Os autores mostram que, em 99\% dos meses, a diferença entre a lei percebida de movimento e a lei real do movimento é inferior a um ponto de grid.

Com as equações expostas acima, é possível resolver o problema da firma de forma recursiva via equação de Bellman, dada por:

$$
V\left(A_{t}(z), \frac{p_{t-1}(z)}{P_{t}}, \frac{S_{t}}{P_{t}}\right)=\max _{p_{t}(z)}\left\{\Pi_{t}^{R}(z)+E_{t}\left[D_{t, t+1}^{R} V\left(A_{t+1}(z), \frac{p_{t}(z)}{P_{t+1}}, \frac{S_{t+1}}{P_{t+1}}\right)\right]\right\}
$$

Onde $V(\cdot)$ denota a função valor, o sobrescrito $R$ denota que as variáveis estão em termos reais, assim $D_{t, t+1}^{R}$ é o preço do ativo financeiro desta economia em termos reais; por fim, $\Pi_{t}^{R}(z)$ denota o lucro de uma dada firma $z$ em termos reais no período $t$. A dedução da função valor está no Apêndice D.

\subsubsection{Equilíbrio}

Um equilíbrio nesta economia é uma sequência de alocações para as famílias $\left\{C_{t}, L_{t} \text { e } B_{t+1}\right\}_{t=0}^{\infty}$; uma sequência de preços e alocações para empresas $\left\{p_{t}(z), y_{t}(z) \text { e } L_{t}(z)\right\}_{t=0}^{\infty}$; e um conjunto de preços agregados $\left\{W_{t}, P_{t} \text { e } D_{t, t+1}\right\}_{t=0}^{\infty}$, tais que:

(i) Dados os preços, $\left\{C_{t}, L_{t} \text { e } B_{t+1}\right\}_{t=0}^{\infty}$ resolve o problema de maximização de utilidade das famílias.

(ii) Dados o nível de produtividade das firmas e variáveis agregadas, $\left\{p_{t}(z), y_{t}(z) \text { e } L_{t}(z)\right\}_{t=0}^{\infty}$ resolve o problema de maximização de lucro de cada empresa $z$.

(iii) Os mercados estão em equilíbrio em todos os períodos (market clearing).

\subsubsection{Estratégia computacional}

Como descrito, o equilíbrio nesta economia é um conjunto de processos estocásticos para os preços, alocações de recursos que resolvem o problema de maximização da utilidade das famílias e o problema de maximização do lucro das empresas, além da evolução das variáveis exógenas $A_{t}(z)$ e $S_{t}$. Para resolver o equilíbrio, foi utilizada a seguinte estratégia sugerida por Nakamura e Steinsson (2008): 
i) Especificar um grid finito de pontos para as variáveis de estado, $A_{t}(z), p_{t-1}(z) / P_{t}$ e $S_{t} / P_{t}$

ii) Propor uma função $\Gamma\left(S_{t} / P_{t-1}\right)$. Como discutido acima, a função escolhida foi a função logarítmica;

iii) Dado o $\Gamma(\cdot)$ proposto, é possível resolver a policy function da empresa, $F$, por iterações da função valor;

iv) Verificar as consistências de $\Gamma(\cdot)$ e $F(\cdot)$. O processo utilizado para verificação está descrito no Apêndice D. Se consistente, é possível calcular as outras variáveis do equilíbrio. Caso contrário, atualizamos $\Gamma(\cdot)$ e $F$ voltamos para (iii).

Os processos estocásticos $A_{t}(z)$ e $S_{t}$ são aproximados através do método proposto por Tauchen (1986).

\subsection{O modelo de CalvoPlus}

Para fins comparativos, também será proposta uma extensão do modelo de Custo de Menu que incorpora alguns preceitos do modelo de Calvo (1983), Nakamura e Steinsson (2010) denomina este modelo de CalvoPlus. Enquanto no Modelo de Calvo (1983), em um determinado período $t$, as empresas têm a oportunidade de alterar seus preços sem nenhum custo com probabilidade $(1-\alpha)$ e com custo extremamente elevado com probabilidade $\alpha$, o Modelo de CalvoPlus ameniza tal dualidade. Neste, com probabilidade $\left(1-\alpha_{j}\right)$, as firmas recebem a oportunidade de alterar seus preços a um custo relativamente baixo, $\chi_{j, b}$, e, com probabilidade $\alpha_{j}$, enfrentam um custo de menu alto $\chi_{j, a}$. Portanto, em ambas situações alterações de preços são factíveis. Estas suposições mantêm a tratabilidade do modelo Calvo, mas ao mesmo tempo, capturam a ideia de que o momento em que a empresa recebe a oportunidade de ajustar seus preços ao baixo custo é amplamente ortogonal à vontade da empresa de alterar seu preço.

Com relação ao modelo de Custo de Menu, o problema do consumidor se mantém igual, há mudanças apenas no problema da firma. Ao invés de se defrontar com o lucro descrito pela equação (31), a firma visa maximizar a equação:

$$
\Pi_{t}(z)=p_{t}(z) y_{t}(z)-W_{t} L_{t}(z)-P_{t} M_{t}(z)-I_{t}(z) W_{t} \chi_{j, \alpha}-P_{t} U
$$

Em que:

$$
\chi_{j, \alpha}=\left\{\begin{array}{ll}
\chi_{j, b}, & \text { com } \operatorname{Pr}=1-\alpha_{j} \\
\chi_{j, a}, & \text { com } \operatorname{Pr}=\alpha_{j}
\end{array} \quad \text {,em que } \chi_{j, b}<\chi_{j, a}, \alpha_{j} \in[0,1]\right.
$$


Em resumo, o diagrama abaixo compila os modelos e as variações que serão calibrados por este trabalho. Ressalta-se ainda que para cada variação dos modelos será calibrada uma versão considerando a introdução de insumos intermediários e outra sem a introdução desses.

Figura 7 - Diagrama de representação dos modelos

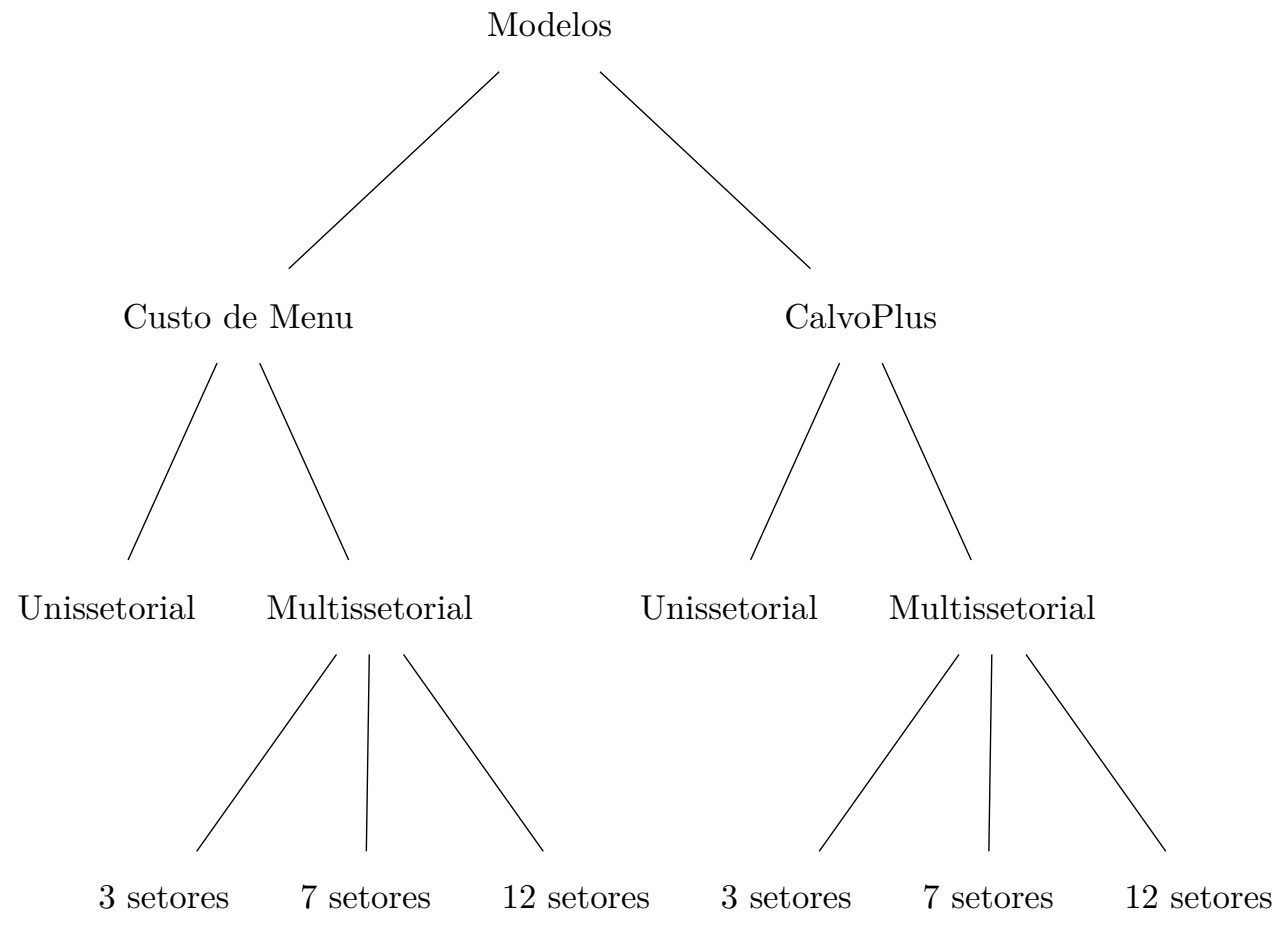

\subsection{Parâmetros}

Este trabalho visa entender o grau de não neutralidade monetária frente à rigidez de preços no caso brasileiro, dado um conjunto específico de valores dos parâmetros. O modelo calibrado é anual. Os valores de alguns parâmetros são recorrentes na literatura, estes serão baseados nos trabalhos de Hansen (1985), Rogerson (1988), Nakamura e Steinsson (2010) e Burstein e Hellwig (2007), enquanto outros foram estimados com base nos dados brasileiros. A Tabela 9 sintetiza os valores dos parâmetros utilizados na calibração dos modelos deste trabalho.

Entre os parâmetros já estabelecidos pela literatura e em linha com o modelo proposto: $\beta$, o fator de desconto anual é 0,$96 ; \gamma=1$, a utilidade do consumo assume a forma logarítmica; e $\psi=0$, de modo que a utilidade retirada do indivíduo ao trabalhar segue uma função linear. Ainda, $\omega$ é o preço flexível no estado estacionário, $1 / 3$. Por sua vez, o parâmetro $\theta$ está relacionado com a elasticidade de substituição. O valor utilizado será $\theta=4$, valor definido com base no trabalho de Burstein e Hellwig (2007) e em linha com 
Tabela 9 - Parâmetros

Parâmetros com base na Literatura e dados brasileiros

\begin{tabular}{lr}
\hline Parâmetros com base na literatura & \\
\hline \hline Fator de Desconto Intertemporal & $\beta=0,96$ \\
Coeficiente de Aversão ao Risco & $\gamma=1$ \\
Inverso da Elasticidade da Oferta de trabalho & $\psi=0$ \\
Elasticidade da Demanda & $\theta=4$
\end{tabular}

Parâmetros com base nos dados brasileiros

Crescimento médio da demanda agregada nominal $\quad \mu=0,07$

Desvio padrão do Crescimento médio da demanda agregada nominal $\sigma_{\eta}=0,03$

Porcentagem de Inputs Intermediários na produção $\quad s_{m}=0,54$

Velocidade média de conversão do processo de produtividade $\quad \rho=0,88$

Notas: Elaboração Próprio autor

a literatura sobre Organização Industrial (Chevalier, Kashyap e Rossi (2003) e Nakamura e Steinsson (2010)).

Com relação aos parâmetros que definem a trajetória do valor adicionado ao produto em termos nominais, $\mu$ e $\sigma_{\eta}$ são definidos com base nos dados agregados de Produto Interno Bruto, disponibilizados pelo Instituto Brasileiro de Geografia e Estatística - IBGE, Fundo Monetário Internacional - FMI e Organisation for Economic Co-operation and Development - OECD. Como proposto por Nakamura e Zerom (2010), uma vez que o modelo não incorpora nenhuma tendência do PIB, $\mu$ é definido como a diferença das médias do crescimento do PIB nominal e do PIB real, enquanto $\sigma_{\eta}$ é o desvio padrão do crescimento do PIB nominal. Portanto, os parâmetros serão definidos com base nos dados anuais brasileiros de 2000-2019, de modo que, $\mu=0,07$ e $\sigma_{\eta}=0,03^{13}$.

O parâmetro $s_{m}$ é a fração dos custos com insumos intermediários em relação aos custos totais. As informações sobre os custos de insumos intermediários por produtos são obtidas na Matriz Insumo Produto, disponibilizada pelo Núcleo de Economia Regional e Urbana da USP - NEREUS ${ }^{14}$. Os dados utilizados são de 2017 e a agregação dos produtos em setores foi feita com base na Classificação Nacional de Atividades Econômicas - CNAE-IBGE. .

A Tabela 10 apresenta a fração de insumos intermediários utilizados no setor em

13 Por motivos computacionais, os valores destes dois parâmetros foram ligeiramente ajustados na calibração dos modelos.

14 O Instituto Brasileiro de Geografia e Estatística - IBGE, também disponibiliza tais dados, no entanto, os dados mais recentes divulgados em seu site se refere ao ano de 2015 
relação ao produto bruto de cada setor (Ins. Intermediários (\%)); porcentagem dos insumos intermediários provenientes daquele setor em relação ao total de insumos intermediários na economia (Ins. Proveniente (\%)); o peso do setor em relação ao produto total da economia (Peso Setor Y (\%)); e por fim, ponderação do setor com base na POF - FIPE (IPC (\%) $)^{15}$. Para calcular as ponderações da IPC, foi necessário reclassificar os produtos da Matriz Insumo produto segundo os critérios da FIPE.

Tabela 10 - Insumos intermediários

Insumos intermediários nos setores brasileiros

\begin{tabular}{lcccc}
\hline Setor & Ins. Intermediários(\%) & Ins. Proveniente(\%) & Peso Setor Y(\%) & IPC(\%) \\
\hline \hline Agropecuária & 50,4 & 9,5 & 7,6 & 14,3 \\
Transformação & 75,9 & 32,8 & 28,0 & 12,4 \\
Energia & 57,5 & 5,7 & 3,5 & 6,7 \\
Construção & 57,5 & 2,4 & 5,2 & 3,5 \\
Comércio & 55,2 & 11,4 & 11,6 & 15,4 \\
Serviços & 38,5 & 37,6 & 31,4 & 47,7 \\
Governo & 55,1 & 0,6 & 12,8 & 0 \\
\hline
\end{tabular}

Notas: Elaboração Próprio autor

Segundo a Tabela 10, os produtos do setor de Serviços são os mais utilizados como insumos intermediários, nota-se que o setor agrega atividades como consultoria, marketing, serviços, atividades imobiliárias, entre outras. O setor de Transformação, que é intensivo na utilização de insumos intermediários, também provê grande parte dos insumos intermediários utilizados na economia, de modo que o peso do setor no produto final da economia é menor do que a sua participação no fornecimento de insumos intermediários para outros setores.

A ponderação do percentual de insumos intermediários no produto bruto de cada setor (Ins. Intermediários (\%)) pelo seu respectivo Índice de Preços ao Consumidor (IPC) é de aproximadamente $41 \%$. A medida representa a média ponderada da participação de insumos intermediários na receita dos setores na economia. Nakamura e Steinsson (2010) encontram o valor de 52,0\% para o parâmetro aplicado aos EUA no ano de 2002. A diferença é relacionada ao maior peso do setor de manufatura no IPC $(51,2 \%)$ no caso norte-americano, setor intensivo em utilização de insumos intermediários, 64,9\%. No Brasil,

15 A POF -Pesquisa de Orçamentos Familiares utilizada se refere aos anos de 2011-2013 e é disponibilizada pela FIPE. A pesquisa tem como população alvo os habitantes da Cidade de São Paulo. A ponderação é feita tal que a soma dos setores some 1. 
o setor com maior relevância no IPC é o de Serviços $(47,7 \%)$, cuja utilização de insumos provenientes de outros setores corresponde a 38,5\% do produto bruto do setor.

A parcela dos custos de insumos intermediários, $s_{m}$, é dada pela média ponderada da participação de insumos intermediários na receita multiplicada pelo markup da economia. A elasticidade da demanda é $\theta=4$, de modo que o markup da economia é de aproximadamente 1,3. Portanto, a estimativa da parcela de custos de insumos intermediários ponderada pelos setores é de aproximadamente 54,0\%. Assim, $s_{m}=0,54$ nos modelos que consideram introdução de insumos intermediários.

Comparado ao modelo estimado por Nakamura e Steinsson (2010), o parâmetro $s_{m}$ assume o valor de 0,7. O menor parâmetro no caso brasileiro indica que a produção brasileira, em média, utiliza menos insumos intermediários frente à produção norte-americana. Além disso, no caso americano, o setor de Manufatura corresponde a maior porcentagem do IPC $(51,2 \%)$, e é o setor com maior porcentagem de insumos intermediários (64,9\%). Por sua vez, no caso brasileiro, o setor com maior peso no IPC é o de Serviços, cuja porcentagem de insumos intermediários é 38,5\%. Esta comparação corrobora o fato de que o parâmetro brasileiro tende a ser menor do que o norte-americano.

Por fim, com relação a $\rho$, o parâmetro é o coeficiente do modelo autorregressivo de ordem 1 proposto para modelar a produtividade, representando a velocidade média de conversão do processo de produtividade. Com base nos dados disponibilizados pela Penn World Table 9.0, os dados de Nível de produtividade total dos fatores para o Brasil ${ }^{16}$, mostram que o valor estimado para $\rho$ é 0,88 .

Assim, com os valores propostos para os parâmetros, poderá se suceder a calibração do custo do menu, $\chi_{j}$, e o desvio padrão dos choques idiossincráticos em cada setor, $\sigma_{\epsilon}$, dos modelos com base nas evidências sobre a frequência e o tamanho das mudanças de preço encontradas na base de dados do IPC. A não neutralidade monetária será medida como a variância do valor adicionado ao produto, denotado por $C_{t}$, quando é simulado um choque nominal no modelo, $S_{t}$, mesma medida utilizada por Midrigan (2011) e Nakamura e Steinsson (2010).

16 Considera-se o período de 1983-2017. Os dados consideram a produtividade total dos fatores nas atuais paridades do poder de compra para o Brasil, sendo a base de comparação os Estados Unidos da América $(\mathrm{EUA}=1)$ 


\section{Resultados}

Os resultados serão dispostos de tal forma, em primeiro lugar, serão reportados os resultados referentes aos modelos unissetoriais. Será apresentado o Modelo de Custos de Menu, como descrito na seção 4.1, considerando um único setor ${ }^{17}$ e sem insumos intermediários. Este modelo é o modelo Baseline. Em seguida, será incorporada ao modelo a hipótese de insumos intermediários. A introdução dos inputs é feita através do parâmetro $s_{m}$. O parâmetro pode assumir dois valores, $s_{m}=0$, em modelos sem insumos intermediários, e $s_{m}=0,54$, em modelos que incorporam a presença de inputs intermediários. Adiante, serão apresentadas as mesmas análises para o Modelo CalvoPlus, descrito na seção 4.2.

Logo em seguida, na subseção 5.3, serão apresentados os modelos multissetoriais, que adicionam ao modelo Baseline a hipótese de heterogeneidade entre os setores. As estatísticas referentes a estes modelos e a cada painel utilizado para calibração foram apresentadas na Tabela 8. Por fim, a seção 5.4 objetiva dimensionar a não neutralidade monetária gerada pelos modelos apresentados ao longo deste trabalho. Para isto, será estimado o modelo VAR, inspirado em Shapiro e Watson (1988), que mensura a porcentagem da variação do ciclo do produto devida aos choques nominais. Assim, será possível comparar os resultados do presente trabalho, não neutralidade decorrente da rigidez de preços, frente a não neutralidade da monetária total gerada por choques nominais, mensurada pelo VAR.

\subsection{Modelo de Custo de menu - Baseline}

A Tabela 11 apresenta os valores calibrados para o custo anual de menu como fração da receita anual de estado estacionário $(\Delta p)^{18}$, o desvio padrão do choque idiossincrático $\left(\sigma_{\epsilon}\right)$ e a variância do produto real $\left(\operatorname{Var}\left(C_{t}\right)\right)$. Os dois primeiros parâmetros são calibrados de modo que as estatísticas de frequência e tamanho das variações de preço resultantes dos modelos coincidam com as estatísticas apresentadas na Tabela 4. Por sua vez, a variância do produto, $\operatorname{Var}\left(C_{t}\right)$, resulta da calibração do modelo e é a medida utilizada neste trabalho como não neutralidade monetária. A variância do produto real é calculada após ser simulado um choque puramente nominal no modelo, $S_{t}$. Outros trabalhos como Midrigan (2008) e Nakamura e Steinsson (2010) utilizam a mesma métrica.

As três primeiras colunas da tabela apresentam os resultados do modelo de custo de menu baseline, sem insumos intermediários, enquanto as três últimas colunas representam os resultados considerando o mesmo modelo mas com introdução de insumos intermediários.

$\overline{17}$ A calibração dos parâmetros retorna as estatísticas médias de frequência de mudança de preço e tamanho da variação de preço, reportadas na Tabela 4

18 Ao invés de apresentar o custo de menu, como descrito no modelo $(\mu)$, a tabela apresenta o custo de menu em termos anual $(\Delta p)$. A relação entre as duas variáveis é dada por $(\theta-1) / \theta) *(\mu / Y)$. 
Tabela 11 - Resultados dos modelos de Custo de Menu unissetoriais

\begin{tabular}{ccccccccc}
\hline & \multicolumn{3}{c}{$s_{m}=0$} & & \multicolumn{3}{c}{$s_{m}=0,54$} \\
\cline { 2 - 4 } \cline { 7 - 9 } & $\begin{array}{c}\Delta p \\
\times 10^{-2}\end{array}$ & $\begin{array}{c}\sigma_{e} \\
\times 10^{-2}\end{array}$ & $\begin{array}{c}\operatorname{Var}\left(C_{t}\right) \\
\times 10^{-6}\end{array}$ & & $\begin{array}{c}\Delta p \\
\times 10^{-2}\end{array}$ & $\begin{array}{c}\sigma_{e} \\
\times 10^{-2}\end{array}$ & $\begin{array}{c}\operatorname{Var}\left(C_{t}\right) \\
\times 10^{-6}\end{array}$ \\
\hline Modelo Unissetorial & 0,411 & 8,8 & 0,6 & & 0,001 & 6,1 & 1,5 \\
\hline
\end{tabular}

Notas: Elaboração Próprio autor. A unidade da variância, $\operatorname{Var}\left(C_{t}\right)$, é reais ao quadrado.

Os resultados mostram que os custos de menu anuais das empresas é menor do que 0,5\% de suas receitas. Quando o modelo incorpora os insumos intermediários, o custo é, em média, um décimo do custo observado sem insumos. O choque idiossincrático varia de $6 \%$ a $8 \%$, sendo menor no modelo com introdução de insumos intermediários. Pela construção do modelo, e como enfatizado por Golosov e Lucas Jr. (2007) e Nakamura e Steinsson (2010), a alta variância deste choque é crucial para gerar mudanças de preços suficientemente grandes para corresponder aos dados. Também é importante para gerar o número substancial de quedas de preços observadas nos dados. Nakamura e Steinsson (2010) argumentam que os choques idiossincráticos de produtividade devem ser vistos como um substituto para uma classe mais ampla de choques idiossincráticos que causam variação nos preços desejados das empresas. Golosov e Lucas Jr. (2007) complementam que os choques idiossincráticos podem ser vistos como diferenças de produtividade entre as empresas, como respostas a acúmulos de estoque ou outros fatores. Consequentemente, a alta variação dos choques idiossincráticos amplifica o intervalo de tamanho das variações de preços.

Os modelos unissetoriais de Custo de Menu apresentados acima, ao simularem um choque puramente nominal, causam variações no produto real iguais a $0,6 \times 10^{-6} \mathrm{e}$ $1,5 \times 10^{-6}$, considerando, respectivamente, o modelo sem insumos intermediários e com insumos. O modelo que considera inputs gera duas vezes mais não neutralidade monetária frente ao modelo sem matérias-primas. A introdução de insumos amplifica o grau de não neutralidade monetária uma vez que as decisões das firmas se tornam complementares.

Com a introdução de insumos intermediários, a matéria prima utilizada na produção são outros produtos, e o custo marginal de uma empresa depende do preço de outros produtos. A introdução de insumos torna a resposta das empresas a um choque nominal mais lenta, uma vez que o custo marginal da empresa responde menos a este choque $S_{t}$ quando há insumos intermediários, ou seja, $s_{m} \neq 0$. O custo marginal é dado por $C M(z)=\omega S_{t}^{1-s_{m}} P_{t}^{s_{m}} A_{t}(z)^{-1}$. Como descrito por Nakamura e Steinsson (2010), as firmas ajustam seus preços de forma mais lenta e a variação implementada é menor do que a variação que ocorreria caso o único insumo da produção fosse trabalho. As empresas optam por não alterarem tanto seus preços pois o preço de muitos dos insumos utilizados na 
produção ainda não responderam ao choque nominal. Desse modo, a rigidez de preços observada no modelo com insumo é maior frente ao modelo sem inputs.

\subsection{CalvoPlus}

Segundo o modelo de CalvoPlus, em cada período a firma pode receber a oportunidade de mudar seus preços a um custo relativamente alto e, com probabilidade complementar, o custo para ajustar os preços é baixo. Ainda considerando modelos com um único setor, a Tabela 12 apresenta a calibração dos parâmetros utilizados para o modelo CalvoPlus e a não neutralidade gerada pelos modelos CalvoPlus. Nota-se que neste modelo há dois custos de menu, o custo de menu alto, $\chi_{j, a}$, e baixo, $\chi_{j, b}$. A tabela apresenta apenas o custo de menu alto, e o custo de menu baixo é uma parcela deste. Para a calibração, utilizou-se a seguinte relação $\chi_{j, b}=\chi_{j, a} / 40$, também utilizada por Nakamura e Steinsson (2010).

As três primeiras colunas da tabela apresentam os resultados referentes ao modelo sem inputs intermediários $s_{m}=0$, e as três últimas apresentam os resultados para o modelo com insumos intermediários, $s_{m}=0,54$.

Tabela 12 - Resultados dos modelos CalvoPlus unissetoriais

\begin{tabular}{|c|c|c|c|c|c|c|}
\hline & \multicolumn{3}{|c|}{$s_{m}=0$} & \multicolumn{3}{|c|}{$s_{m}=0,54$} \\
\hline & $\begin{array}{c}\Delta p \\
\times 10^{-2}\end{array}$ & $\begin{array}{c}\sigma_{e} \\
\times 10^{-2}\end{array}$ & $\begin{array}{c}\operatorname{Var}\left(C_{t}\right) \\
\times 10^{-6}\end{array}$ & $\begin{array}{c}\Delta p \\
\times 10^{-2}\end{array}$ & $\begin{array}{c}\sigma_{e} \\
\times 10^{-2}\end{array}$ & $\begin{array}{c}\operatorname{Var}\left(C_{t}\right) \\
\times 10^{-6}\end{array}$ \\
\hline Modelo Unissetorial & 1,517 & 0,08 & 1,3 & 0,145 & 0,05 & 5,5 \\
\hline
\end{tabular}

Notas: Elaboração Próprio autor. A unidade da variância, $\operatorname{Var}\left(C_{t}\right)$, é reais ao quadrado.

Nota-se que o grau de não neutralidade gerada pelo modelo CalvoPlus é maior do que a do modelo de Custo de Menu. Carvalho (2006) ressalta a relevância da interação das empresas em modelos com dependência temporal na tomada da decisão de ajustar os preços. A maior não neutralidade monetária gerada por tais modelos reflete a decisão das firmas em esperar para ajustar seus preços apenas quando se defrontam com o custo de menu relativamente menor, gerando maior demora na resposta das empresas a choques nominais. No modelo com inputs intermediários, Nakamura e Steinsson (2010) ressalta o grau de complementariedade na estratégia das empresas aumenta e gera mais não neutralidade. $\mathrm{O}$ argumento é semelhante ao utilizado para explicar o aumento da rigidez no modelo de custo de menu quando são introduzidos os insumos intermediários. 


\subsection{Heterogeneidade e não neutralidade}

A Tabela 13 apresenta a parametrização do custo de menu e o desvio padrão do choque idiossincrático para os modelos multissetoriais. Como exposto anteriormente, foram feitos três painéis, painel A com três setores, B com sete, e C com doze setores. Os parâmetros calibrados permitem que o modelo retorne as estatísticas de frequência e tamanho das mudanças de preço apresentadas na Tabela 8. Para a comparação entre os modelos unissetoriais e multissetoriais, a tabela apresenta a calibração dos parâmetros para o modelo com apenas um setor (denominado "Geral"), cujos resultados já foram apresentados acima.

Em todos os casos, o custo anual para variar o preço, $\Delta p$, é menor do que $1 \%$ da receita do setor, e na maior parte deles, menor do que $0,5 \%$. Quando o modelo incorpora os insumos intermediários, o custo é, em média, um décimo do custo observado sem insumos. Por sua vez, o choque idiossincrático varia de $2 \%$ a $10 \%$, sendo, em média, menor nos modelos com insumos intermediários.

A Tabela 14 apresenta o grau de não neutralidade monetária para cada modelo após um choque puramente nominal no modelo. As duas primeiras colunas apresentam os resultados considerando o modelo de custo de menu sem insumos intermediários $\left(1^{\text {a }}\right.$ coluna) e com insumos intermediários ( $2^{\mathrm{a}}$ coluna). As duas últimas colunas da tabela apresentam a variação do produto considerando o modelo de CalvoPlus, sem insumos intermediários ( $3^{\mathrm{a}}$ coluna) e com a introdução deles ( $4^{\mathrm{a}}$ coluna). A comparação entre as linhas da tabela permite analisar a rigidez do preço no produto real entre modelos com diferentes números de setores ${ }^{19}$. A tabela explicita que quanto maior o número de setores na economia, maior a não neutralidade do produto. Além disso, a introdução de insumos intermediários aumenta de 2 a 3 vezes a não neutralidade monetária.

No primeiro caso em que há um único setor e o modelo é calibrado pelas estatísticas médias, a variância do produto real a um choque nominal é aproximadamente de $0,6 \times 10^{-6}$. Por sua vez, o modelo que contempla doze setores apresenta variância três vezes maior, $1,9 \times 10^{-6}$. Comparando o modelo unissetorial com o modelo que considera 12 de setores, observa-se que o modelo multissetorial produz aproximadamente três vezes mais não neutralidade. Isto ocorre uma vez que o grau de não neutralidade entre os diferentes setores da economia é uma função convexa da frequência de variação de preços entre os setores. Carvalho (2006) mostra que os efeitos de um choque monetário em modelos calibrados para a economia norte-americana apresentam efeitos maiores e mais persistentes em economias heterogêneas quando comparado a economias com firmas idênticas. Resultados que são corroborados Nakamura e Steinsson (2010).

19 Nota-se que o modelo com um único setor foi calibrado para coincidir com as estatísticas médias de frequência de mudança de preço e tamanho da variação de preço. 
Tabela 13 - Calibração dos parâmetros nos modelos multissetoriais

\begin{tabular}{|c|c|c|c|c|c|c|c|c|}
\hline & \multicolumn{4}{|c|}{ Modelo de custo de menu } & \multicolumn{4}{|c|}{ Modelo CalvoPlus } \\
\hline & \multicolumn{2}{|c|}{$s_{m}=0,0$} & \multicolumn{2}{|c|}{$s_{m}=0,54$} & \multicolumn{2}{|c|}{$s_{m}=0,0$} & \multicolumn{2}{|c|}{$s_{m}=0,54$} \\
\hline & $\begin{array}{c}\Delta p \\
\times 10^{-2}\end{array}$ & $\begin{array}{c}\sigma_{\epsilon} \\
\times 10^{-2}\end{array}$ & $\begin{array}{c}\Delta p \\
\times 10^{-2}\end{array}$ & $\begin{array}{c}\sigma_{\epsilon} \\
\times 10^{-2}\end{array}$ & $\begin{array}{c}\Delta p \\
\times 10^{-2}\end{array}$ & $\begin{array}{c}\sigma_{\epsilon} \\
\times 10^{-2}\end{array}$ & $\begin{array}{c}\Delta p \\
\times 10^{-2}\end{array}$ & $\begin{array}{c}\sigma_{\epsilon} \\
\times 10^{-2}\end{array}$ \\
\hline & \multicolumn{8}{|c|}{ Único setor } \\
\hline \multirow[t]{2}{*}{ I. Geral } & 0,411 & 08,8 & 0,001 & 06,1 & 1,517 & 0,08 & 0,145 & 0,05 \\
\hline & \multicolumn{8}{|c|}{ Painel A: Três Setores } \\
\hline I. Alimentos & 0,488 & 10,4 & 0,001 & 06,6 & 2,468 & 0,10 & 0,264 & 0,08 \\
\hline II. Bens Industriais & 0,404 & 08,8 & 0,002 & 06,9 & 1,925 & 0,09 & 0,190 & 0,06 \\
\hline \multirow[t]{2}{*}{ III. Serviços } & 0,200 & 05,0 & 0,002 & 03,3 & 1,053 & 0,05 & 0,104 & 0,03 \\
\hline & \multicolumn{8}{|c|}{ Painel B: Sete Setores } \\
\hline I. Alimentação & 0,512 & 10,4 & 0,038 & 05,4 & 2,402 & 0,10 & 0,096 & 0,04 \\
\hline II. Despesas pessoais & 0,302 & 06,1 & 0,016 & 03,4 & 1,085 & 0,05 & 0,141 & 0,05 \\
\hline III. Educação & 0,358 & 05,3 & 0,019 & 02,7 & 0,99 & 0,05 & 0,113 & 0,03 \\
\hline IV. Habitação & 0,338 & 07,4 & 0,031 & 05,0 & 1,978 & 0,09 & 0,208 & 0,06 \\
\hline V. Saúde & 0,473 & 05,9 & 0,041 & 03,1 & 0,482 & 0,05 & 0,072 & 0,06 \\
\hline VI. Transportes & 0,123 & 04,4 & 0,045 & 06,0 & 0,987 & 0,05 & 0,074 & 0,03 \\
\hline \multirow[t]{2}{*}{ VII. Vestuário } & 0,199 & 08,1 & 0,041 & 06,6 & 1,948 & 0,10 & 0,199 & 0,08 \\
\hline & \multicolumn{8}{|c|}{ Painel C: Doze Setores } \\
\hline I. Alimentos in natura & 0,237 & 08,6 & 0,036 & 07,9 & 2,015 & 0,10 & 0,229 & 0,08 \\
\hline II. Alimentos semielaborados & 0,522 & 10,4 & 0,038 & 06,4 & 2,381 & 0,10 & 0,072 & 0,04 \\
\hline III. Alimentação fora do domicílio & 0,266 & 04,0 & 0,017 & 02,4 & 1,223 & 0,05 & 0,167 & 0,03 \\
\hline IV. Habitação & 0,324 & 07,2 & 0,042 & 05,8 & 1,942 & 0,08 & 0,222 & 0,06 \\
\hline V. Móveis e eletrodomésticos & 0,414 & 09,4 & 0,038 & 06,4 & 2,454 & 0,10 & 0,070 & 0,04 \\
\hline VI. Roupas e calçados & 0,282 & 10,4 & 0,037 & 07,1 & 2,013 & 0,10 & 0,226 & 0,08 \\
\hline VII. Transporte público & 0,551 & 04,7 & 0,036 & 02,6 & 0,893 & 0,03 & 0,165 & 0,03 \\
\hline VIII. Veículo próprio & 0,608 & 10,4 & 0,043 & 06,0 & 2,154 & 0,08 & 0,203 & 0,06 \\
\hline IX. Serviços e produtos de saúde & 0,485 & 06,0 & 0,039 & 03,6 & 0,796 & 0,03 & 0,158 & 0,03 \\
\hline X. Cuidados e serviços pessoais & 0,299 & 05,5 & 0,023 & 03,6 & 1,164 & 0,05 & 0,112 & 0,03 \\
\hline XI. Recreação. fumo e fotografia & 0,325 & 07,0 & 0,041 & 05,7 & 1,974 & 0,08 & 0,193 & 0,06 \\
\hline XII. Educação & 0,297 & 04,6 & 0,017 & 05,2 & 1,009 & 0,04 & 0,119 & 0,03 \\
\hline
\end{tabular}

Notas: Elaboração Próprio autor.

Considerando ainda o modelo com custo de menu, nota-se que a neutralidade monetária é em média de duas a três vezes maior no modelo com insumos intermediários frente ao modelo cujo único insumo é o trabalho. Com a introdução de insumos intermediários, a matéria prima utilizada na produção são outros produtos e o custo marginal de uma empresa depende do preço de outros produtos. Nota-se que a introdução de insumos torna a resposta das empresas a um choque nominal mais lenta, uma vez que o custo marginal da empresa em resposta a este choque é menor quando há insumos intermediários.

Por sua vez, a variância do produto a um choque nominal é maior no modelo 
Tabela 14 - Heterogeneidade e Não neutralidade monetária $\left(\times 10^{-6}\right)$

\begin{tabular}{lccccc}
\hline & \multicolumn{2}{c}{ Modelo Custo de Menu } & & \multicolumn{2}{c}{ Modelo de CalvoPlus } \\
\cline { 2 - 3 } \cline { 5 - 6 } & $s_{m}=0$ & $s_{m}=0,54$ & & $s_{m}=0$ & $s_{m}=0,54$ \\
\hline \hline & Não & neutralidade & monetária & Var $\left(C_{t}\right)$ & \\
Modelo Um setor & 0,6 & 1,5 & & 1,3 & 05,5 \\
Modelo Três setores & 0,9 & 2,5 & & 5,0 & 11,5 \\
Modelo Sete setores & 1,2 & 2,6 & & 5,1 & 13,3 \\
Modelo Doze setores & 1,9 & 4,7 & & 5,4 & 18,7 \\
\hline
\end{tabular}

Notas: Elaboração Próprio autor. A variância do produto apresentada na tabela está multiplicada por $10^{6}$

CalvoPlus em relação ao modelo de custo de menu. Isto decorre do fato de que no modelo CalvoPlus, após um choque monetário, as primeiras empresas a ajustarem seus preços pertencem aos setores cuja frequência de variação do preço é relativamente maior. Como descrito por Carvalho (2006), ao longo dos períodos, a distribuição da frequência das mudanças de preço torna-se progressivamente dominada por empresas em setores cujas frequências de ajuste são relativamente baixas. Assim, há uma desaceleração da velocidade de ajuste em uma economia heterogênea frente a uma economia homogênea. O autor denomina este processo de "efeito de composição de frequência", ou seja, setores de alta frequência dominam a parte inicial do processo de ajuste após o choque enquanto setores de baixa frequência conduzem grande parte do processo nos períodos subsequentes.

\subsection{Dimensionamento da não neutralidade monetária}

Como resultado dos modelos aplicados neste trabalho, foi mensurada a não neutralidade monetária devida à rigidez de preços. Com o objetivo de dimensionar a não neutralidade gerada pela inflexibilidade dos preços frente ao total foi estimado um modelo de vetores autorregressivos - VAR, inspirado pelo Shapiro e Watson (1988). O modelo tem como objetivo estimar os impactos de curto prazo de choques nominais no produto real.

O modelo de Shapiro e Watson (1988) é motivado pela premissa de que as variáveis reais são determinadas por um modelo de crescimento neoclássico. Movimentos do produto no longo prazo podem ser atribuídos a variações na quantidade de trabalho e progresso tecnológico. No curto prazo, no entanto, o produto se desvia do estado estacionário de longo prazo em dois casos, caso seja afetado por choques permanentes de trabalho ou tecnológico, que conduzirão o produto a um novo estado estacionário, ou então influenciado por variações na demanda agregada. Lucas (2003) entende que o que os autores denominam choques de demanda são, na verdade, choque nominais. Portanto, a partir de um modelo VAR, os autores então decompõem a variação do produto devida aos choques nominais e 
às outras variáveis reais, tecnologia e horas trabalhadas.

Modelo semelhante ao dos autores será utilizado no presente trabalho. O modelo contempla quatro variáveis, taxa de juros nominal, produto real, quantidade de horas trabalhadas e inflação. O período considerado na análise é o período pós inflacionário, de 1995 a 2018, os dados são anuais e o modelo será aplicado no nível Brasil. Com relação às fontes dos dados, a série de juros nominais utilizada no modelo é a Selic acumulada no mês anualizada base 252 cuja fonte é o Banco Central do Brasil. As séries de produto interno bruto real e de inflação são disponibilizadas pelo Banco Mundial ${ }^{20}$. Por fim, a série de número de horas totais trabalhadas foi disponibilizada pelo Federal Reserve Bank of St. Louis. ${ }^{21}$

O VAR estimado é de ordem 3, ou seja, contempla 3 defasagens de cada variável. Os resultados da estimação do modelo e a função impulso resposta do modelo mensurado estão reportados no Apêndice E. O objetivo central da aplicação do VAR é estimar a variação do produto real de curto prazo devida aos choques nominais, cujos resultados completos estão no apêndice citado, mas o resultado principal é reportado na Tabela 15. A decomposição da variância mostra a contribuição de cada choque estrutural para explicar a variância do erro de previsão de cada variável endógena do VAR para cada horizonte de previsão.

A Tabela 15 apresenta a fração da variância prevista do produto real atribuído a cada um dos choques. No curto prazo, é esperado que choques nominais impactem o produto. Os resultados da tabela sugerem que nos primeiros anos aproximadamente $15 \%$ da variabilidade do produto no curto prazo é atribuído aos choques de demanda, representados pelo juros nominal ( $3^{\mathrm{a}}$ coluna da tabela). Conforme o horizonte aumenta, o impacto decai gradualmente, e a demanda agregada explica aproximadamente 14,7\% da variação na produção, considerando o horizonte de nove anos. Os resultados são consistentes com os encontrados na literatura internacional. Shapiro e Watson (1988) atribui 28\% da variação na produção aos choques nominais. Outros autores encontram resultados semelhantes ou um pouco maiores, no entanto, todos resultados mostram um efeito relevante mas aquém a $50 \%$.

20 A série considerada para inflação é o deflator do PIB. Testes foram feitos considerando a série de inflação obtida através do IPC e não houve mudanças significativas no modelo.

21 O número médio total de horas trabalhadas, aplicada no modelo, foi obtido através da multiplicação de duas séries disponibilizadas pela instituição: Número de horas trabalhadas média por empregado no Brasil e Número de pessoas empregadas no brasil. 
Tabela 15 - Decomposição da variância do produto real

\begin{tabular}{ccccc}
\hline \multicolumn{4}{c}{ Produto real } \\
\hline & Inflação & Horas totais & Juros nominal & Produto real \\
\hline \hline 1 & 0,000 & 0,438 & 0,123 & 0,439 \\
2 & 0,019 & 0,392 & 0,159 & 0,430 \\
3 & 0,019 & 0,398 & 0,156 & 0,427 \\
4 & 0,021 & 0,402 & 0,154 & 0,423 \\
5 & 0,021 & 0,416 & 0,150 & 0,413 \\
6 & 0,023 & 0,419 & 0,149 & 0,409 \\
7 & 0,023 & 0,424 & 0,148 & 0,406 \\
8 & 0,024 & 0,425 & 0,147 & 0,404 \\
9 & 0,024 & 0,426 & 0,147 & 0,403 \\
\hline
\end{tabular}

Notas: Elaboração Próprio autor. A tabela apresenta a fração da variância dos resíduos previstos do produto real atribuído a cada uma das variáveis que compõem o modelo VAR.

A fim de comparar os números encontrados pelo modelo VAR, a Tabela 16 apresenta as variâncias do produto real geradas pelos modelos calibrados neste trabalho expressas como porcentagem da variância do ciclo do produto real. O ciclo foi obtido pela aplicação do filtro Hodrick-Prescott (HP). Segundo a tabela, os modelos apresentados neste trabalho explicam entre $0,4 \%$ da variação total do ciclo do produto até $12,6 \%$. Considerando os mesmos modelos, os modelos calibrados por Nakamura e Steinsson (2010) correspondem de $2 \%$ a $23 \%$ da variação total do ciclo do produto. Assim, há menor evidência de rigidez de preços nos dados brasileiros.

Tabela 16 - Não neutralidade monetária em termos da variância total do produto (\%)

\begin{tabular}{lccccc}
\hline & \multicolumn{2}{c}{ Modelo Custo de Menu } & & \multicolumn{2}{c}{ Modelo de CalvoPlus } \\
\cline { 2 - 3 } \cline { 5 - 6 } & $s_{m}=0$ & $s_{m}=0,54$ & & $s_{m}=0$ & $s_{m}=0,54$ \\
\hline \hline Modelo Um setor & 0,4 & 1,0 & & 0,9 & 3,7 \\
Modelo Três setores & 0,6 & 1,6 & & 3,4 & 7,8 \\
Modelo Sete setores & 1,8 & 1,7 & & 3,5 & 8,9 \\
Modelo Doze setores & 1,3 & 3,1 & & 3,6 & 12,6
\end{tabular}

Notas: Elaboração Próprio autor.

O modelo que gera a menor não neutralidade monetária é o Modelo de Custo de Menu unissetorial, Baseline, explicando 0,4\% da variação do produto real, muito aquém às contribuições dos choques nominais no VAR. Este modelo não incorpora as 
hipóteses de heterogeneidade e de introdução dos insumos intermediários. Além disso, como explicado anteriormente, por ser um modelo de custo de menu, o efeito da seleção é mais forte do que nos modelos que incluem time-dependent, gerando menor não neutralidade monetária. A introdução da hipótese de heterogeneidade ao modelo de Custo de Menu eleva a porcentagem do produto explicada pelos modelos. Nota-se que esta porcentagem aumenta proporcionalmente ao aumento do número de setores considerados no modelo. Assim, o modelo com doze setores é o que explica a maior porcentagem, 1,3\%. Embora o modelo multissetorial aumente mais de 3 vezes a porcentagem explicada em comparação ao modelo unissetorial, o modelo ainda está distante da contribuição dos choques nominais no VAR.

A adição da hipótese de insumos intermediários ao Modelo de Custo de Menu eleva a não neutralidade explicada pelo modelo em um fator próximo a três. O modelo unissetorial passa a explicar 1\% da variância, enquanto o modelo com 12 setores explica $3,1 \%$. Com a introdução de insumos intermediários, a matéria prima utilizada na produção são outros produtos, e o custo marginal de uma empresa depende do preço dos outros produtos, tornando a resposta das empresas a um choque nominal mais lenta.

Os modelos CalvoPlus introduzem o componente de time dependent ao modelo e reduzem os efeitos de seleção gerados pelo modelo, gerando mais não neutralidade. O modelo unissetorial de CalvoPlus sem insumos intermediários explica 0,9\% da variação no produto total, duas vezes mais do que o modelo correspondente de Custo de Menu. Ainda considerando o modelo sem inputs a porcentagem explicada é quatro vezes maior, 3,6\%, considerando o modelo com 12 setores. A introdução de insumos intermediários eleva em até quatro vezes a não neutralidade do modelo, considerando o modelo multissetorial com 12 setores, a porcentagem da variância do produto atribuída à rigidez de preços é de 12,6\%. Nota-se que a introdução das hipóteses de heterogeneidade e insumos no modelo CalvoPlus alavanca mais a não neutralidade monetária explicada pelo modelo em comparação ao Modelo Custo de Menu. Isto ocorre visto que neste modelo não há efeitos de seleção de forma que o modelo se torna mais sensível a introdução de novas hipóteses.

Os resultados encontrados por esta dissertação estão em linha com a literatura. A introdução de insumos intermediários aos modelos aumenta em até quatro vezes a não neutralidade explicada pelo modelo. Por sua vez, a adição da hipótese de múltiplos setores alavanca em um a três vezes a variância no produto real. Por sua vez, o modelo com time dependent gera mais não neutralidade do que o modelo de custo de menu. Assim sendo, o modelo que explica a maior porcentagem da variância é o modelo de CalvoPlus com 12 setores e que considera insumos intermediários.

Adicionalmente, Nakamura e Steinsson (2010) estimam que os modelos aplicados aos dados americanos explicam de $2 \%$, modelo unissetorial sem insumos intermediários, a $23 \%$, modelo multissetorial com insumos intermediários. Os autores comparam os resultados 
encontrados por eles à estimação de não neutralidade monetária feita por Shapiro e Watson (1988). Estes atribuem $28 \%$ da variação do produto em horizontes curtos à choques nominais, que contemplam rigidez de preços. Portanto, no modelo de Nakamura e Steinsson (2010) dos $28 \%$ da variação do produto devido a choques nominais, até $23 \%$ são explicadas por rigidez de preço. Neste trabalho, $15 \%$ da variância do produto são devidas a choques nominais e até $12,6 \%$ são explicados pelos modelos.

Portanto, os resultados encontrados pelos modelos multissetoriais são consistentes com a estimação de choques nominais nas flutuações de curto prazo do produto, representada pelo modelo VAR estimado anteriormente. Os modelos multissetoriais estimados neste trabalho atribuem até aproximadamente 12,6\% da variação do business cycle à rigidez de preços. Por sua vez, a replicação de um modelo VAR bem estabelecido na literatura, estima que $15 \%$ da variação do produto em horizontes curtos é devida a choques nominais. A diferença entre as porcentagens é pequena, corroborando a validade dos modelos calibrados nesta dissertação. Esta pequena diferença pode ser explicada por outros fatores que compõem os choques nominais e afetam o produto real além de rigidez de preços. 


\section{Conclusão}

Com a ampliação das bases de microdados, a literatura recente sobre rigidez de preços desenvolveu modelos utilizando microdados para entender impactos macroeconômicos. Os modelos visam compreender melhor a importância da rigidez de preços como fonte da não neutralidade monetária. As estatísticas de frequência de variação de preço e tamanho destes ajustes encontradas neste trabalho estão em linha com alguns estudos anteriores que utilizaram microdados brasileiros, como Araujo (2018) e Barros (2009). Além disso, a heterogeneidade entre os setores também foi abordada por este trabalho e em conformidade com as evidências internacionais, corroborou para a presença de assimetria na fixação de preços entre setores.

O modelo utilizado neste trabalho é o mesmo utilizado por Nakamura e Steinsson (2010). O modelo contém duas principais características, a heterogeneidade da frequência de mudança de preços entre os setores, cuja importância no modelo foi ressaltada anteriormente, e a introdução de insumos intermediários. Para melhor considerar a heterogeneidade entre os produtos e os setores, foram construídos 3 painéis com números distintos de setores. Para cada um destes painéis foram estimados 4 modelos diferentes, modelo de custo de menu sem insumos intermediários e com insumo, além de dois modelos CalvoPlus, com e sem inputs intermediários.

Os modelos multissetoriais estimados explicam até 12,6\% das flutuações no produto real. Em outras palavras, $12,6 \%$ da variação do produto no curto é devida a morosidade das empresas em ajustarem seus preços. Os resultados encontrados são consistentes com a estimação de choques nominais nas flutuações de curto prazo do produto, representada pelo modelo VAR, estimado com base no modelo de Shapiro e Watson (1988). Neste modelo, aproximadamente $15 \%$ da variação do produto real é devido aos choques nominais.

Em linha com a literatura internacional, os modelos multissetoriais ampliam a não neutralidade monetária em comparação ao modelo unissetorial. Isto ocorre uma vez que o grau de não neutralidade entre os diferentes setores da economia é uma função convexa da frequência de variação de preços entre os setores. A assimetria com relação as estatísticas de frequência de preços entre os setores também corrobora para a ampliação da não neutralidade. A introdução de insumos intermediários, por sua vez, também amplifica o grau de não neutralidade. Frente aos modelos sem insumos intermediários, a não neutralidade dos modelos com inputs é até três vezes maior. A utilização de outros produtos como insumos introduz aos modelos a complementariedade na estratégia de fixação de preços entre as diferentes firmas. Em outras palavras, a escolha da empresa em ajustar os preços se torna dependente do time em que as outras empresas, que produzem seus insumos, corrigem seus preços. 


\section{Referências}

ALVAREZ, F.; LIPPI, F. Price Setting With Menu Cost for Multiproduct Firms. Econometrica, v. 82, n. 1, p. 89-135, January 2014. Disponível em: <https://ideas.repec.org/a/wly/emetrp/v82y2014i1p89-135.html>.

ÁLVAREZ, F. et al. From hyperination to stable prices: Argentina's evidence on menu cost models. In: . [S.1.: s.n.], 2011.

ARAUJO, J. Price Setting in Brazil from 1989 to 2007. n. 3, p. 134, 2018.

BARROS, R. W. d. S. Price setting and macroeconomic variables: evidence from brazilian cpi. Tese (Doutorado em Economia) - Fundação Getúlio Vargas, p. 71, 2009. Disponível em: <http://bibliotecadigital.fgv.br/dspace/handle/10438/4248>.

BASU, S. Intermediate Goods and Business Cycles: Implications for Productivity and Welfare. [S.l.], 1994. (Working Paper Series, 4817). Disponível em: <http: //www.nber.org/papers/w4817>.

BERNANKE, B. S.; BOIVIN, J.; ELIASZ, P. Measuring the Effects of Monetary Policy: A Factor-Augmented Vector Autoregressive (FAVAR) Approach. The Quarterly Journal of Economics, v. 120, n. 1, p. 387-422, 2005. Disponível em: <https://ideas.repec.org/a/oup/qjecon/v120y2005i1p387-422..html>.

BILS, M.; KLENOW, P. Some evidence on the importance of sticky prices. Journal of Political Economy, v. 112, p. 947-985, 022004.

BURSTEIN, A.; HELLWIG, C. Prices and market shares in a menu cost model. C.E.P.R. Discussion Papers, CEPR Discussion Papers, 012007.

CABAllero, R. J.; ENGEL, E. M. R. A. Dynamic (S, s) Economies. Econometrica, v. 59, n. 6, p. 1659-1686, November 1991. Disponível em: <https://ideas.repec.org/a/ ecm/emetrp/v59y1991i6p1659-86.html>.

CABAllERO, R. J.; ENGEL, E. M. R. A. Heterogeneity and Output Fluctuations in a Dynamic Menu-Cost Economy. Review of Economic Studies, v. 60, n. 1, p. 95-119, 1993. Disponível em: <https://ideas.repec.org/a/oup/restud/v60y1993i1p95-119..html>.

CALVO, G. A. Staggered prices in a utility-maximizing framework. Journal of Monetary Economics, v. 12, n. 3, p. 383-398, September 1983. Disponível em: <https://ideas.repec.org/a/eee/moneco/v12y1983i3p383-398.html>.

CARVALHO. Heterogeneity in Price Stickiness and the Real Effects of Monetary Shocks. The B.E. Journal of Macroeconomics, v. 6, n. 3, p. 1-58, December 2006. Disponível em: <https://ideas.repec.org/a/bpj/bejmac/vfrontiers.2y2006i1n1.html>.

ELLINGSEN, T.; FRIBERG, R.; HASSLER, J. Menu Costs and Asymmetric Price Adjustment. [S.l.], 2006. Disponível em: <https://ideas.repec.org/p/cpr/ceprdp/5749. html>. 
GAGNON, E. Price setting during low and high inflation: Evidence from mexico. The Quarterly Journal of Economics, Oxford University Press, v. 124, n. 3, p. 1221-1263, 2009. ISSN 00335533, 15314650. Disponível em: <http://www.jstor.org/stable/40506256>.

GIAMBIAGI VILlELA, d. C. e. J. H. Economia Brasileira Contemporânea: 1945-2010. $2^{\mathrm{a}}$. ed. ed. [S.l.]: Elsevier/Campus, 2011. volume. ISBN ISBN.

GOLOSOV; LUCAS. Menu Costs and Phillips Curves. Journal of Political Economy, v. 115, p. 171-199, 2007. Disponível em: <https://ideas.repec.org/a/ucp/jpolec/ v115y2007p171-199.html>.

GOLOSOV, M.; LUCAS JR., R. Menu costs and phillips curves. Journal of Political Economy, The University of Chicago Press, v. 115, n. 2, p. 171-199, 2007. ISSN 00223808, 1537534X. Disponível em: <http://www.jstor.org/stable/10.1086/512625>.

GOUVEA, S. Price Rigidity in Brazil: Evidence from CPI Micro Data. [S.1.], 2007. Disponível em: < https://ideas.repec.org/p/bcb/wpaper/143.html>.

GUILHOTO, J. U. S. F. "estimação da matriz insumo-produto utilizando dados preliminares das contas nacionais: Aplicação e análise de indicadores econômicos para o brasil em 2005". Economia Aplicada. Vol. 9. N. 2. pp. 277-299. Abril-Junho., 012010.

GUILHOTO, J. U. S. F. "estimação da matriz insumo-produto utilizando dados preliminares das contas nacionais: Aplicação e análise de indicadores econômicos para o brasil em 2005". Economia e Tecnologia. UFPR/TECPAR. Ano 6, Vol 23, Out, 012010.

HANSEN, G. D. Indivisible labor and the business cycle. Journal of Monetary Economics, v. 16, n. 3, p. 309 - 327, 1985. ISSN 0304-3932. Disponível em: <http://www.sciencedirect.com/science/article/pii/030439328590039X>.

KEHOE, P. J.; MIDRIGAN, V. Prices are Sticky After All. [S.l.], 2010. Disponível em: $<$ https://ideas.repec.org/p/nbr/nberwo/16364.html>.

KLENOW, P. J.; KRYVTSOV, O. State-Dependent or Time-Dependent Pricing: Does it Matter for Recent U.S. Inflation? The Quarterly Journal of Economics, v. 123, n. 3, p. 863-904, 2008. Disponível em: < https://ideas.repec.org/a/oup/qjecon/ v123y2008i3p863-904..html>.

KLENOW, P. J.; MALIN, B. A. Microeconomic Evidence on Price-Setting. In: FRIEDMAN, B. M.; WOODFORD, M. (Ed.). Handbook of Monetary Economics. Elsevier, 2010, (Handbook of Monetary Economics, v. 3). cap. 6, p. 231-284. Disponível em: $<$ https://ideas.repec.org/h/eee/monchp/3-06.html>.

KONIECZNY, J. D.; SKRZYPACZ, A. Inflation and price setting in a natural experiment. Journal of Monetary Economics, v. 52, n. 3, p. 621-632, April 2005. Disponível em: <https://ideas.repec.org/a/eee/moneco/v52y2005i3p621-632.html>.

KRUSELL, P.; SMITH, J. A. A. Income and Wealth Heterogeneity in the Macroeconomy. [S.l.], 1998. Disponível em: <https://ideas.repec.org/p/cmu/gsiawp/108.html>.

LACH, S.; TSIDDON, D. Staggering and Synchronization in Price-Setting: Evidence from Multiproduct Firms. American Economic Review, v. 86, n. 5, p. 1175-1196, December 1996. Disponível em: <https://ideas.repec.org/a/aea/aecrev/v86y1996i5p1175-96.html>. 
LOPES, L. T. A rigidez nominal de preços na cidade de São Paulo : evidências baseadas em microdados do indice de preços ao consumidor da FIPE. [S.1.], 2008. Disponível em: <http://www.teses.usp.br/teses/disponiveis/12/12140/tde-13012009-165431/pt-br. php\# referencias $>$.

LUCAS, R.; GOLOSOV, M. Menu Costs and Phillips Curves. [S.1.], 2004. Disponível em: $<$ https://ideas.repec.org/p/red/sed004/144.html>.

LUCAS, R. E. J. Macroeconomic Priorities. American Economic Review, v. 93, n. 1, p. 1-14, March 2003. Disponível em: <https://ideas.repec.org/a/aea/aecrev/ v93y2003i1p1-14.html>.

MAćKOWIAK, B.; MOENCH, E.; WIEDERHOLT, M. Sectoral price data and models of price setting. Journal of Monetary Economics, v. 56, n. S, p. 78-99, 2009. Disponível em: <https://ideas.repec.org/a/eee/moneco/v56y2009isps78-s99.html>.

MCCALLUM, A.; SMETS, F. Real wages and monetary policy transmission in the euro area. [S.l.], 2007. Disponível em: <https://ideas.repec.org/p/zbw/ifwkwp/1360.html>.

MIDRIGAN, V. On implications of micro price data for macro models - comments. Conference Series ; [Proceedings], v. 53, 2008. Disponível em: < https://ideas.repec.org/a/ fip/fedbcp/y2008n53x9.html>.

MIDRIGAN, V. Menu Costs, Multiproduct Firms, and Aggregate Fluctuations. Econometrica, v. 79, n. 4, p. 1139-1180, July 2011. Disponível em: < https: //ideas.repec.org/a/ecm/emetrp/v79y2011i4p1139-1180.html>.

NAKAMURA, E.; STEINSSON, J. Five Facts about Prices: A Reevaluation of Menu Cost Models. The Quarterly Journal of Economics, v. 123, n. 4, p. 1415-1464, 2008. Disponível em: <https://ideas.repec.org/a/oup/qjecon/v123y2008i4p1415-1464..html>.

NAKAMURA, E.; STEINSSON, J. Monetary Non-neutrality in a Multisector Menu Cost Model. The Quarterly Journal of Economics, v. 125, n. 3, p. 961-1013, 2010. Disponível em: <https://ideas.repec.org/a/oup/qjecon/v125y2010i3p961-1013..html>.

NAKAMURA, E.; STEINSSON, J. Price Rigidity: Microeconomic Evidence and Macroeconomic Implications. Annual Review of Economics, v. 5, n. 1, p. 133-163, May 2013. Disponível em: <https://ideas.repec.org/a/anr/reveco/v5y2013p133-163.html>.

NAKAMURA, E.; STEINSSON, J. Fiscal stimulus in a monetary union: Evidence from us regions. American Economic Review, v. 104, n. 3, p. 753-92, March 2014. Disponível em: <http://www.aeaweb.org/articles?id=10.1257/aer.104.3.753>.

NAKAMURA, E.; ZEROM, D. Accounting for Incomplete Pass-Through. Review of Economic Studies, v. 77, n. 3, p. 1192-1230, 2010. Disponível em: < https: //ideas.repec.org/a/oup/restud/v77y2010i3p1192-1230.html>.

RAMEY, V. Identifying government spending shocks: It's all in the timing. The Quarterly Journal of Economics, v. 126, n. 1, p. 1-50, 2011. Disponível em: <https://EconPapers.repec.org/RePEc:oup:qjecon:v:126:y:2011:i:1:p:1-50>.

ROGERSON, R. Indivisible labor, lotteries and equilibrium. Journal of Monetary Economics, v. 21, n. 1, p. 3 - 16, 1988. ISSN 0304-3932. Disponível em: < http: //www.sciencedirect.com/science/article/pii/0304393288900426>. 
SHAPIRO, M.; WATSON, M. Sources of business cycles fluctuations. National Bureau of Economic Research, Inc, p. 111-156, 1988. Disponível em: <https: //EconPapers.repec.org/RePEc:nbr:nberch:10953>.

SMETS, F.; MAćKOWIAK, B. On implications of micro price data for macro models. [S.l.], 2008. Disponível em: <https://ideas.repec.org/p/ecb/ecbwps/2008960.html>.

SMETS, F.; WOUTERS, R. An Estimated Dynamic Stochastic General Equilibrium Model of the Euro Area. Journal of the European Economic Association, v. 1, n. 5, p. 1123-1175, September 2003. Disponível em: < https://ideas.repec.org/a/tpr/jeurec/ v1y2003i5p1123-1175.html>.

TAUCHEN, G. Finite state markov-chain approximations to univariate and vector autoregressions. Economics Letters, v. 20, n. 2, p. 177-181, 1986. ISSN 0165-1765. Disponível em: <https://www.sciencedirect.com/science/article/pii/0165176586901680>.

TAYLOR, J. The staying power of staggered wage and price setting models in macroeconomics. In: . Elsevier, 2016. v. 2, cap. Chapter 25, p. 2009-2042. Disponível em: <https://EconPapers.repec.org/RePEc:eee:macchp:v2-2009>.

TAYLOR, J. B. Aggregate Dynamics and Staggered Contracts. Journal of Political Economy, v. 88, n. 1, p. 1-23, February 1980. Disponível em: <https: //ideas.repec.org/a/ucp/jpolec/v88y1980i1p1-23.html>. 


\section{APÊNDICE A - Aderência dos dados de São Paulo aos do Brasil}

Este apêndice visa enfatizar que apesar da base de dados utilizada se concentrar em apenas uma cidade, tais dados se aproximariam do que seria visto caso os dados abrangessem todo o território nacional. Tal fato já está bem documentado por Araujo (2018), Gouvea (2007) e Barros (2009) de modo que este primeiro passo terá a única finalidade de corroborar a validade dos resultados que serão encontrados pela dissertação.

Uma vez que os dados desagregados não estão disponíveis para o território nacional, a adesão dos dados de inflação será feita com base nos índices agregados. Para o Brasil, será utilizado o INPC ${ }^{22}$ - Índice Nacional de Preços ao Consumidor, disponibilizado pelo IBGE. O índice abrange as regiões metropolitanas de Belém, Fortaleza, Recife, Salvador, Belo Horizonte, Rio de Janeiro, São Paulo, Curitiba e Porto Alegre, Brasília, Vitória, Campo Grande e município de Goiânia ${ }^{23}$. O peso dado à cidade de São Paulo é 24,6\%. Com relação aos dados da cidade de SP, será utilizado o Índice agregado do IPC-FIPE ${ }^{24}$.

A Figura 8 ilustra a correlação entre a inflação da capital paulista e o correspondente índice à nível Brasil. A correlação entre o índice paulista e o brasileiro é de 99,49\%, considerando o período de julho de 1994 a dezembro de 2019.

$\overline{22}$ O período de coleta do INPC estende-se, em geral, do dia 01 a 30 do mês de referência. A população objetivo do INPC abrange as famílias com rendimentos mensais compreendidos entre 1 (hum) e 5 (cinco) salários-mínimos, cujo chefe é assalariado em sua ocupação principal e residente nas áreas urbanas das regiões.

23 As áreas geográficas pesquisadas foram implantadas na seguinte ordem cronológica: Rio de Janeiro (janeiro/1979); Porto Alegre, Belo Horizonte e Recife (junho/1979); São Paulo, Brasília e Belém (janeiro/1980); Fortaleza, Salvador e Curitiba (outubro/1979); Goiânia (janeiro/1991); Vitória e Campo Grande (janeiro/2014).

24 O IPC-FIPE mede a variação de preços para o consumidor na cidade de São Paulo com base nos gastos de quem ganha de um a vinte salários mínimos. Os grupos de despesas estão compostos de acordo com o POF (Pesquisas de Orçamentos Familiares) em constante atualização 


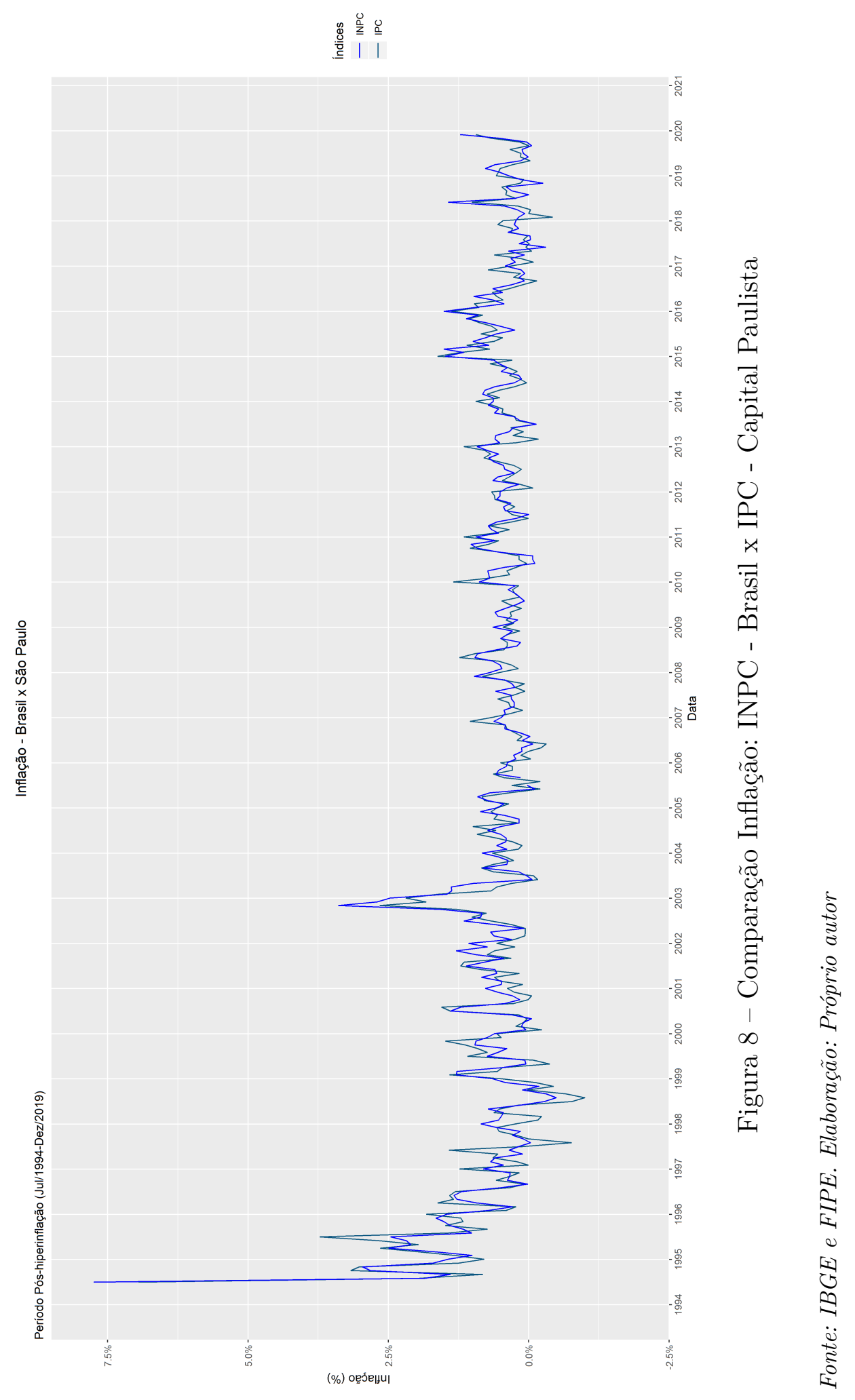




\section{APÊNDICE B - Período 1994 a 2000}

A figura 9 apresenta a relação entre frequência de variação de preços mensal total (considerando aumentos e quedas), frequência dos aumentos de preços e frequência das quedas de preços. Nota-se que nos meses subsequentes à implementação do Plano Real há maior flexibilidade de mudanças de preços. Observa-se uma maior estabilidade das variáveis a partir dos anos 2000, como apresentado na Tabela 17. Esta apresenta as estatísticas de mudanças de preços considerando 3 períodos distintos: A base de dados completa (Janeiro de 1994 a Dezembro de 2019), Julho de 1994 a Dezembro de 1999, e por fim, Janeiro de 2000 a Dezembro de 2019. Considerando o período pré-anos 2000, em um mês, em média, 43,5\% dos preços apresentam alguma variação, enquanto considerando o período pós-anos 2000, 38,9\% dos preços apresentam alguma variação. Diferenças entre os períodos são observadas também ao comparar apenas aumento de preços $(23,8 \%$ frente a $21,8 \%$ no período pós-anos 2000) e apenas quedas de preços (19,7\% frente a 17,11\%). Frente às diferenças expostas e a implementação do sistema de metas de inflação, adotado em 1999, para manter a consistência dos resultados apresentados neste trabalho, a base de dados que proverá as estatísticas para calibração do modelo contempla o período de Janeiro de 2000 a Dezembro de 2019.

Figura 9 - Frequência de variação de preços mensal

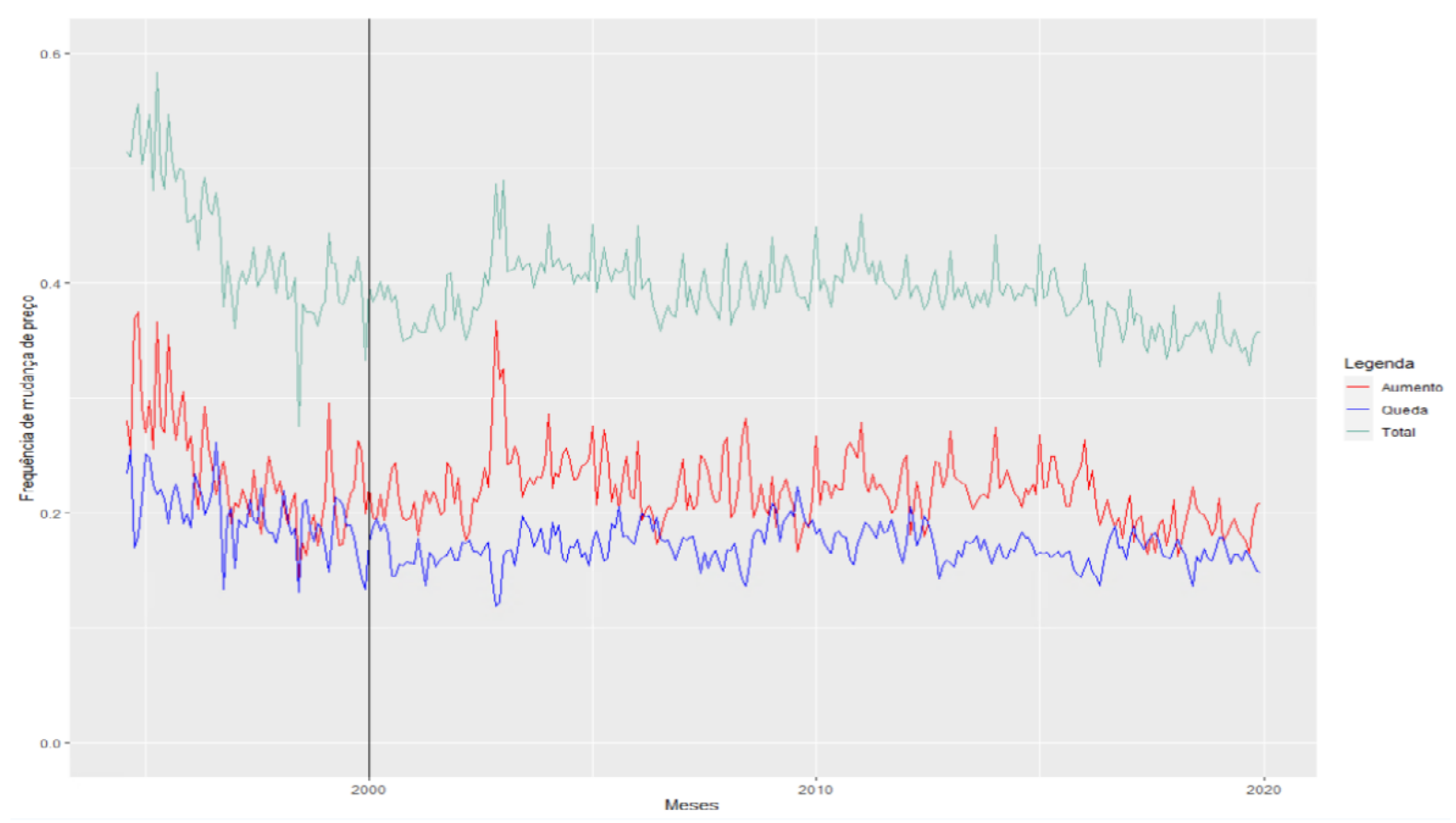


Tabela 17 - Frequência das variações de preços (\%)

\begin{tabular}{lcccc}
\hline & Média & Mediana & Aumentos & Quedas \\
\hline \hline Base completa & 39,9 & 39,3 & 22,2 & 17,6 \\
Base pré anos 2000 & 43,5 & 41,8 & 23,8 & 19,7 \\
Base pós anos 2000 & 38,9 & 39,0 & 21,8 & 17,1 \\
\hline
\end{tabular}

Notas: Elaboração Próprio autor. A primeira linha da Tabela mostra a frequência de mudança de preços observada entre todos os períodos da base de dados. A linha seguinte apresenta o tamanho destas variações. 


\section{APÊNDICE C - Preços administrados}

Tabela 18 - Preços administrados

\begin{tabular}{l}
\hline I. Habitação \\
Energia elétrica \\
Água/esgoto \\
Gás de botijão \\
Gás canalizado \\
Imposto predial \\
Carvão vegetal \\
Telefone fixo (conta) \\
Telefone celular (conta/recarga) \\
Cartão telefônico \\
Correio \\
\hline III. Transportes \\
\hline \hline Gasolina \\
Etanol \\
Gás natural veicular \\
Ônibus \\
Integração \\
Metrô \\
Táxi \\
Trem \\
Pedágio \\
Licenciamento \\
\hline IV. Despesas Pessoais \\
\hline \hline Passagem aérea \\
Loterias e outros jogos \\
Cartório \\
\hline V. Saúde \\
\hline \hline Contrato de assistência médica \\
Anti-infecciosos sistêmicos \\
Aparelho locomotor \\
Pele e mucosas \\
Aparelho cardiovascular \\
Vitaminas \\
Aparelho respiratório \\
Aparelho digestivo \\
Modificadores do metabolismo \\
Sistema nervoso \\
Oftalmológicos \\
Aparelho geniturinário \\
Algodão hidrófilo \\
Curativo pronto \\
Preservativo \\
Água oxigenada \\
Aparelho dentário \\
Aparelho auditivo \\
Lentes de óculos ón de pressão \\
\hline
\end{tabular}




\section{APÊNDICE D - Estratégia Computacional}

\section{Derivação da função valor}

Do problema de minimização de uma firma $z$ temos que:

$$
\begin{aligned}
\frac{W_{t}}{P_{t}} & =\left(1-s_{m}\right) A_{t} L_{t}(z)^{-s_{m}} M_{t}(z)^{s_{m}} \Omega_{t}(z) \\
1 & =s_{m} A_{t} L_{t}(z)^{1-s_{m}} M_{t}(z)^{s_{m}-1} \Omega_{t}(z)
\end{aligned}
$$

Sendo $\Omega_{t}(z)$ o custo marginal da firma $z$ no período $t$.

A equação do lucro da firma é dada por:

$$
\Pi_{t}(z)=p_{t}(z) y_{t}(z)-W_{t} L_{t}(z)-P_{t} M_{t}(z)-\chi_{j} W_{t} I_{t}(z)-P_{t} U
$$

Combinando as três equações acima e reescrevendo o lucro como lucro real, temos:

$$
\Pi_{t}^{R}(z)=\left(\frac{p_{t}(z)}{P_{t}}\right) y_{t}(z)-\frac{1}{1-s_{m}}\left(\frac{W_{t}}{P_{t}}\right) L_{t}(z)-\chi_{j}\left(\frac{W_{t}}{P_{t}}\right) I_{t}(z)-U
$$

Combinando a função de produção e as equações derivadas do problema de minimização da firma:

$$
L_{t}(z)=\left(\frac{y_{t}(z)}{A_{t}(z)}\right)\left(\frac{s_{m}}{1-s_{m}}\right)^{-s_{m}}\left(\frac{W_{t}}{P_{t}}\right)^{-s_{m}}
$$

Inserindo esta equação no lucro real, temos:

$$
\Pi_{t}^{R}(z)=\left(\frac{p_{t}(z)}{P_{t}}\right) y_{t}(z)-\left(1-s_{m}\right)^{s_{m}-1} s_{m}^{-s_{m}}\left(\frac{W_{t}}{P_{t}}\right)^{1-s_{m}}\left(\frac{y_{t}(z)}{A_{t}(z)}\right)-\chi_{j}\left(\frac{W_{t}}{P_{t}}\right) I_{t}(z)-U
$$

Inserindo as equações (26) e (32) no lucro real:

$\Pi_{t}^{R}(z)=Y_{t}\left(\frac{p_{t}(z)}{P_{t}}\right)^{1-\theta}-\frac{\omega^{1-s_{m}} L_{t}^{\psi\left(1-s_{m}\right)} C_{t}^{\gamma\left(1-s_{m}\right)}}{\left(1-s_{m}\right)^{1-s_{m}} s_{m}^{s_{m}}}\left(\frac{1}{A_{t}(z)}\right) Y_{t}\left(\frac{p_{t}(z)}{P_{t}}\right)^{-\theta}-\chi_{j} \omega L_{t}^{\psi} C_{t}^{\gamma} I_{t}(z)-U$

Por fim, é necessário calcular as versões log-linearizadas de $Y_{t}=C_{t}+\int_{0}^{1} M_{t}(z) d z$, da função de produção e da oferta de trabalho, todas ao redor do estado estacionário. Utilizando também a equação $C_{t}=S_{t} / P_{t}$, o lucro real das empresas pode ser reescrito como uma função de $\left(A_{t}(z), p_{t-1}(z) / P_{t}, S_{t} / P_{t}\right)$ e $p_{t}(z)$. 


\section{Consistência das funções}

Para resolver a distribuição estacionária sobre o espaço de estado do problema da firma através do seguinte algoritmo:

(i) Calcular uma distribuição inicial para a economia de estado estacionário, denominada $Q\left(A(z), p_{-1}(z) / P, S / P\right)$. Como distribuição inicial, Nakamura e Steinsson (2010) propõem uma distribuição uniforme.

(ii) Mapear $Q\left(A(z), p_{-1}(z) / P, S / P\right)$ em $Q(A(z), p(z) / P, S / P)$ usando a policy function $F$.

(iii) Mapear $Q(A(z), p(z) / P, S / P)$ em $Q\left(A_{+1}(z), p(z) / P, S / P\right)$ usando a matriz de probabilidade de transição para o processo de produtividade.

(iv) Mapear $Q\left(A_{+1}(z), p(z) / P, S / P\right)$ em $Q\left(A_{+1}(z), p(z) / P, S_{+1} / P\right)$ usando a matriz de probabilidade de transição para o processo de demanda agregada nominal, $S$.

(v) Mapear $Q\left(A_{+1}(z), p(z) / P, S_{+1} / P\right)$ em $Q\left(A_{+1}(z), p(z) / P_{+1}, S_{+1} / P_{+1}\right)$ utilizando a função $\Gamma$.

(vi) Verificar se $\left\|Q\left(A_{+1}(z), p(z) / P_{+1}, S_{+1} / P_{+1}\right)-Q\left(A(z), p_{-1}(z) / P, S / P\right)\right\|<\xi$ em que $\|\cdot\|$ denota a norma superior. Caso atenda a condição descrita, parar. Caso contrário, voltar para a etapa (ii). 


\section{APÊNDICE E - Vetor autorregressivo - VAR}

\section{Resultados da estimação}

Tabela 19 - Estimação dos resultados para a variável dependente inflação

\begin{tabular}{lcccc}
\hline & Estimação & Desvio Padrão & Valor & $\operatorname{Pr}(>|\mathrm{t}|)$ \\
\hline \hline Inflação, t-1 & $-462,30$ & 200,20 & $-2,31$ & $0,0367 * *$ \\
Horas totais, t-1 & 25,96 & 41,34 & 0,63 & 0,54 \\
Juros nominais, t-1 & $-95,70$ & 93,30 & $-1026,00$ & 0,32 \\
Produto, t-1 & $-5233000,00$ & 3621000,00 & $-1445,00$ & 0,17 \\
Inflação, t-2 & $-360,60$ & 169,50 & $-2127,00$ & $0,0517 *$ \\
Horas totais, t-2 & 68,98 & 47,26 & 1460,00 & 0,17 \\
Juros nominais, t-2 & $-4504,00$ & 18,31 & $-0,25$ & 0,81 \\
Produto, t-2 & $-7902000,00$ & 3778000,00 & $-2092,00$ & $0,0552 *$ \\
Inflação, t-3 & $-335,20$ & 154,30 & $-2173,00$ & $0,0475 * *$ \\
Horas totais, t-3 & 46,21 & 40,37 & 1145,00 & 0,27 \\
Juros nominais, t-3 & 34,05 & 14,01 & 2431,00 & $0,0291 * *$ \\
Produto, t-3 & $-1052000,00$ & 4560000,00 & $-0,23$ & 0,82 \\
Constante & $-919,50$ & 197200,00 & $-0,01$ & 1,00 \\
\hline
\end{tabular}

Notas: Elaboração Próprio autor. 
Tabela 20 - Estimação dos resultados para a variável dependente horas totais trabalhadas

\begin{tabular}{lcccc}
\hline & Estimação & Desvio Padrão & Valor & $\operatorname{Pr}(>|\mathrm{t}|)$ \\
\hline \hline Inflação, t-1 & 27926 & 15846 & 1762 & $0,0998^{*}$ \\
Horas totais, t-1 & 0,2051 & 0,3272 & 0,627 & 0,5409 \\
Juros nominais, t-1 & 0,7239 & 0,7386 & 0,98 & 0,3437 \\
Produto, t-1 & -13722981 & 286626889 & $-0,048$ & 0,9625 \\
Inflação, t-2 & $-0,387$ & 13420 & $-0,288$ & 0,7773 \\
Horas totais, t-2 & 0,104 & 0,3742 & 0,278 & 0,7851 \\
Juros nominais, t-2 & 0,1937 & 0,145 & 1336 & 0,2028 \\
Produto, t-2 & 111527989 & 299059560 & 0,373 & 0,7148 \\
Inflação, t-3 & 10592 & 12216 & 0,867 & 0,4005 \\
Horas totais, t-3 & $-0,1124$ & 0,3196 & $-0,352$ & 0,7303 \\
Juros nominais, t-3 & 0,167 & 0,1109 & 1505 & 0,1545 \\
Produto, t-3 & 26246763 & 360976625 & 0,073 & 0,9431 \\
Constante & 14841616 & 15612511 & 0,951 & 0,3579 \\
\hline
\end{tabular}

Notas: Elaboração Próprio autor.

Tabela 21 - Estimação dos resultados para a variável dependente juros nominais

\begin{tabular}{lcccc}
\hline & Estimação & Desvio Padrão & Valor & $\operatorname{Pr}(>|\mathrm{t}|)$ \\
\hline \hline Inflação, t-1 & 202,6 & 386,2 & 0,524 & 0,608156 \\
Horas totais, t-1 & 181,8 & 79,77 & 2279 & $0,038846^{*}$ \\
Juros nominais, t-1 & -654 & 180 & -3633 & $0,002717^{* *}$ \\
Produto, t-1 & -4044000 & 6986000 & $-0,579$ & 0,571862 \\
Inflação, t-2 & $-191,8$ & 327,1 & $-0,586$ & 0,566912 \\
Horas totais, t-2 & 147,8 & 91,2 & 1621 & 0,127378 \\
Juros nominais, t-2 & $-189,5$ & 35,34 & -5363 & $0,000100 * * *$ \\
Produto, t-2 & 18050000 & 7289000 & 2476 & $0,026692 *$ \\
Inflação, t-3 & $-454,1$ & 297,8 & -1525 & 0,149504 \\
Horas totais, t-3 & $-127,6$ & 77,9 & -1638 & 0,123755 \\
Juros nominais, t-3 & $-149,2$ & 27,03 & -5520 & $7,55 \mathrm{e}-05 * * *$ \\
Produto, t-3 & 25350000 & 8799000 & 2881 & $0,012096 *$ \\
Constante & -1875000 & 380500 & -4928 & $0,000222 * * *$ \\
\hline
\end{tabular}

Notas: Elaboração Próprio autor. 
Tabela 22 - Estimação dos resultados para a variável dependente produto real

\begin{tabular}{lcccc}
\hline & Estimação & Desvio Padrão & Valor & $\operatorname{Pr}(>|\mathrm{t}|)$ \\
\hline \hline Inflação, t-1 & 0,009063 & 0,01748 & 0,518 & 0,612 \\
Horas totais, t-1 & $-0,001071$ & 0,003611 & $-0,297$ & 0,771 \\
Juros nominais, t-1 & $-0,005664$ & 0,008149 & $-0,695$ & 0,498 \\
Produto, t-1 & 433,3 & 316,2 & 1370 & 0,192 \\
Inflação, t-2 & 0,004527 & 0,01481 & 0,306 & 0,764 \\
Horas totais, t-2 & 0,001955 & 0,004128 & 0,473 & 0,643 \\
Juros nominais, t-2 & 0,001109 & 0,0016 & 0,693 & 0,499 \\
Produto, t-2 & $-21,57$ & 330 & $-0,065$ & 0,949 \\
Inflação, t-3 & 0,001736 & 0,01348 & 0,129 & 0,899 \\
Horas totais, t-3 & $-0,0001172$ & 0,003526 & $-0,033$ & 0,974 \\
Juros nominais, t-3 & $-0,0002371$ & 0,001224 & $-0,194$ & 0,849 \\
Produto, t-3 & 294,6 & 398,3 & 0,74 & 0,472 \\
Constante & 4427 & 17,23 & 0,257 & 0,801 \\
\hline
\end{tabular}

Notas: Elaboração Próprio autor. 


\section{Função impulso resposta}

Figura 10 - Função impulso resposta da variável Inflação

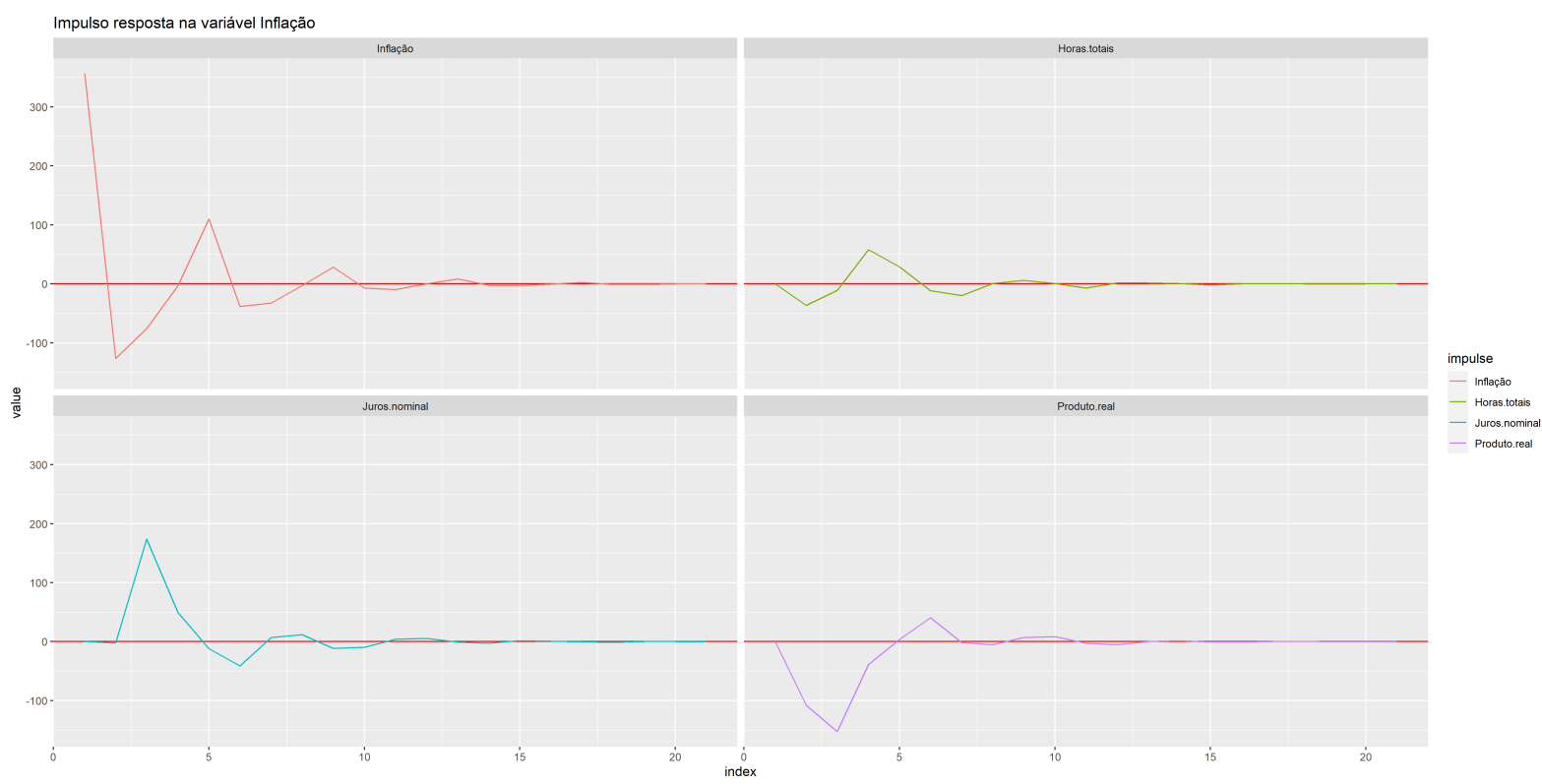

Notas: Elaboração Próprio autor

Figura 11 - Função impulso resposta da variável Horas trabalhadas

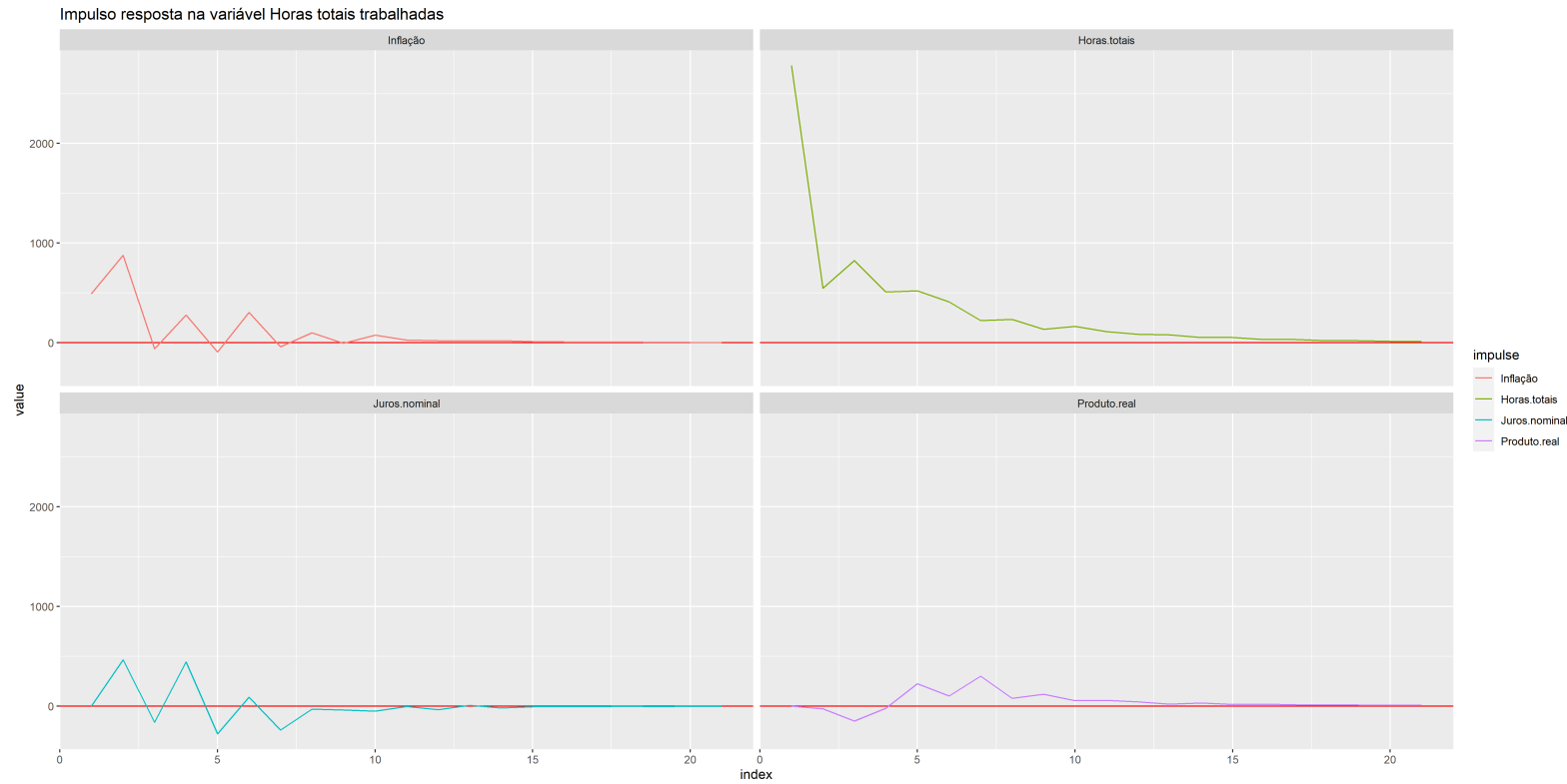

Notas: Elaboração Próprio autor 
Figura 12 - Função impulso resposta da variável Juros nominal

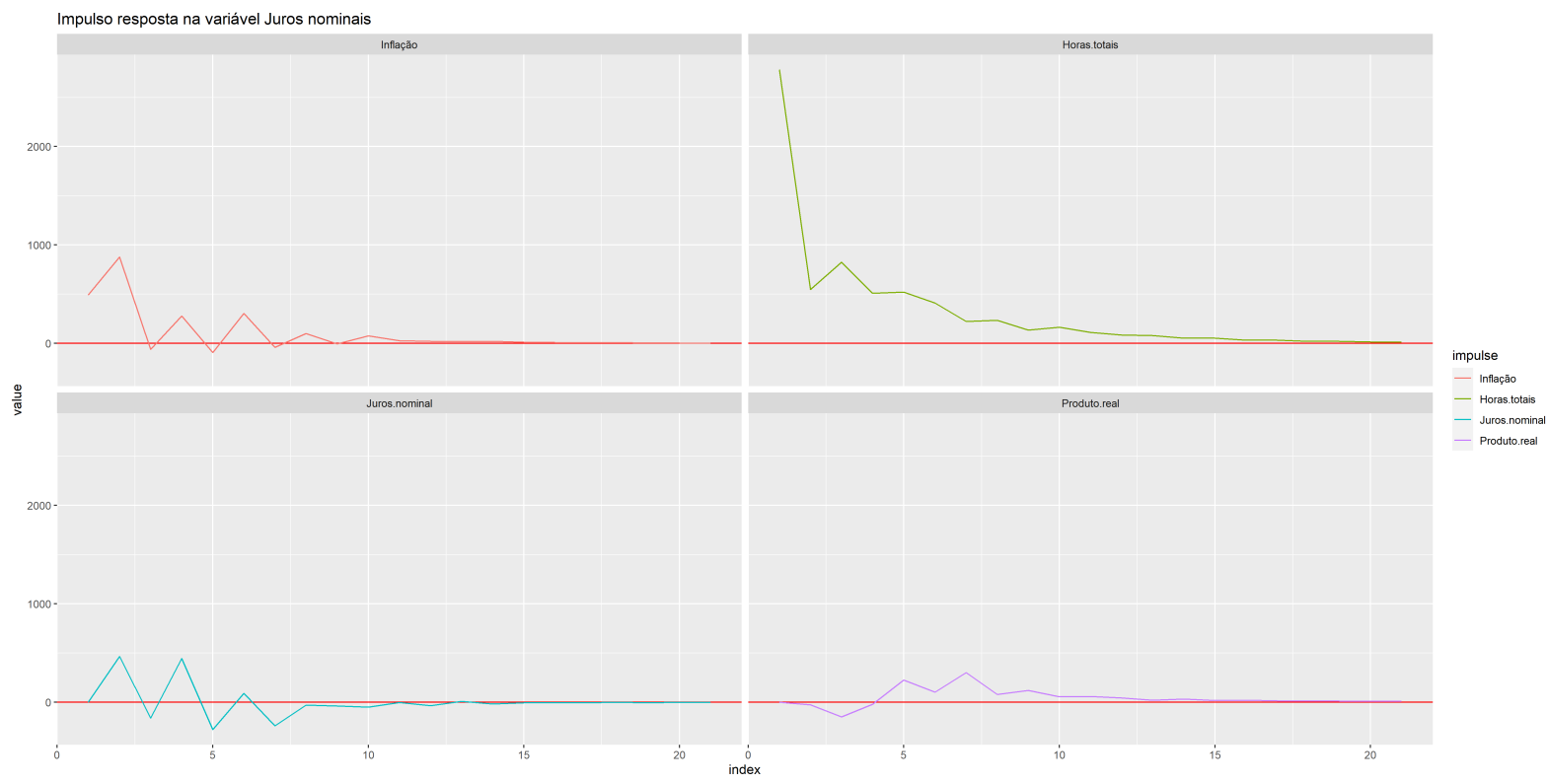

Notas: Elaboração Próprio autor

Figura 13 - Função impulso resposta da variável Produto Real

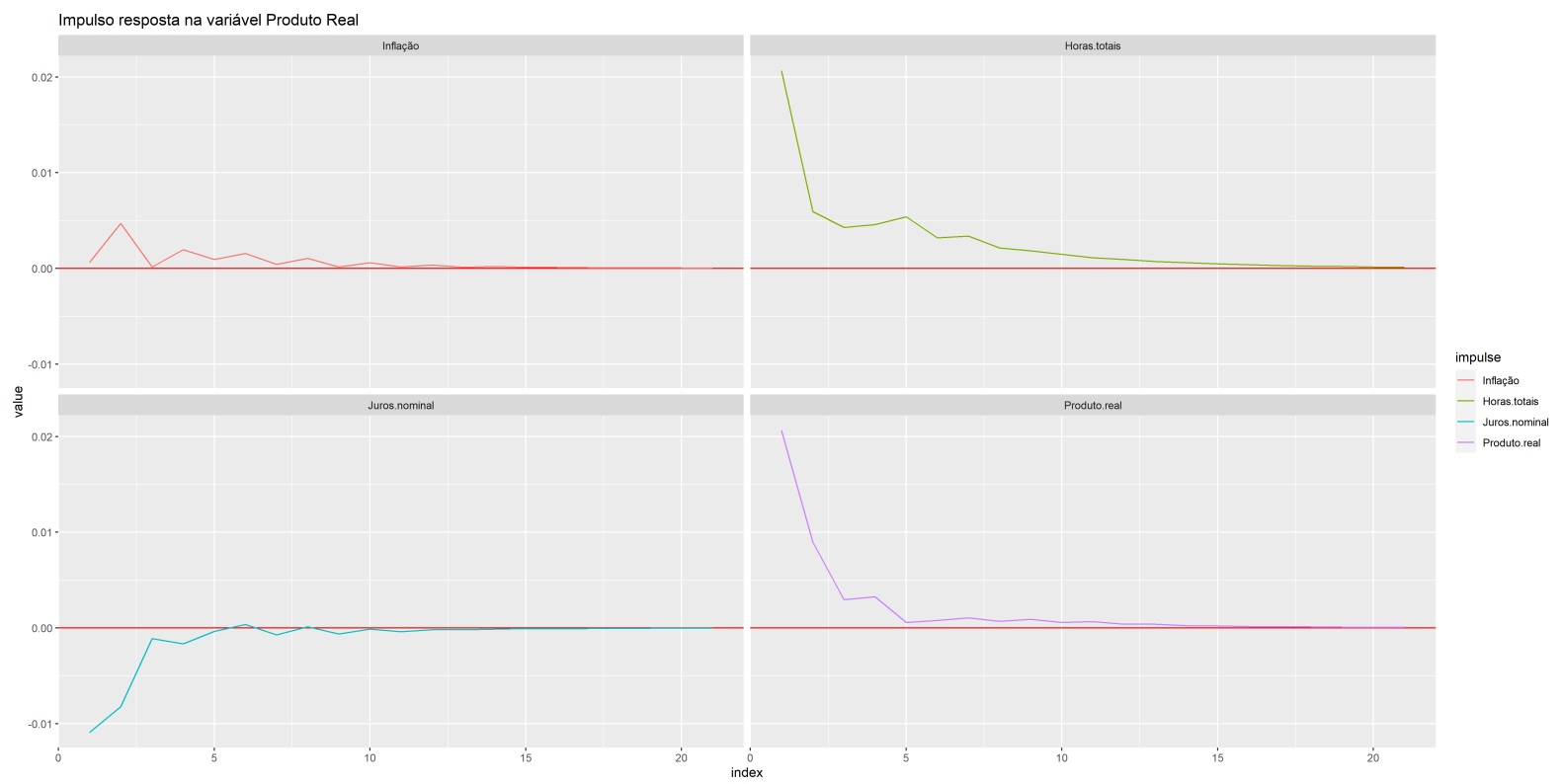

Notas: Elaboração Próprio autor 


\section{Decomposição da variância}

Tabela 23 - Decomposição da variância

\begin{tabular}{|c|c|c|c|c|}
\hline & \multicolumn{4}{|c|}{ Inflação } \\
\hline & Inflação & Horas totais & Juros nominal & Produto real \\
\hline 1 & 1,000 & 0,000 & 0,000 & 0,000 \\
\hline 2 & 0,917 & 0,008 & 0,000 & 0,075 \\
\hline 3 & 0,691 & 0,007 & 0,014 & 0,162 \\
\hline 4 & 0,668 & 0,022 & 0,015 & 0,164 \\
\hline 5 & 0,682 & 0,024 & 0,014 & 0,155 \\
\hline 6 & 0,674 & 0,024 & 0,014 & 0,158 \\
\hline 7 & 0,675 & 0,026 & 0,014 & 0,157 \\
\hline 8 & 0,674 & 0,026 & 0,014 & 0,157 \\
\hline 9 & 0,675 & 0,026 & 0,014 & 0,157 \\
\hline \multicolumn{5}{|c|}{ Horas totais } \\
\hline & Inflação & Horas totais & Juros nominal & Produto real \\
\hline$\overline{1}$ & 0,030 & 0,970 & 0,000 & 0,000 \\
\hline 2 & 0,109 & 0,867 & 0,023 & 0,000 \\
\hline 3 & 0,102 & 0,872 & 0,024 & 0,002 \\
\hline 4 & 0,104 & 0,852 & 0,042 & 0,002 \\
\hline 5 & 0,101 & 0,845 & 0,047 & 0,007 \\
\hline 6 & 0,107 & 0,839 & 0,047 & 0,008 \\
\hline 7 & 0,105 & 0,829 & 0,051 & 0,015 \\
\hline 8 & 0,105 & 0,828 & 0,051 & 0,016 \\
\hline 9 & 0,105 & 0,828 & 0,051 & 0,017 \\
\hline \multicolumn{5}{|c|}{ Juros nominal } \\
\hline & Inflação & Horas totais & Juros nominal & Produto real \\
\hline$\overline{1} 1$ & 0,193 & 0,000 & 0,807 & 0,000 \\
\hline 2 & 0,240 & 0,191 & 0,561 & 0,008 \\
\hline 3 & 0,160 & 0,367 & 0,372 & 0,101 \\
\hline 4 & 0,130 & 0,298 & 0,393 & 0,180 \\
\hline 5 & 0,129 & 0,311 & 0,385 & 0,175 \\
\hline 6 & 0,131 & 0,305 & 0,381 & 0,183 \\
\hline 7 & 0,128 & 0,320 & 0,374 & 0,178 \\
\hline 8 & 0,128 & 0,319 & 0,374 & 0,178 \\
\hline 9 & 0,127 & 0,322 & 0,373 & 0,177 \\
\hline \multicolumn{5}{|c|}{ Produto real } \\
\hline & Inflação & Horas totais & Juros nominal & Produto real \\
\hline 1 & 0,000 & 0,438 & 0,123 & 0,439 \\
\hline 2 & 0,019 & 0,392 & 0,159 & 0,430 \\
\hline 3 & 0,019 & 0,398 & 0,156 & 0,427 \\
\hline 4 & 0,021 & 0,402 & 0,154 & 0,423 \\
\hline 5 & 0,021 & 0,416 & 0,150 & 0,413 \\
\hline 6 & 0,023 & 0,419 & 0,149 & 0,409 \\
\hline 7 & 0,023 & 0,424 & 0,148 & 0,406 \\
\hline 8 & 0,024 & 0,425 & 0,147 & 0,404 \\
\hline 9 & 0,024 & 0,426 & 0,147 & 0,403 \\
\hline
\end{tabular}

Notas: Elaboração Próprio autor. 